\title{
Charakterisierung molekularer Mechanismen der antiangiogenen Aktivität von GBP-1 in Endothelzellen
}

\author{
Der Naturwissenschaftlichen Fakultät der \\ Friedrich-Alexander-Universität Erlangen-Nürnberg \\ zur \\ Erlangung des Doktorgrades
}

vorgelegt von

Kristina Weinländer

aus Fürth 
Als Dissertation genehmigt von der Naturwissenschaftlichen Fakultät der Universität Erlangen-Nürnberg

Tag der mündlichen Prüfung: 28.11.2008

Vorsitzender der

Promotionskomission: Prof. Dr. Eberhard Bänsch

Erstberichterstatter: $\quad$ Prof. Dr. Michael Stürzl

Zweitberichterstatter: $\quad$ Prof. Dr. Thomas Winkler 


\section{Danksagung}

Die vorliegende Arbeit wäre ohne die Hilfe und Unterstützung vieler Menschen nicht möglich gewesen. An dieser Stelle möchte ich mich bei ihnen allen bedanken.

Mein erster Dank gilt Prof. Dr. Michael Stürzl für die Aufnahme in seine Arbeitsgruppe und die in jeder Hinsicht gewährte Unterstützung. Er bereicherte diese Arbeit sehr durch viele kreative Anregungen, konstruktive Kritik und seine umfassende wissenschaftliche Erfahrung.

Bei Prof. Dr. Werner Hohenberger möchte ich mich für sein Interesse an der Wissenschaft und die hervorragende Ausstattung der Abteilung für Molekulare und Experimentelle Chirurgie bedanken.

Prof. Dr. Thomas Winkler gilt mein Dank für die Übernahme des Zweitgutachtens.

Ganz besonders herzlich möchte ich mich bei Dr. Elisabeth Naschberger für die umfassende und fortwährend gute Betreuung bedanken. Sie hat nie aufgehört mich zu motivieren, stand mir mit ihrem fundamentierten Fachwissen immer mit Rat und Tat zur Seite und gab mir vor allem in der Endphase viele gute Tipps und Ratschläge. Vielen Dank!

Sehr dankbar bin ich auch Dr. Michael Lehmann für die Einarbeitung in die Methode des RNase Protection Assays, Dr. Christoph Garlichs für die Benutzung des FACS-Calibur-Geräts und Prof. Dr. Hannes Stockinger für die Bereitstellung des ITGB1-Antikörpers und der shRNA-kodierenden Plasmide.

Ich danke auch allen weiteren, aktuellen und ehemaligen Mitgliedern der Abteilung für Molekulare und Experimentelle Chirurgie für die stets gute Zusammenarbeit. Insbesondere möchte ich Dr. Mathias Thurau, Dr. Michael Bauer und Dr. Nathalie Laurent für ihre bereitwillige Beantwortung aller wissenschaftlicher Fragen und ihre Hilfsbereitsschaft danken. Für die Hilfe in administrativen Angelegenheiten danke ich Susanne Reed. Gertrud Hoffmann danke ich für ihre Hilfe bei der Kultivierung der Zellen und Mahimaidos Manoharan für das Lösen aller „speziellen“ Probleme im Labor. Dr. Philipp Tripal sei gedankt für seine umfassende Hilfe beim Erlernen aller wichtigen Methoden, insbesondere der retroviralenTransduktion. Ein ganz großer Dank geht auch an Gaby Sander, Mirjam Metzner, Andreas Konrad und Ramona Jochmann, die sich mit mir das Büro geteilt haben und immer ein offenes Ohr gehabt haben, wenn es mal wieder Ergebnisse und Probleme (seien es private oder wissenschaftliche) zu diskutieren gab. Ein spezielles, riesengroßes Dankeschön geht auch an Helene Demund, Christina von Kleinsorgen, Melanie Nurtsch und Elisabeth Kuhn, die mich nicht nur tatkräftig unterstützt haben, sondern auch für den nötigen Spaß im Laboralltag gesorgt haben.

Allen meinen Freunden und ungewollt nicht namentlich genannten Personen, die direkt oder indirekt zum Gelingen dieser Arbeit in Form von fachlicher oder anderweitiger Unterstützung beigetragen haben, sei an dieser Stelle auch gedankt.

Zuletzt geht auch ein ganz besonderes Dankeschön an meine Familie. Besonders bei meinen Eltern möchte ich mich, neben der finanziellen Unterstützung auch für ihr Verständnis und den liebevollen Rückhalt bedanken. Auch bei Luca und Mia möchte ich mich bedanken. Ihr habt mich immer wieder daran erinnert, was die wirklich wichtigen Dinge im Leben sind! 


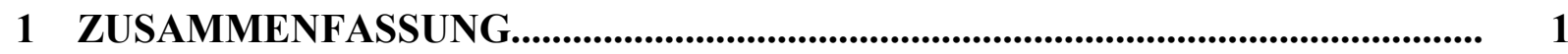

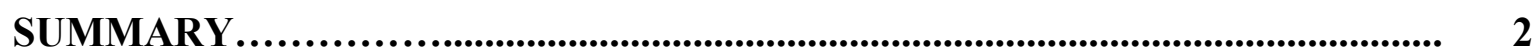

2 EINLEITUNG

2.1 Die Bildung Neuer BlutgefäßE: VASKulogenese Und ANGIOGENESE.............. 3

2.1.1 Die Aktivierungsphase der Angiogenese................................................................ 5

2.1.2 Die Reifungsphase der Angiogenese.................................................................. 7

2.2 INTEGRINE UND IHRE BEDEUTUNG WÄHREND DER ANGIOGENESE............................. 8

2.2.1 Allgemeiner Aufbau von Integrinen und Integrin-vermittelte Signalwege..................... 9

2.2.2 Integrine und ihre Bedeutung bei der Migration von Endothelzellen........................... 12

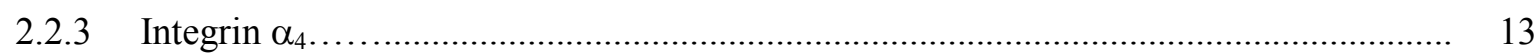

2.3 INFLAMMATORISCHE ZYTOKINE UND IHRE WIRKUNG AUF ENDOTHELZELLEN.......... 14

2.3.1 Die Wirkung von IL-1 und TNF- $\alpha$ auf Endothelzellen............................................... 15

2.3.2 Der Einfluss von IFN- $\gamma$ auf Endothelzellen............................................ 15

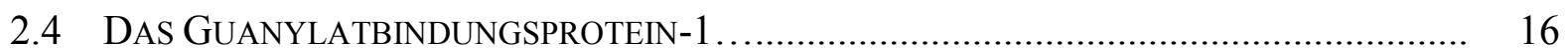

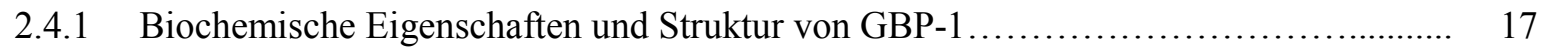

2.4.2 Expression und transkriptionelle Regulation von GBP-1 .......................... 18

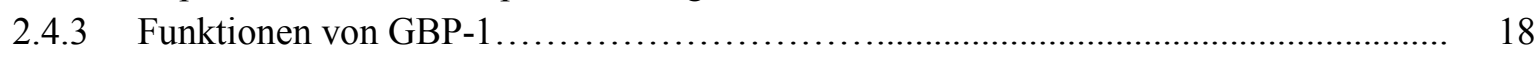

2.5 ZIELE DIESER ARBEIT ..................................................................................... 19

3 MATERIAL UND METHODEN........................................................................ 21

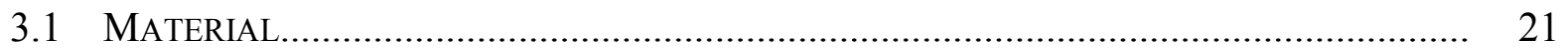

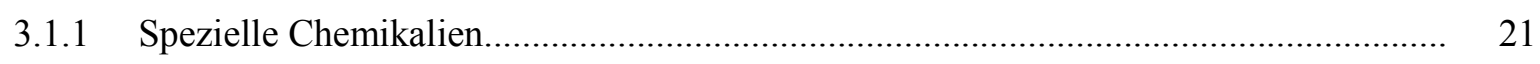

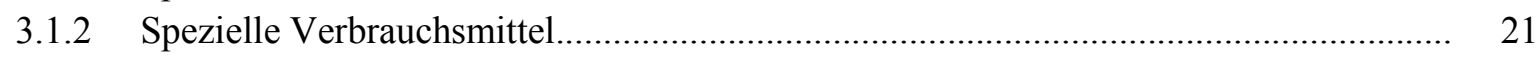

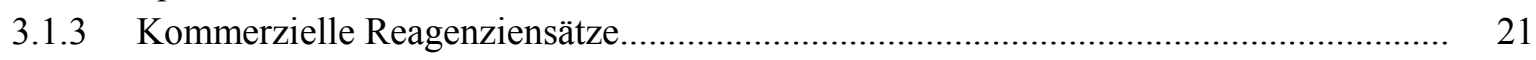

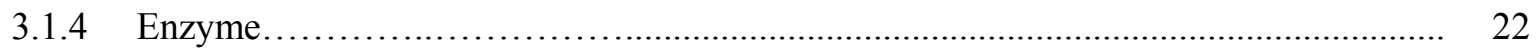

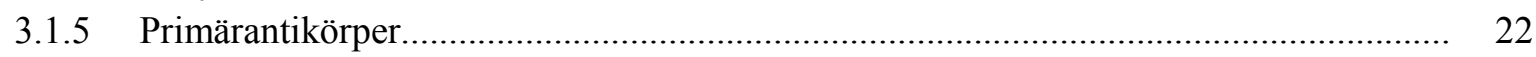

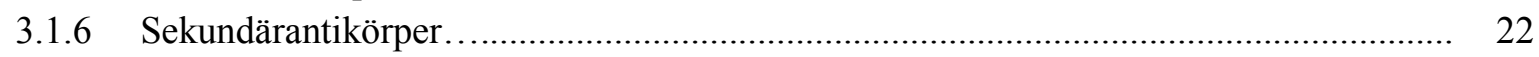

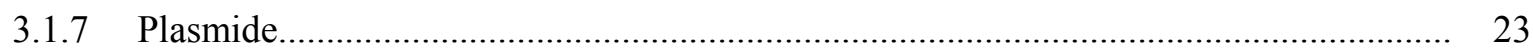

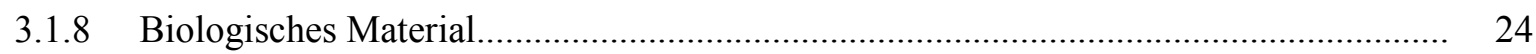

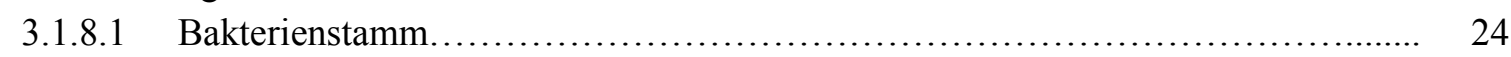

3.1.8.2 Eukaryontische Zellen............................................... 24

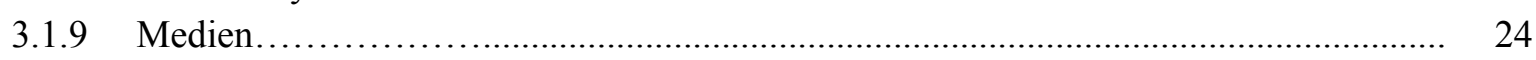

3.1.9.1 Bakterien-Nährmedium................................................... 24

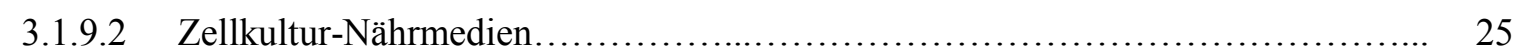

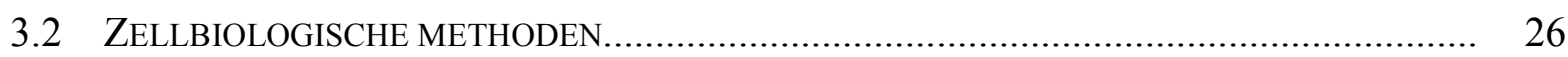

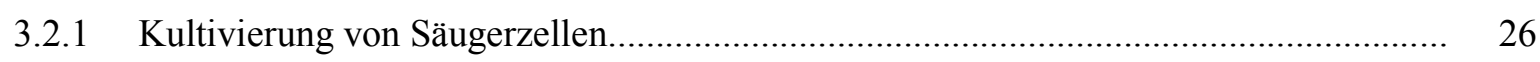

3.2.2 Stimulierung von primären Endothelzellen mit inflammatorischen Zytokinen........... 27

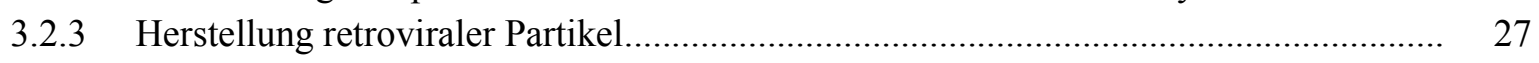

3.2.3.1 Produktion von infektiösen PG13-Überständen................................. 27

3.2.3.2 Produktion infektiöser Partikel in HEK293T-Zellen.............................. 28

3.2.4 Retrovirale Transduktion von HUVEC............................................. 28

3.2.4.1 Infektion mit PG13-Überständen............................................. 29

3.2.4.2 Infektion mit viralen Partikeln aus HEK293T................................... 29

3.2.5 Untersuchungen zur Bildung endothelialer Lamellipodien............................. 29

3.2.6 In vitro Wundheilungstest................................................. 30

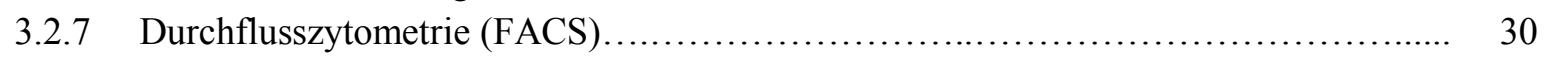

3.3 MolekUlarbiologische Methoden................................................................ 32 


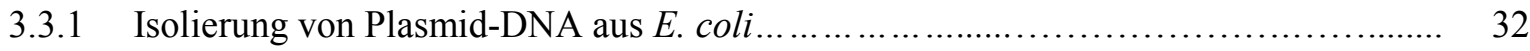

3.3.2 Bestimmung von Nukleinsäurekonzentrationen................................ 32

3.3.3 Restriktionsspaltungen von DNA................................................. 32

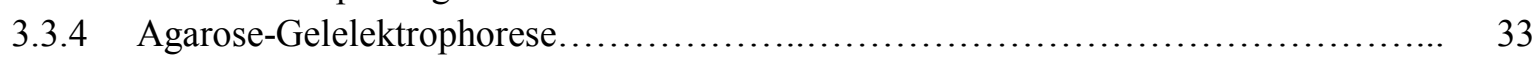

3.3.4.1 Größenstandards für die Agarose-Gelelektrophorese............................ 34

3.3.4.2 Elution von DNA aus Agarosegelen....................................... 34

3.3.5 Auffüllen von 5'-Überhängen mit dem „Klenow“-Fragment der DNA-Polymerase I... 34

3.3.6 Dephosphorylierung von DNA-Fragmenten...................................... 35

3.3.7 Ligation von DNA-Fragmenten............................................ 35

3.3.8 Transformation von kompetenten E. coli-Zellen................................ 35

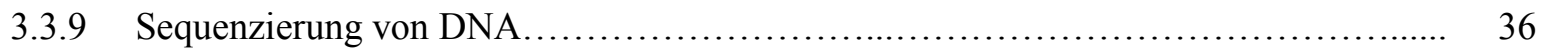

3.3.10 Isolierung von zellulärer Gesamt-RNA.......................................... 36

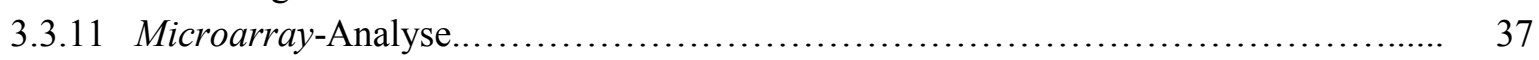

3.3.12 Reverse Transkriptase-Polymerasekettenreaktion (RT-PCR) ...................... 38

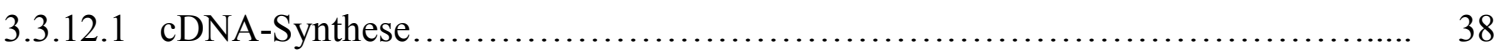

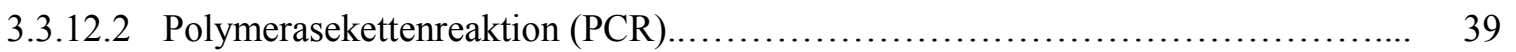

3.3.13 RNase Protection Assay (RPA) ............................................ 40

3.3.13.1 In vitro Transkription zur Herstellung Biotin-markierter RNA-Sonden............... 41

3.3.13.2 RNA-Probenvorbereitung und Hybridisierung.................................. 41

3.3.13.3 RNase A-Behandlung................................................... 42

3.3.13.4 Tris-Borat-Harnstoff-Gelelektrophorese und Membrantransfer.................... 42

3.3.13.5 Proben-Detektion................................................................ 43

3.3.14 Quantifizierung und Normalisierung von Bandensignalen......................... 43

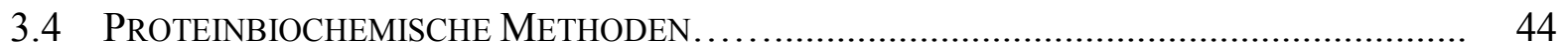

3.4.1 Herstellung von Gesamtproteinzellextrakten.................................. 44

3.4.2 Bestimmung von Gesamtproteinkonzentrationen.................................. 44

3.4.3 SDS-Polyacrylamid-Gelelektrophorese...................................... 44

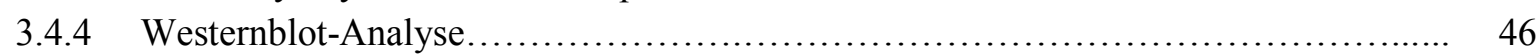

3.4.5 Immunfärbung des Westernblots................................................. 46

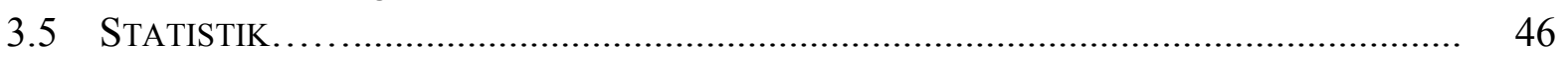

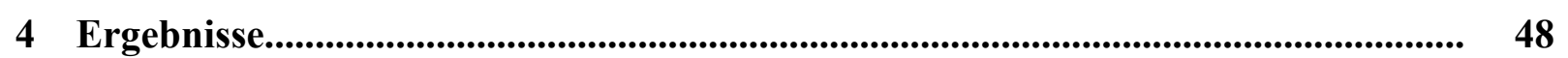

4.1 DiE EKTOPISCHE EXPRESSION VON GBP-1 HEMMT DIE BILDUNG STABILER

4.1.1 Ektopische Expression und Nachweis von GBP-1 in HUVEC........................ 48

4.1.2 Die ektopische Expression von GBP-1 hemmt die Bildung endothelialer Lamellipodien auf FN-beschichteten Oberflächen.

4.1.3 Die ektopische Expression von GBP-1 hemmt die Migration von Endothelzellen auf FN-beschichteten Oberflächen................................................ 51

4.2 GBP-1 INDUZIERT DIE EXPRESSION VON INTEGRIN $\alpha_{4}$ IN ENDOTHELZELLEN.............. 53

4.2.1 Identifizierung von GBP-1-regulierten Genen mittels Microarray-Analyse............... 53

4.2.2 GBP-1 erhöht die mRNA-Transkription von itga4 in Endothelzellen................... 54

4.2.3 GBP-1 induziert die Exposition von ITGA4 an der Oberfläche von Endothelzellen...... 57

4.3 Die GTPASE-AKTIVITÄT VON GBP-1 IST AN DER HOCHREGULATION DER ITGA4EXPRESSION BETEILIGT ......................................................................... 58

4.4 Die GBP-1-VERMitTELTE HEMMUNG DER LAMELLIPODIENBILDUNG UND DER MIGRATION IST ABHÄNGIG VON DER BINDUNG ZWISCHEN ITGA4 UND FN............... 60

4.5 IL-1 $\beta$ UND TNF- $\alpha$ INDUZIEREN DIE OBERFLÄCHENEXPRESSION VON ITGA4 UND HEMMEN DIE LAMELLIPODIENBILDUNG VON HUVEC AUF FN. 
4.5.1 Nachweis von endogenem GBP-1 in IL-1 $\beta$-, TNF- $\alpha$ - und IFN- $\gamma$-behandelten HUVEC 64

4.5.2 IL-1 $\beta$ und TNF- $\alpha$ induzieren die Oberflächenexpression von ITGA4 ................... 65

4.5.3 IL-1 $\beta$ und TNF- $\alpha$ hemmen die Bildung endothelialer Lamellipodien auf

FN-beschichteten Oberflächen in Abhägigkeit von ITGA4....

4.6 GBP-1 VERMITTELT DIE DURCH IL-1 $\beta$ - UND TNF- $\alpha$-INDUZIERTE HEMMUNG DER LAMELLIPODIENBILDUNG UND DER MIGRATION DURCH INDUKTION VON ITGA4.

4.6.1 Klonierung der shRNAs in retrovirale Expressionsplasmide............................. 68

4.6.2 Nachweis von endogenem GBP-1 in Ktrl-shRNA- und GBP-1-shRNAexprimierenden HUVEC nach Stimulation mit IL-1 $\beta$ und TNF- $\alpha$. .

4.6.3 GBP-1 ist notwendig zur Induktion der ITGA4-Expression nach Stimulierung mit IL-1 $\beta$ und TNF- $\alpha$

4.6.4 GBP-1 ist zur Hemmung der endothelialen Lamellipodienbildung auf FNbeschichteten Oberflächen nach Stimulierung mit IL-1 $\beta$ und TNF- $\alpha$ notwendig........

4.6.5 GBP-1 ist zur Hemmung der Migration von HUVEC durch IL-1 $\beta$ und TNF- $\alpha$ notwendig

5 Diskussion.

5.1 GBP-1 INDUZIERT DIE EXPRESSION VON ITGA4 IN ENDOTHELZELLEN...................... 76

5.2 GBP-1 IST HINREICHEND FÜR DIE HEMMUNG DER LAMELLIPODIENBILDUNG UND MIGRATION VON ENDOTHELZELLEN AUF FN-BESCHICHTETEN OBERFLÄCHEN

5.3 DiE INFLAMMATORISCHEN ZYTOKINE IL-1 $\beta$ UND TNF- $\alpha$, ABER NICHT IFN- $\gamma$ HEMMEN DIE BILDUNG ENDOTHELIALER LAMELLIPODIEN DURCH EINE GBP-1VERMITTELTE INDUKTION VON ITGA4. ...

5.4 MODELLE ZUR HEMMUNG DER ENDOTHELIALEN LAMELLIPODIENBILDUNG NACH BEHANDLUNG MIT IL- $1 \beta /$ TNF- $\alpha$ BZW. IFN- $\gamma$

5.5 DiE BEDEUTUNG DER GBP-1-ABHÄNGIGEN ITGA4-EXPRESSION IN ENDOTHELZELLEN IM KONTEXT EINER ENTZÜNDUNGSREAKTION UNTER PHYSIOLOGISCHEN BEDINGUNGEN.

6 Literaturverzeichnis.

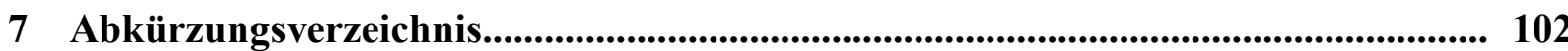

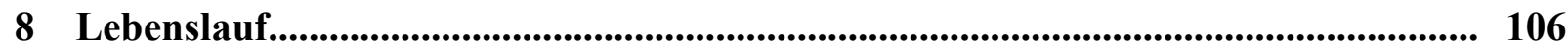




\section{Zusammenfassung}

Das humane Guanylatbindungsprotein (GBP)-1 gehört zur Familie der großen GTPasen und wird durch die inflammatorischen Zytokine Interferon (IFN)- $\gamma$, Interleukin (IL)- $1 \beta$ und Tumornekrosefaktor (TNF)- $\alpha$ in humanen Endothelzellen (EZ) induziert. GBP-1 besitzt zwei wichtige antiangiogene Eigenschaften. Es hemmt die Proliferation und Invasion von EZ.

In dieser Arbeit konnte gezeigt werden, dass GBP-1-exprimierende EZ in ihrer Fähigkeit zur Bildung stabiler Lamellipodien und zur Migration auf Fibronektin (FN)-beschichteten Oberflächen signifikant gehemmt sind. Bei dem Versuch den molekularen Mechanismus dieser inhibitorischen Effekte aufzuklären, konnte gezeigt werden, dass Integrin $\alpha_{4}$ (ITGA4) sowohl auf RNA-Ebene, als auch auf Proteinebene in GBP-1-exprimierenden EZ hochreguliert war. Die Hemmung der Lamellipodienbildung und der Migration war abhängig von der Bindung zwischen ITGA4 und dessen Liganden FN. Die Expression von ITGA4 konnte auch durch die inflammatorischen Zytokine IL-1 $\beta$ und TNF- $\alpha$ in EZ induziert werden. Ein spezifisches Abschalten der GBP-1-Proteinsynthese mittels shRNA nach Induktion mit diesen Zytokinen verhinderte die Expression von ITGA4 und die Fähigkeit der EZ zur Bildung stabiler Lamellipodien und zur Migration konnte dadurch wieder hergestellt werden.

Die Ergebnisse dieser Arbeit machen deutlich, dass GBP-1 hinreichend und notwendig ist, um die durch IL-1 $\beta$ - und TNF- $\alpha$-induzierte Hemmung der endothelialen Lamellipodienbildung und der Migration von EZ aufgrund der Hochregulation von ITGA4 zu vermitteln. Die Migration von EZ ist ein wichtiger Teilprozess während der Angiogenese. Die hier gezeigten Resultate untermauern die Rolle von GBP-1 als regulatorisches Schlüsselprotein bei der antiangiogenen Antwort der EZ nach dessen Aktivierung durch inflammatorische Zytokine. 


\section{Summary}

Human guanylate binding protein (GBP)-1 belongs to the familiy of large GTPases and is induced in human endothelial cells (EC) by the inflammatory cytokines interferon (IFN)- $\gamma$, interleukin (IL)-1 $\beta$ and tumor necrosis factor (TNF)- $\alpha$. GBP-1 exerts two important antiangiogenic activities in EC through inhibition of EC proliferation and invasiveness.

In this study we detected that GBP-1-expressing cells show a significantly reduced spreading and migration on fibronectin (FN)-coated surfaces. Investigating possible molecular mechanisms of these inhibitory effects, we found that integrin $\alpha_{4}$ (ITGA4) was consistently upregulated at both the RNA and protein level in GBP-1-expressing cell cultures. Inhibition of cell spreading and migration by GBP-1 was dependent on the binding of ITGA4 to its ligand FN. The inflammatory cytokines IL-1 $\beta$ and TNF- $\alpha$ induced ITGA4 expression in EC and inhibited cell spreading on FN-matrices. A specific knockdown of GBP-1 by shRNA abrogated inflammatory cytokine induced ITGA4 expression and restored spreading and migration capabilities of the cells.

These results indicate that GBP-1 is necessary and sufficient to mediate the inhibition of cell spreading and motility by IL-1 $\beta$ and TNF- $\alpha$ through induction of ITGA4 expression. Endothelial cell migration is a key process during angiogenesis. These findings highlight the role of GBP-1 as a key regulatory protein of the antiangiogenic response of EC to inflammatory cytokines. 


\section{$2 \quad$ Einleitung}

\subsection{Die Bildung neuer Blutgefäße: Vaskulogenese und Angiogenese}

Eine ausreichende Versorgung mit Sauerstoff und Nährstoffen ist Voraussetzung für das Überleben und Wachstum von Zellen innerhalb eines Organismus. Diese Versorgung wird durch das Blutgefäßsystem gewährleistet. Blutgefäße durchziehen den ganzen Körper und keine Zelle liegt aufgrund des Diffusionslimits von Sauerstoff mehr als 100 - $200 \mu \mathrm{m}$ von einem Blutgefäß entfernt. Das Gefäßsystem eines Menschen hat eine Fläche von ca. $1000 \mathrm{~m}^{2}$ und ist damit eines der größten Organe des menschlichen Körpers (Griffioen and Molema, 2000). Sämtliche Blutgefäße bauen sich aus einer Intima auf, die aus Endothelzellen (EZ) mesodermalen Ursprungs besteht und abluminal von einer Basalmembran (BM) und einer extrazellulären Matrix (EZM) aus Kollagen und Proteoglykanen umgeben ist. An einigen Stellen sind die BM und die EZM durchbrochen, um so Kontakte zu Perizyten und glatten Muskelzellen (GMZ) der Media zu ermöglichen. Die äußerste Hülle eines reifen Blutgefäßes (Adventitia) bilden Fibroblasten aus.

Im gesunden, reifen Gefäß sind die EZ vollständig durch Kontaktinhibition wachstumsarretiert und haben eine durchschnittliche Lebensdauer von mehreren Jahren. Die Fähigkeit zur Zellteilung (Proliferation) und Zellwanderung (Migration), sowie zur Selbstorganisation in Netzwerken und zur Lumenbildung behalten sie bei. Kommt es innerhalb des Organismus zur Entstehung bzw. Vergrößerung eines Organs oder Gewebes, wie beispielsweise während der Embryonalentwicklung oder dem Wachstum eines Tumors, müssen neue Blutgefäße gebildet werden.

Die de novo Entstehung von Blutgefäßen während der Embryonalentwicklung wird als Vaskulogenese bezeichnet. Bei diesem Prozess differenzieren hämatopoietische Stammzellen mesodermaler Herkunft über Angioblasten zu EZ, die als vaskuläre Lakunen bezeichnete Blutinseln umschließen. Durch Fusionierung bildet sich schließlich ein primitives Netzwerk aus, der sogenannte primäre vaskuläre Plexus (Carmeliet, 2003; Conway et al., 2001; Risau, 1997). Vaskulogenese ist nicht ausschließlich auf die Embryonalentwicklung beschränkt, sondern spielt auch im postnatalen Organismus eine wichtige Rolle (z.B. Neovaskularisierung nach Infarkt). Dabei werden endotheliale Vorläuferzellen, die aus dem Knochenmark stammen und im Blut zirkulieren, in neue Gefäße mit inkooperiert (Asahara et al., 1999). 
Abgelöst wird die Vaskulogenese von der (teilweise parallel) einsetzenden Entwicklung neuer Gefäße aus bereits bestehenden, der sogenannten Angiogenese. Hierbei unterscheidet man zwei Mechanismen: 1) die Aussprossung von bereits existierenden Gefäßen, auch als klassische Angiogenese bezeichnet, und 2) die Gefäßteilung nach einem nicht-sprossenden Muster (Abb. 1). Die Gefäßvermehrung nach diesem Prinzip kann entweder durch Kompartimentierung via intrakapillar einwachsender Endothelzellbrücken oder durch längsseitige Teilung einer Kapillare aufgrund einer Einschnürung (Intussusseption) erfolgen (Carmeliet, 2000; Conway et al., 2001). Bei letzterer wird interstitielles Gewebe in die Gefäße eingelagert, so dass es zur Gefäßteilung kommt (Patan et al., 1996).

Im adulten Organismus kommt der Prozess der Angiogenese im physiologischen Kontext beinahe vollständig zum Erliegen. Das Endothel befindet sich im Ruhezustand und die biologische Erneuerung der EZ ist sehr gering. Für EZ aus verschiedenen Geweben wurden Teilungsraten von 100 bis 10.000 Tagen angegeben (Denekamp, 1984). Lediglich während des weiblichen, ovariellen Zyklus im Uterus findet noch eine physiologische, angiogene Gefäßneubildung statt. Die pathophysiologische Angiogenese ist im adulten Organismus mit Erkrankungen, wie Wundheilung, chronischen Entzündungen, Herz-Kreislauf-Erkrankungen, Tumorwachstum, Metastasierung und Retinopathien assoziiert (Griffioen and Molema, 2000).

Verschiedene externe Stimuli, wie beispielsweise ein unzureichendes Sauerstoff- und Nährstoffangebot oder eine Verletzung der Gefäße, können eine angiogene Kaskade auslösen, welche $\mathrm{zu}$ erheblichen morphologischen und funktionellen Veränderungen der EZ führt. Diese Kaskade stellt einen komplexen Mehrschrittprozess dar, welcher sich in eine Aktivierungs- und Reifungsphase (oder Resolutionsphase) untergliedert (Carmeliet, 2000; Goumans et al., 2003; Yancopoulos et al., 2000). 


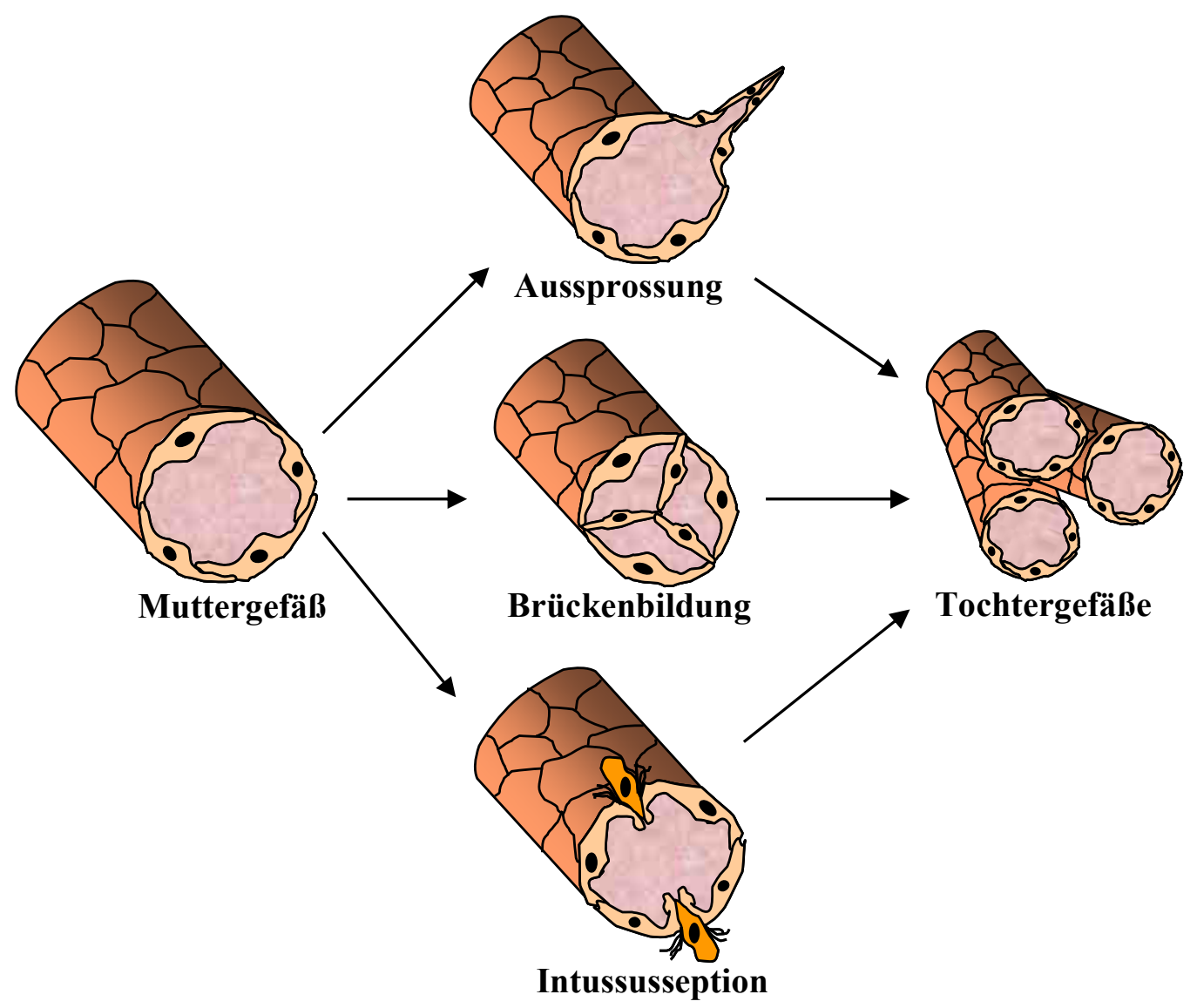

Abb. 1: Schematische Darstellung unterschiedlicher Mechanismen der Angiogenese.

Die Ausbildung neuer Blutgefäße aus bereits bestehenden Gefäßen bezeichnet man als Angiogenese. Neue Blutgefäße können aufgrund unterschiedlicher Mechanismen entstehen: 1) durch Aussprossung und 2) durch Gefäßteilung nach einem nicht-sprossenden Muster. Hierbei unterscheidet man zwischen Kompartimentierung via intrakapillar einwachsender Endothelzellbrücken (Brückenbildung) und der längsseitigen Teilung einer Kapillare durch Einschnürung (Intussusseption). Modifizierte Abbildung nach Carmeliet (Carmeliet, 2000).

\subsubsection{Die Aktivierungsphase der Angiogenese}

Der komplexe Vorgang der Angiogenese wird von zahlreichen Aktivatoren und Inhibitoren gesteuert (Bouck, 1990; Conway et al., 2001; Liotta et al., 1991; Pepper, 1996). Im gesunden Organismus herrscht ein koordiniertes Gleichgewicht zwischen pro- und antiangiogenen Faktoren (Tab. 1). Im Normalfall dominieren die inhibitorischen Faktoren, so dass keine Angiogenese stattfinden kann. Angiogenese wird induziert, sobald sich das Gleichgewicht zu Gunsten angiogener Faktoren verschiebt. 
Tab. 1: Auswahl von humanen pro- und antiangiogenen Faktoren.

\begin{tabular}{|c|c|}
\hline Proangiogene Faktoren & Antiangiogene Faktoren \\
\hline $\begin{array}{l}\text { vaskulärer-endothelialer Wachstumsfaktor } \\
\text { (VEGF) (Carmeliet, 2005; Veikkola et al., 2000) }\end{array}$ & $\begin{array}{l}\text { Thrombospondin (Rodriguez-Manzaneque et } \\
\text { al., 2001) }\end{array}$ \\
\hline $\begin{array}{l}\text { basischer Fibroblastenwachstumsfaktor } \\
\text { (bFGF) (Dow and deVere White, 2000) }\end{array}$ & Angiostatin (O'Reilly et al., 1994) \\
\hline $\begin{array}{l}\text { platelet-derived growth factor (PDGF) (Ostman, } \\
\text { 2004) }\end{array}$ & Interferon (IFN)- $\gamma$ (Friesel et al., 1987) \\
\hline $\begin{array}{l}\text { Angiopoietin (Ang)-1 und } \\
\text { Tyrosinkinaserezeptor (Tie)-2 (Koblizek et al., } \\
\text { 1998) }\end{array}$ & Interleukin (IL)-1 (Cozzolino et al., 1990) \\
\hline $\begin{array}{l}\text { Integrin } \alpha_{v} \beta_{3} \text { und Integrin } \alpha_{5} \beta_{1} \text { (Brooks et al., } \\
\text { 1994a) }\end{array}$ & $\begin{array}{l}\text { Tumornekrosefaktor (TNF)- } \alpha \text { (Schweigerer et } \\
\text { al., 1987) }\end{array}$ \\
\hline $\begin{array}{l}\text { Matrixmetalloproteinasen (MMP) (Stetler- } \\
\text { Stevenson, 1999) }\end{array}$ & $\begin{array}{l}\text { Guanylatbindungsprotein (GBP)-1 (Guenzi et } \\
\text { al., 2001; Guenzi et al., 2003) }\end{array}$ \\
\hline Nitritoxidsynthase (NOS) (Ziche et al., 1994) & $\begin{array}{l}\text { Angiopoietin (Ang)-2 (Maisonpierre et al., } \\
\text { 1997) }\end{array}$ \\
\hline Heparanase (Elkin et al., 2001) & Plättchenfaktor (PF)-4 (Gupta et al., 1995) \\
\hline
\end{tabular}

Bestimmte Schritte der Angiogenese lassen sich einzelnen Faktoren zuordnen (Conway et al., 2001). Der Initiation der Angiogenese geht stets eine durch Stickstoffmonoxid (NO)induzierte Vasodilatation voraus (Carmeliet, 2000). Anschließend erfolgt ein Permeabilitätsanstieg der Blutgefäße durch die Auflösung interendothelialer Kontakte zwischen benachbarten EZ, der vor allem durch den vaskulären-endothelialen Wachstumsfaktor (VEGF) vermittelt wird (Eliceiri et al., 1999; Gale and Yancopoulos, 1999). Die Expression von VEGF wird durch den Hypoxie-induzierbaren Faktor (HIF)-1 induziert, der aufgrund von Sauerstoffmangel aktiviert wird (Abb. 2A) (Cramer and Johnson, 2003; Plate et al., 1992; Shweiki et al., 1992). Durch die erhöhte Gefäßdestabilisierung treten verschiedene Plasmaproteine (Gerinnungsfaktoren, Fibrinogen, Vitronektin und Fibronektin) aus dem Blut in das umliegende Gewebe aus. Die Ansammlung dieser Plasmaproteine im subendothelialen Raum bewirkt, dass sich eine provisorische Matrix ausbildet, welche die Migration der EZ aus dem ,alten“ Gefäß ermöglicht. Für die Bildung neuer Blutgefäße mit intakter Mikrozirkulation ist VEGF alleine jedoch nicht ausreichend. Viele andere proangiogene Faktoren, wie beispielsweise der Tyrosinkinaserezeptor (Tie)-2 und sein Ligand 
Angiopoietin (Ang)-1 spielen neben VEGF bei der Angiogenese eine bedeutende Rolle (Koblizek et al., 1998). Das Ergebnis einer primär durch VEGF-induzierten Angiogenese ist ein für die Sauerstoffversorgung unzureichendes, unstrukturiertes Gefäßnetz aus Kurzschlussverbindungen und langen Kapillarschleifen. Derartige Netzwerke sind besonders für die Tumorangiogenese charakteristisch (Carmeliet and Jain, 2000).

Eine weitere Voraussetzung für Angiogenese ist die Degradation der BM und der EZM (Abb. 2B). Dieser Abbau erfolgt unter Beteiligung vieler verschiedener Matrixmetalloproteinasen (MMP) (Nelson et al., 2000; Shapiro, 1998) und anderen Proteinasen, wie beispielsweise der Heparanase (Nakajima et al., 1988). Dadurch wird zum einen Platz für die auswandernden EZ geschaffen, zum anderen werden die an Matrixproteinen verankerten angiogenen Wachstumsfaktoren, wie der basische Fibroblastenwachstumsfaktor (bFGF) und VEGF freigesetzt und deren Verfügbarkeit durch proteolytische Spaltung erhöht (Nelson et al., 2000; Schonherr and Hausser, 2000). Nach Degradation der EZM migrieren die EZ in das neu zu vaskularisierende Gewebe. Durch eine erhöhte Proliferation der EZ kommt es schließlich zu einer Ansammlung von locker miteinander verbundenen EZ (Abb. 2C).

\subsubsection{Die Reifungsphase der Angiogenese}

Während der Reifungsphase differenzieren die neugebildeten, einfachen Kapillaren zum reifen Gefäß. Die EZ stellen ihre Wanderung vollständig ein und es kommt zur Ausbildung neuer Zell-Zell-Kontakte, zur Hemmung der Proliferation, sowie zum Wiederaufbau der BM. Aufgrund einer endothelialen Sekretion von platelet-derived growth factor (PDGF) werden Perizyten und glatte Muskelzellen (GMZ) zu den EZ rekrutiert. Die GMZ und Perizyten ummanteln die EZ, erhöhen dadurch deren Stabilität und führen zur Enddifferenzierung der frisch formierten Gefäße (Carmeliet, 2000) (Abb. 2D). Die Reifung der Gefäße wird weiterhin von der endothelialen Synthese extrazellulärer Matrixproteine begleitet. 


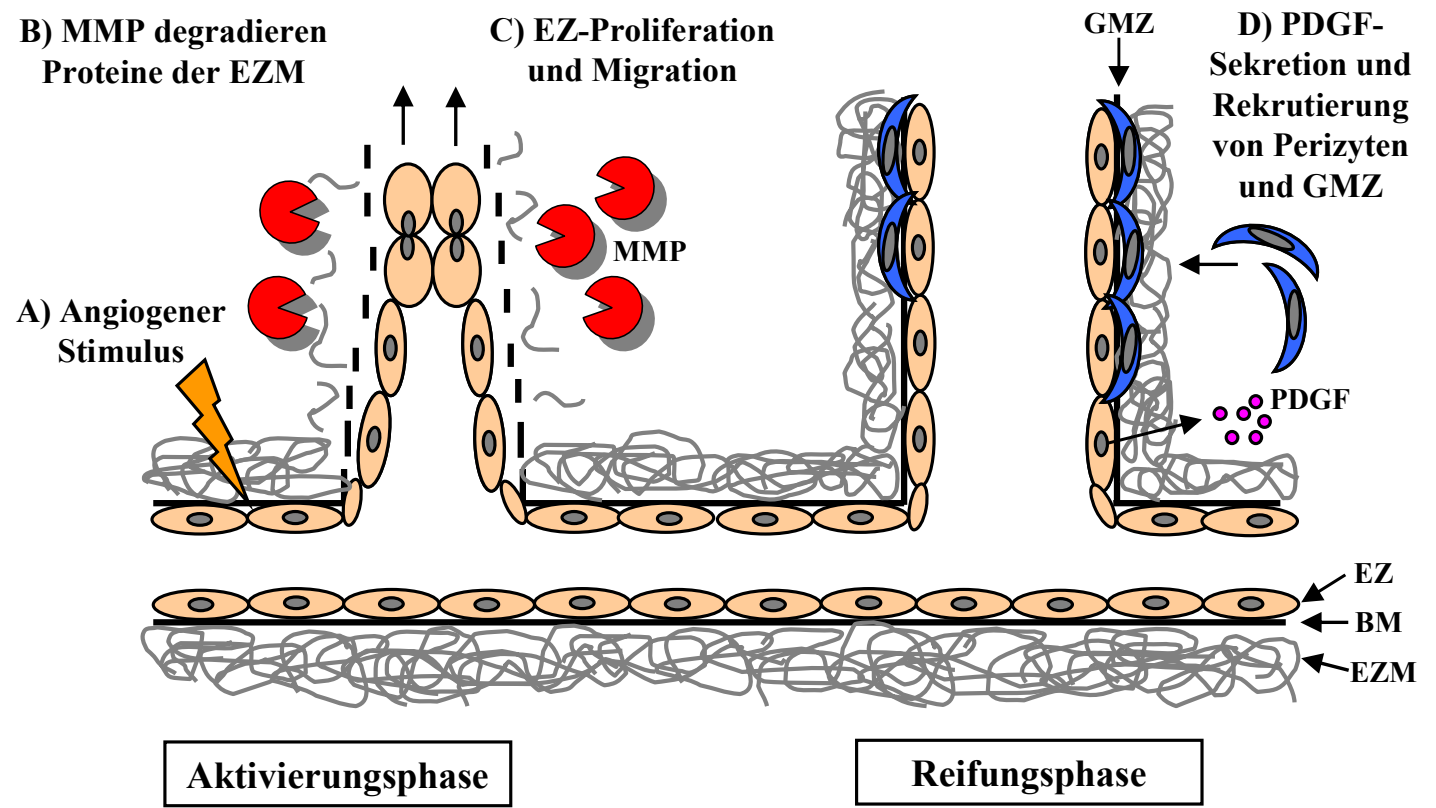

Abb. 2: Schematische Darstellung der verschiedenen Prozesse während der Angiogenese.

(A) Angiogenese kann durch verschiedene Stimuli, wie z.B. Sauerstoffmangel oder Verletzung induziert werden. Proangiogene Faktoren binden an ihre Rezeptoren und aktivieren Signaltransduktionskaskaden. (B) Matrixmetalloproteinasen (MMP) werden aktiviert und bauen sowohl die extrazelluläre Matrix (EZM), als auch die Basalmembran (BM) ab. (C) Diese Degradation ermöglicht es den EZ aus der Kapillarwand in das zu vaskularisierende Gewebe einzuwandern und dort zu proliferieren. (D) Während der Reifungsphase sekretieren EZ platelet-derived growth factor (PDGF), der wiederum Perizyten und glatte Muskelzellen (GMZ) rekrutiert. Die GMZ ummanteln die EZ der neu gebildeten Gefäße, was eine weitere Proliferation und Migration der EZ verhindert und die Gefäße stabilisiert. Modifizierte Abbildung nach Goumans et al. (Goumans et al., 2003).

\subsection{Integrine und ihre Bedeutung während der Angiogenese}

Die Adhäsion und Migration von EZ während der Aktivierungsphase der Angiogenese wird hauptsächlich durch Mitglieder der Integrinfamilie gesteuert. Integrine sind auf vielfältige Weise an der Angiogenese beteiligt. Dies stützt sich auf verschiedene Beobachtungen: 1) Auf ruhendem Endothel wird weder Integrin $\alpha_{v} \beta_{3}$ noch Integrin $\alpha_{5} \beta_{1}$ exprimiert. Nach Aktivierung des Endothels durch proangiogene Faktoren wie VEGF oder bFGF wird die Expression dieser beiden Integrine auf EZ induziert (Brooks et al., 1994a; Enaida et al., 1998; Kim et al., 2000a). 2) Integrine vermitteln proangiogene Zellfunktionen, wie die Migration, die Matrix-abhängige Proliferation und die Regulation der Matrixdegradation (Kim et al., 2000a; Kim et al., 2000b; Stupack and Cheresh, 2004). 3) Eine Antikörper- oder Peptidvermittelte Blockade Integrin-abhängiger Adhäsions- und Migrationsprozesse verhindert Angiogenese in vitro und in vivo (Bazzoni et al., 1999; Brooks et al., 1994a; Brooks et al., 1994b). 4) Ein spezifisches Ausschalten der Gene von bestimmten Integrinuntereinheiten in sogenannten „Knock-out“-Mäusen führt zu vielfältigen vaskulären Entwicklungsstörungen (Hynes and Bader, 1997). 


\subsubsection{Allgemeiner Aufbau von Integrinen und Integrin-vermittelte Signalwege}

Integrine sind heterodimere Transmembranrezeptoren und bestehen aus jeweils zwei Glykoproteinketten, die nicht-kovalent miteinander verbunden sind. Sie vermitteln sowohl Zell-Matrix-, als auch Zell-Zell-Interaktionen (Hynes, 1992). Ihr Name, der zum ersten Mal von Hynes 1986 verwendet wurde, bezieht sich auf ihre Rolle in der Integration der EZM mit dem intrazellulären Aktinzytoskelett (van der Flier and Sonnenberg, 2001).

Jedes Integrin besteht aus einer $\alpha$ - und einer $\beta$-Untereinheit (Hynes, 1992; Hynes, 2002). Die bisher bekannten $18 \alpha$-Untereinheiten variieren in ihrer Größe zwischen 120 und $180 \mathrm{kDa}$, während die acht unterschiedlichen $\beta$-Untereinheiten zwischen 90 und $110 \mathrm{kDa}$ groß sind. In Säugern sind bisher insgesamt 24 verschiedene Integrinheterodimere bekannt, die sich aus verschiedenen Kombinationen der beiden Untereinheiten ergeben (Abb. 3) (Hynes, 2002; Ruegg et al., 2004).

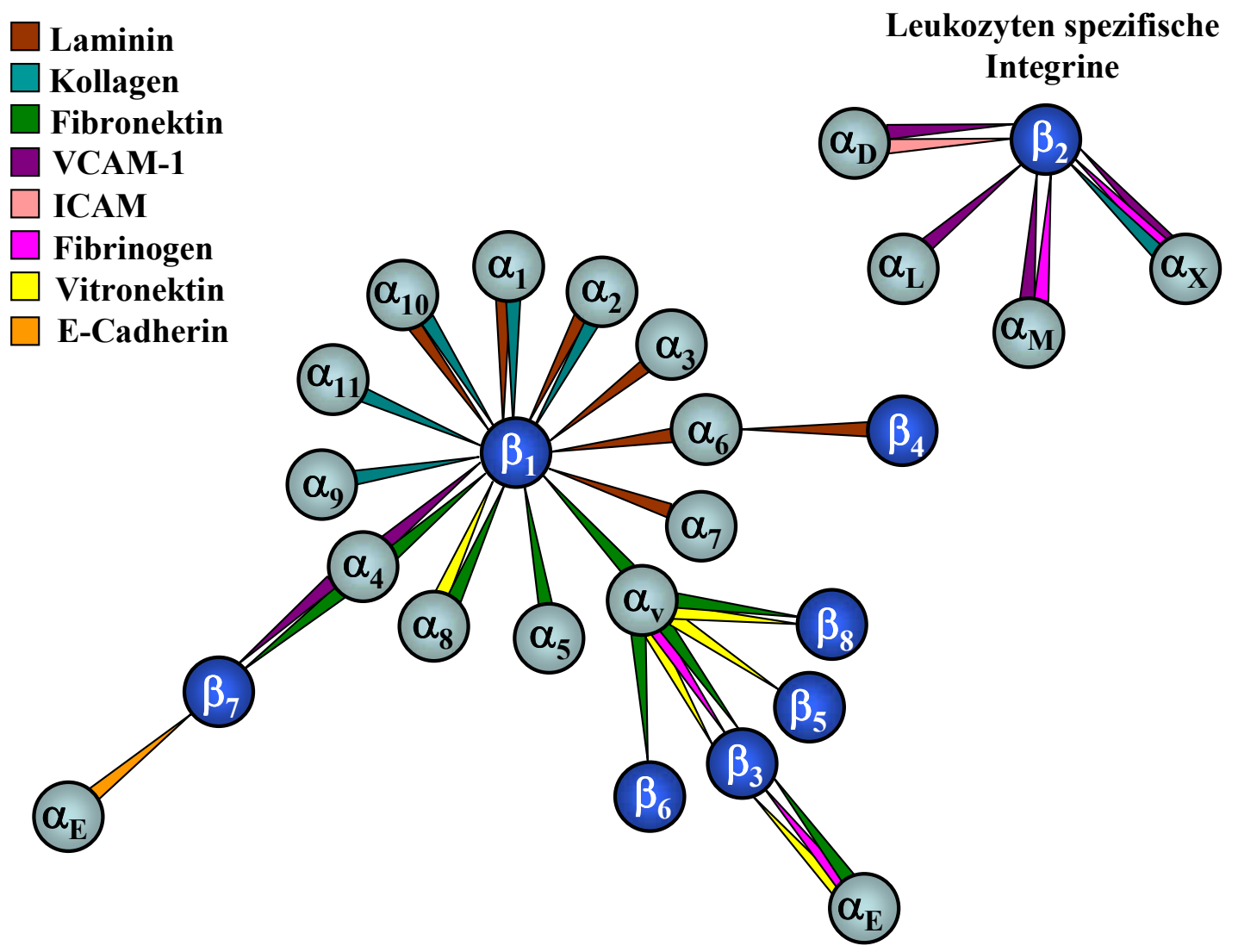

Abb. 3: Die Integrinfamilie und ihre Hauptliganden.

In Säugern sind $18 \alpha$ - (hellblaue Kreise) und acht $\beta$-Untereinheiten (dunkelblaue Kreise) bekannt, die zusammen 24 verschiedene Heterodimere ausbilden können, welche in ihrer Ligandenspezifität sehr variieren (langgezogene Dreiecke). Obwohl Integrine hauptsächlich mit Proteinen der EZM interagieren, können sie auch mit zellulären Rezeptoren (z.B. ICAM, VCAM-1) und Pathogenen (Viren, Pilze, Bakterien) wechselwirken. Die Expression von $\beta_{2}$-Integrinen ist auschließlich auf Leukozyten beschränkt. Modifizierte Abbildung nach Hynes und Ruegg et al. (Hynes, 2002; Ruegg et al., 2004). 
Alle Integrinuntereinheiten besitzen eine große extrazelluläre Domäne, welche als Rezeptor fungiert, eine Transmembrandomäne und einen sehr kurzen intrazellulären Bereich (Abb. 4) (Hood and Cheresh, 2002). Während einige Integrine nur eine spezifische Komponente der EZM binden, können andere Integrine mehrere verschiedene Komponenten der EZM erkennen (Abb. 3). Integrin $\alpha_{v} \beta_{3}$ beispielsweise bindet an Vitronektin, Fibronektin (FN) und Fibrinogen, wohingegen Integrin $\alpha_{5} \beta_{1}$ ausschließlich mit FN interagiert (Hynes, 2002; Ruegg et al., 2004; van der Flier and Sonnenberg, 2001). Beide Untereinheiten sind an der Bindung und Erkennung des jeweiligen Liganden beteiligt. Die zytoplasmatischen Domänen der $\alpha-$ und $\beta$-Ketten besitzen keine intrinsische Enzymaktivität, sind aber nach ihrer Aktivierung durch Ligandenbindung an der Rekrutierung vieler verschiedener Adapterproteine und Proteine des Aktinzytoskeletts beteiligt. Durch die Rekrutierung intrazellulärer Proteine sind Integrine direkt an der Initiation von Signaltransduktionskaskaden beteiligt. Integrin-abhängig kann beispielsweise die Aktivierung der kleinen GTPasen der Rho-Familie (Rho, Rac, Cdc42) induziert werden, was schließlich zur Reorganisation des Aktinzytoskeletts (Abb. 4) und zur gerichteten Migration der Zelle führt (Abb. 5) (Clark et al., 1998; Nobes and Hall, 1995; Ren et al., 1999).

Integrine sind weit verbreitete Transmembranrezeptoren, die auf vielen unterschiedlichen Zelltypen, wie EZ, GMZ, Monozyten, Leukozyten und Thrombozyten, exprimiert werden (Clemetson and Clemetson, 1998). Von den 24 bekannten Integrinen spielen 16 eine bedeutende Rolle in der vaskulären Biologie, wobei acht dieser Integrine von EZ selbst exprimiert werden (Rupp and Little, 2001). Hierzu zählen die Integrine $\alpha_{v} \beta_{3}, \alpha_{2} \beta_{1}, \alpha_{3} \beta_{1}$ und $\alpha_{5} \beta_{1}$ (Luscinskas and Lawler, 1994), aber auch $\alpha_{1} \beta_{1}, \alpha_{6} \beta_{1}, \alpha_{4} \beta_{1}$ und $\alpha_{v} \beta_{5}$ (Brezinschek et al., 1996; Clemetson and Clemetson, 1998; Rupp and Little, 2001). Das Expressionsmuster der beschriebenen Integrine in EZ ist in der Literatur nicht einheitlich beschrieben. Dies könnte in unterschiedlichen Kulturbedingungen, sowie in der Verwendung unterschiedlich differenzierter EZ begründet sein.

Integrine, die an der Oberfläche von hämatopoietischen Zellen exprimiert werden, binden meist nicht an Komponenten der EZM, sondern an die Rezeptoren anderer Zellen. Dazu gehört beispielsweise das intrazelluläre Adhäsionsmolekül (ICAM)-1 oder das vaskuläre Zelladhäsionsmolekül (VCAM)-1. Integrine können aber auch von Bakterien, Pilzen und Viren als Rezeptoren erkannt werden (Kerr, 1999). 


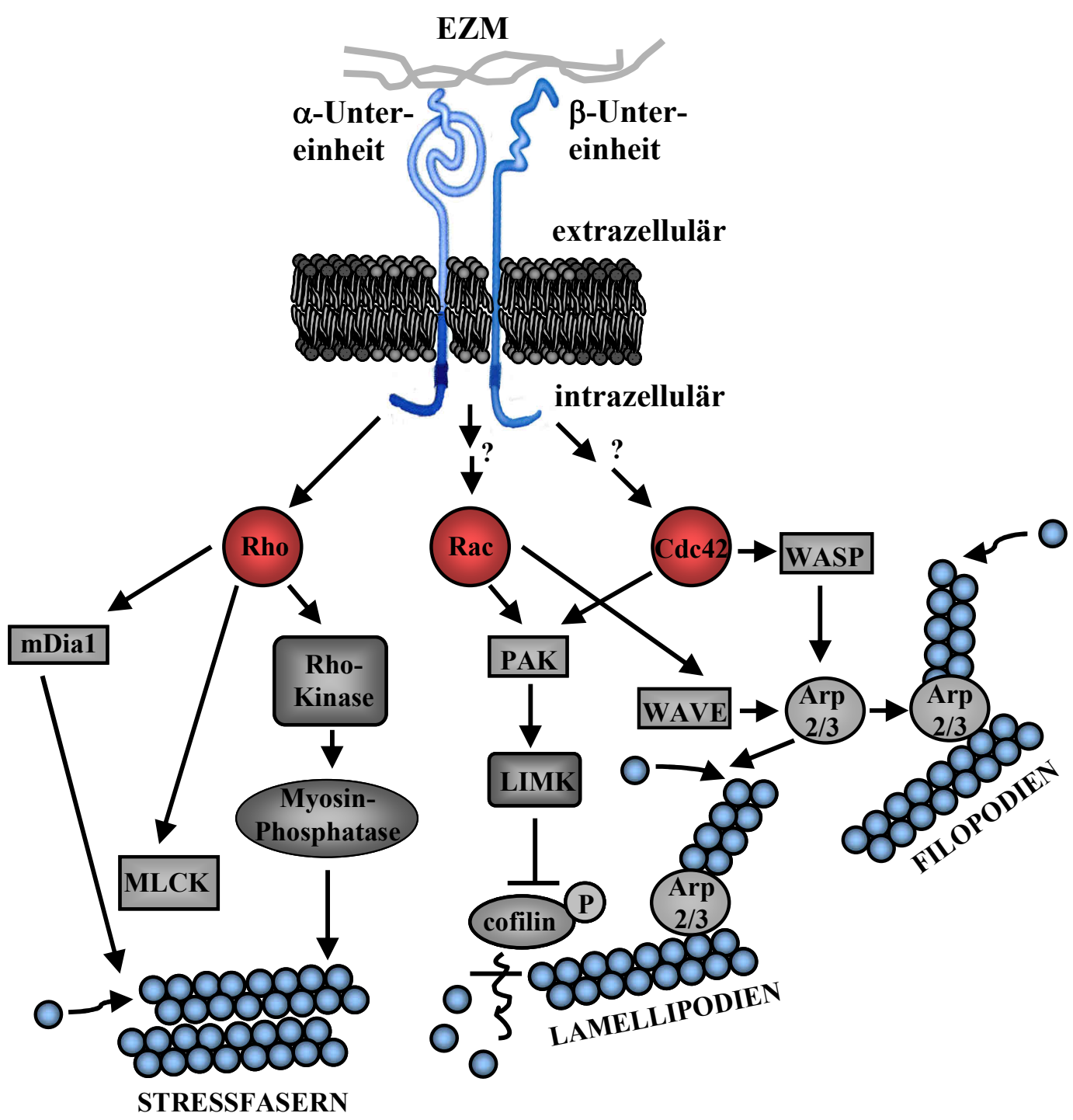

Abb. 4: Struktur der Integrine und deren Modulation des Aktinzytoskeletts über die kleinen GTPasen der Rho-Familie.

Integrine aktivieren nach Bindung ihres Liganden (EZM) kleine GTPasen der Rho-Familie (Rho, Rac, Cdc42) indirekt über noch nicht im Detail charakterisierte Signalwege. Über den Cdc42-WASP-Signalweg kommt es zur Aktivierung des Aktinpolymerisationskomplexes Arp2/3 und zur Bildung von Filopodien. Über eine RacAktivierung werden die Serinkinasen PAK und LIMK aktiviert, wodurch Cofilin phosphoryliert und deaktiviert wird. Cofilin ist im unphosphorylierten Zustand an der Depolymerisation von Aktinfilamenten beteiligt. Dies führt zur Bildung von Lamellipodien. Über den Rho-Weg kommt es zur Aktivierung von Rho-Effektorkinasen (ROCK, MLCK), die im Zusammenspiel mit anderen Proteinen (mDia1) die Bildung von Aktinstressfasern hervorrufen. Modifizierte Abbildung nach Juliano (Juliano, 2002). 


\subsubsection{Integrine und ihre Bedeutung bei der Migration von Endothelzellen}

Die Migration von EZ ist ein wichtiger Prozess während der Angiogenese. Erst eine koordinierte Bindung zwischen EZM-Proteinen, Integrinen und Aktinfilamenten ermöglicht eine gerichtete Bewegung der Zellen. Aktinfilamente bilden einen Teil des zellulären Zytoskeletts und polymerisieren intrazellulär unter Mitwirkung von ATP und zweiwertigen Kationen, wie $\mathrm{Ca}^{2+}$ und $\mathrm{Mg}^{2+}$ zu elastischen Bündeln, die wieder in ihre Monomere abgebaut werden können.

Bei der Migration bildet die Zelle in Migrationsrichtung eine Aktin-reiche Vorderseite und eine Aktin-arme Rückseite aus (Abb. 5). Diese unterschiedliche Aktinverteilung innerhalb der Zelle bezeichnet man als Polarisation (Hood and Cheresh, 2002). Durch eine Integrinabhängige Aktinpolymerisation an der Vorderseite der Zelle bilden sich Membranausstülpungen, die frei von Zellorganellen sind und je nach Gestalt als Lamellipodien oder Filopodien bezeichnet werden (Lauffenburger and Horwitz, 1996; Raucher and Sheetz, 2000). Wie bereits in Abschnitt 2.2.1 beschrieben sind die kleinen GTPasen der Rho-Familie an der Ausbildung solcher Membranausstülpungen durch Induktion der Aktinpolymerisation beteiligt (Nobes and Hall, 1995). Lamellipodien sind durch eine breite, flache und flächige Struktur charakterisiert, wohingegen Filopodien dünne, zylindrische oder nadelförmige Gebilde darstellen. Während der Wanderung bewegen sich diese Membranstrukturen von der Vorderseite zur Rückseite der Zelle, indem sie durch eine stetige Aktinpolymerisation nach hinten geschoben werden (Hood and Cheresh, 2002). Integrine sind vor allem an der Vorderseite der Zelle zu finden, wo sie zum einen neue ZellEZM-Kontakte in Bewegungsrichtung knüpfen, und zum anderen der Zelle einen festen Halt am Untergrund (Proteine der EZM) verschaffen. An der Rückseite der Zelle werden dagegen alle bestehenden Zell-Matrix-Verbindungen aufgelöst. Die kontraktile Bewegung der Zelle zur Vorderseite hin resultiert schließlich aus der Aktivierung intrazellulärer Aktin-MyosinEinheiten, welche die Zelle zusammenziehen (Lauffenburger and Horwitz, 1996). 
1) Polarisation

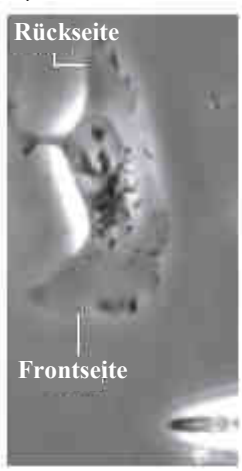

2) Ablösen der Zellrückseite

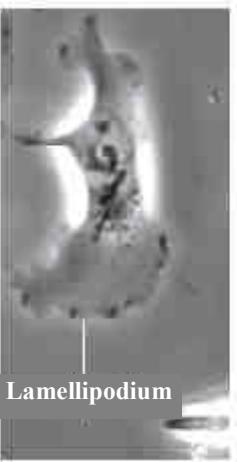

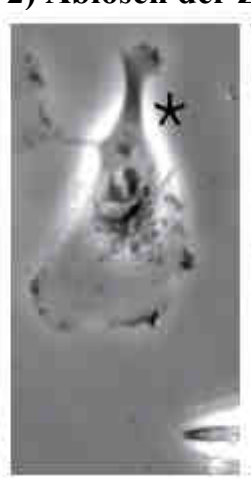

\section{3) Bewegung}

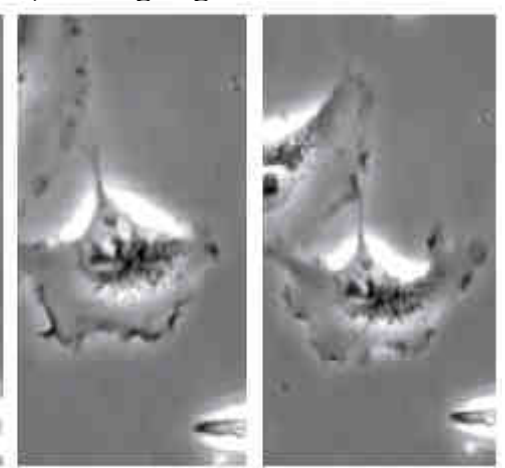

Abb. 5: Mechanismus der Zellmigration am Beispiel einer Adenokarzinomzelle (Hep3) nach Stimulation mit Insulin.

Die Zellmigration ist ein komplexer Prozess, der sich in drei unterschiedliche Phasen untergliedert. Bei der Polarisation der Zelle entstehen eine Aktin-arme Rückseite und eine Aktin-reiche Frontseite. An der Frontseite kommt es zur Aktinpolymerisation und es bilden sich sogenannte Lamellipodien in Richtung des chemotaktischen Stimulus aus. Um ein Fortbewegen der Zelle zu ermöglichen, werden die an der Zellrückseite bestehenden adhäsiven Kontakte zur EZM aufgelöst (mit Stern gekennzeichnet). Nachdem an der Zellfrontseite über Integrine neue Kontakte zur EZM ausgebildet wurden, kommt es intrazellulär schließlich zur Aktivierung von AktinMyosin-Einheiten, welche zur Kontraktion und zu einer gerichteten Fortbewegung des Zellkörpers führen. Modifizierte Abbildung nach Hood und Cheresh (Hood and Cheresh, 2002).

\subsubsection{Integrin $\alpha_{4}$}

Das Integrin $\alpha_{4}$ (ITGA4) unterscheidet sich wesentlich von allen anderen, bisher bekannten Integrinen. ITGA4 bildet zusammen mit den Untereinheiten $\beta_{1}$ (ITGB1) und $\beta_{7}$ (ITGB7) Heterodimere aus, welche als $\alpha_{4} \beta_{1}$ und $\alpha_{4} \beta_{7}$ an FN binden können. Im Vergleich zu allen anderen Integrinen sind die Integrine $\alpha_{4} \beta_{1}$ und $\alpha_{4} \beta_{7}$ die einzigen Integrine, die $\mathrm{FN}$ an einer $\mathrm{C}$ terminalen Bindestelle (Typ III Modul 14-IIICS) erkennen (Abb. 6). Andere Integrine, wie beispielsweise $\alpha_{v} \beta_{3}$ oder $\alpha_{5} \beta_{1}$ binden FN über eine zentrale Integrinbindestelle (Typ III Modul 9-10) (Abb. 6) (Pankov and Yamada, 2002; Plow et al., 2000).

Neben seinem spezifischen FN-Erkennungsmotiv besitzt ITGA4 auch biologische Aktivitäten, die es von den anderen Integrinen deutlich abgrenzt. Es wurde bereits von mehreren Gruppen beobachtet, dass die Expression von ITGA4 die Bildung zellulärer Lamellipodien hemmt (Chan et al., 1992; Kassner et al., 1995; Liu et al., 1999). Weiterhin konnte gezeigt werden, dass die Fähigkeit der Zellen zur Migration und Invasion, welche durch die Integrine $\alpha_{v} \beta_{3}$ und $\alpha_{5} \beta_{1}$ aktiviert wird, nach Expression von ITGA4 reduziert ist (Ignatoski et al., 2000; Jia et al., 2004; White et al., 2003; Zhang et al., 2004). Der molekulare Mechanismus, wie ITGA4 die zelluläre Lamellipodienbildung, die Migration und Invasion hemmt, ist allerdings noch nicht vollständig geklärt. Studien, in denen verschiedene Integrin- 
Chimäre untersucht wurden, zeigten, dass die zytoplasmatische Domäne von ITGA4 für diese inhibitorischen Effekte verantwortlich ist (Chan et al., 1992; Kassner et al., 1995). Paxillin, ein Adapterprotein, bindet direkt und spezifisch an die zytoplasmatische Domäne von ITGA4, wodurch eine Aktivierung der kleinen GTPase Rac verhindert wird und es schließlich zur Hemmung der Lamellipodienbildung kommt (Goldfinger et al., 2003; Liu et al., 1999; Nishiya et al., 2005).
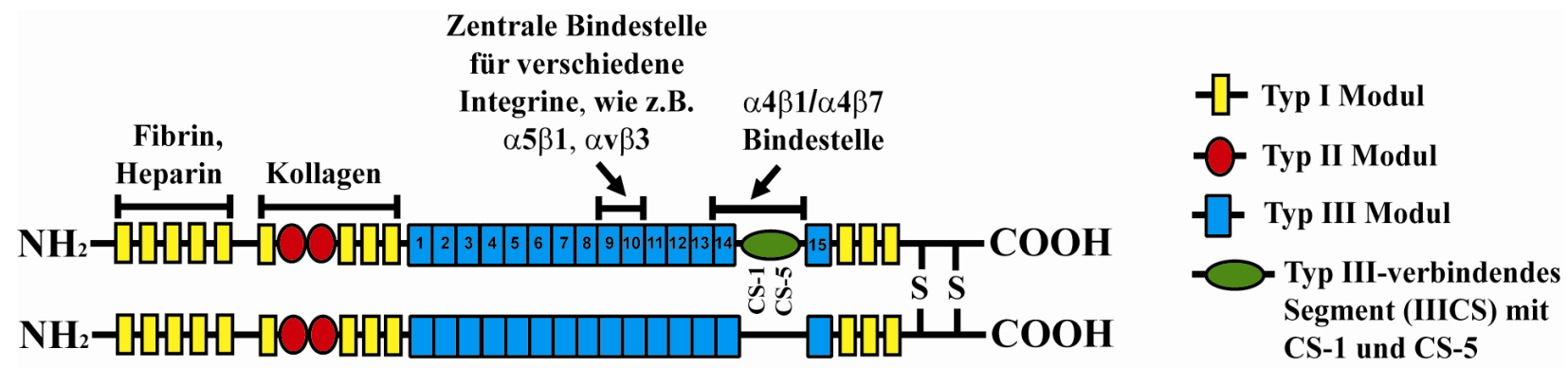

Abb. 6: Schematische Darstellung von FN.

FN besteht aus vier verschiedenen Modulen, welche als Typ I (gelb), Typ II (rot), Typ III (blau) und Typ IIIverbindendes Segment (IIICS) (grün) bezeichnet werden. Neben einer Fibrin/Heparin- und einer KollagenBindestelle am N-Terminus besitzt FN auch zwei Bindestellen für Integrine: (1) eine zentrale Integrinbindestelle, an die viele verschiedene Integrine binden können (Typ III Modul 9-10) und (2) eine C-terminale Bindestelle, welche ausschließlich von den Integrinen $\alpha_{4} \beta_{1}$ und $\alpha_{4} \beta_{7}$ erkannt wird (Typ III Modul 14-IIICS).

\subsection{Inflammatorische Zytokine und ihre Wirkung auf Endothelzellen}

Neben der Aktivierung durch proangiogene Faktoren, die zur Angiogenese führen, kann die Genexpression, Differenzierung und Proliferation von EZ auch durch inflammatorische Zytokine moduliert werden (Spurlock, 1997; Williams, 1991). Inflammatorische Zytokine sind kleine, nicht-enzymatische Glykoproteine, die das Verhalten bzw. das Genexpressionsmuster von EZ und anderen Zellen verändern und somit an der Regulation der Immunantwort beteiligt sind. EZ sind aber nicht nur Zielzellen der Zytokine, sondern können diese während einer Entzündungsreaktion auch selbst exprimieren und sezernieren (Mantovani et al., 1992). Die wichtigsten proinflammatorischen Zytokine sind Interferon (IFN)- $\gamma$, Interleukin (IL)-1 und Tumornekrosefaktor (TNF)- $\alpha$ (Curfs et al., 1997; Larrick and Kunkel, 1988). 


\subsubsection{Die Wirkung von IL-1 und TNF- $\alpha$ auf Endothelzellen}

IL-1, das in zwei Subtypen (IL-1 $\beta$ und IL-1 $\alpha$ ) mit ähnlicher biologischer Aktivität vorkommt (Sauder, 1989) und TNF- $\alpha$ rufen in EZ einen prothrombotischen, proinflammatorischen Phänotyp hervor (Mantovani et al., 1998). Beide Zytokine induzieren die endotheliale Expression von Thromboplastin (Faktor III) (Bevilacqua et al., 1984) und des Plättchenaktivierenden Faktors (PAF) (Nawroth and Stern, 1986). Weiterhin wird durch die Stimulation der EZ mit IL-1 und TNF- $\alpha$ die Expression anderer Zytokine aktiviert, welche bei der Inflammation eine wichtige Rolle spielen. Dazu gehören der Granulozyten/MakrophagenKolonie-stimulierende Faktor (GM-CSF), IL-6, IL-8 und das Monozyten-Chemotaxis-Protein (MCP)-1 (Cotran and Pober, 1990; Pober and Cotran, 1990; Zoja et al., 1991). Neben der Induktion von Zytokinen bewirken IL-1 und TNF- $\alpha$ auch eine Erhöhung der endothelialen Adhäsionskompetenz für Leukozyten, indem sie die Expression von ICAM-1, VCAM-1 und E-Selektin induzieren (Hession et al., 1990; Zhang et al., 2006). Auch die Morphologie der EZ verändert sich nach Stimulation mit IL-1 und TNF- $\alpha$ stark. Die typische pflastersteinartige Zellform der EZ wandelt sich zu einer länglichen, spindelförmigen Morphologie um, was auf eine Reorganisation des Aktinzytoskeletts zurückzuführen ist. Durch diese Veränderung der Zellmorphologie kommt es schließlich zu einer Erhöhung der Gefäßpermeabilität, um so das Auswandern der Leukozyten in das entzündliche Gewebe zu erleichtern (Pober and Cotran, 1990). Des Weiteren wurde sowohl für IL-1, als auch für TNF- $\alpha$ eine antiangiogene Wirkung nachgewiesen. Beide Zytokine lösen einen Zellzyklusarrest in der G1-Phase des Zellzyklus aus, wodurch die Proliferation der EZ gehemmt wird (Cozzolino et al., 1990; Guenzi et al., 2001). Die meisten der durch IL-1- und TNF- $\alpha$-induzierten Funktionen werden durch den Transkriptionsfaktor nukleärer Faktor (NF)- $\mathrm{B}$ und dessen Einfluss auf die Genexpression gesteuert (Osborn et al., 1989).

\subsubsection{Der Einfluss von IFN- $\gamma$ auf Endothelzellen}

Im Gegensatz zu IL-1 und TNF- $\alpha$ ist das proinflammatorische Zytokin IFN- $\gamma$ (Typ IIInterferon) ein bedeutender Regulator der angeborenen und erlernten Immunantwort (Boehm et al., 1997). Die Hauptaufgabe von IFN- $\gamma$ besteht in der Bekämpfung von Pathogenen, wie Viren, Pilzen und intrazellulären Bakterien. Dabei löst das Zytokin eine initiale Abwehrreaktion aus, die den infizierten Organismus in der Zeit bis zum Einsetzen der zellulären Immunantwort schützen soll (Samuel, 2001). IFN- $\gamma$ wird vorrangig von aktivierten 
natürlichen Killer (NK)-Zellen und aktivierten T-Zellen $\left(\mathrm{T}_{\mathrm{H}} 1\right)$ nach einer bakteriellen Infektion oder Stimulation mit IL-12 und IL-18 exprimiert und sezerniert (Boehm et al., 1997; Curfs et al., 1997; Young, 1996). IFN- $\gamma$ moduliert die Expression von über 200 verschiedenen Genen (Boehm et al., 1997). So bewirkt IFN- $\gamma$ beispielsweise eine erhöhte Expression der Haupthistokompatibilitätskomplexe (MHC) der Klasse I und II (Ahmed et al., 2003; Mantovani et al., 1992; Mantovani et al., 1998), sowie eine erhöhte Expression der Adhäsionsmoleküle ICAM-1 (Pober et al., 1986) und des endothelialen Leukozytenadhäsionsmoleküls (ELAM)-1 (Leeuwenberg et al., 1990). Wie IL-1 und TNF- $\alpha$ hemmt auch IFN- $\gamma$ die Proliferation von EZ und wirkt somit antiangiogen (Friesel et al., 1987; Guenzi et al., 2001). Weiterhin führt IFN- $\gamma$ zu einer Veränderung der Zellmorphologie von einer pflastersteinartigen zu einer spindelförmigen Form (Stolpen et al., 1986). Die Wirkung und Funktion vieler IFN- $\gamma$-induzierter Gene ist bis heute noch unbekannt (Boehm et al., 1997).

\subsection{Das Guanylatbindungsprotein-1}

Kürzlich konnte ein Gen identifiziert werden, dessen Expression selektiv durch die inflammatorischen Zytokine IFN- $\gamma$, IL-1 $\beta$ und TNF- $\alpha$ in EZ in vitro und in vivo induziert und durch angiogene Wachstumsfaktoren (VEGF, bFGF) gehemmt wird (Guenzi et al., 2001; Lubeseder-Martellato et al., 2002). Das isolierte Gen kodiert für das Guanylatbindungsprotein (GBP)-1.

GBP-1 gehört zu einer Subfamilie der großen GTPasen, die erstmals als die am stärksten durch IFN- $\gamma$-induzierten Proteine in humanen Fibroblasten beschrieben wurden (Cheng et al., 1983). Bis heute konnten sieben humane (GBP-1 bis GBP-7) und zehn murine GBPMitglieder mit einem Molekulargewicht zwischen 65 und $71 \mathrm{kDa}$ identifiziert werden (Degrandi et al., 2007; Olszewski et al., 2006; Tripal et al., 2007). Neben der GBP-Subfamilie besteht die Familie der großen GTPasen aus weiteren Mitgliedern, wie den Atlastinen (Zhu et al., 2003), den Mx-Proteinen (Aebi et al., 1989) und den Dynaminen (Diatloff-Zito et al., 1995). Über die Expression und Funktion der verschiedenen humanen GBPs ist bisher sehr wenig bekannt. Lediglich GBP-1 wurde durch zahlreiche Analysen zur Struktur und Funktion näher charakterisiert. 


\subsubsection{Biochemische Eigenschaften und Struktur von GBP-1}

GBP-1 kann im Unterschied zu anderen GTPasen sowohl Guanosintriphosphat (GTP), als auch Guanosindiphosphat (GDP) und Guanosinmonophosphat (GMP) binden (Praefcke et al., 1999). Die Bindung von GTP an GBP-1 bewirkt eine Oligomerisierung, wodurch sich die intrinsische Hydrolyseaktivät des Proteins stark erhöht und GTP über GDP zu GMP und anorganischem Phosphat hydrolysiert wird (Prakash et al., 2000b; Schwemmle and Staeheli, 1994). GBP-1 hydrolysiert GTP unabhängig von Guaninnukleotid-Austauschfaktoren (GEF), GTPase-aktivierenden Proteinen (GAP) oder anderen akzessorischen Proteinen (Prakash et al., 2000b).

Mit Hilfe von Röntgenstrukturanalysen wurde die Tertiärstruktur von GBP-1 bereits aufgeklärt (Abb. 7z) (Prakash et al., 2000a; Prakash et al., 2000b). Anhand dieser Struktur kann GBP-1 in zwei, annähernd gleich große Domänen unterteilt werden: 1) eine Nterminale, kompakte, globuläre Domäne, welche die GTPase-Aktivität enthält und 2) eine Cterminale, lange, $\alpha$-helikale Domäne. Weiterhin besitzt GBP-1 am C-Terminus ein CaaXMotiv ( $\mathrm{C}=$ Cystein, $\mathrm{a}=$ aliphatische Aminosäure, $\mathrm{X}=$ beliebige Aminosäure), welches als Isoprenylierungssignal fungiert und zur Farnesylierung von GBP-1 in vitro und in vivo führt (Nantais et al., 1996; Schwemmle and Staeheli, 1994).

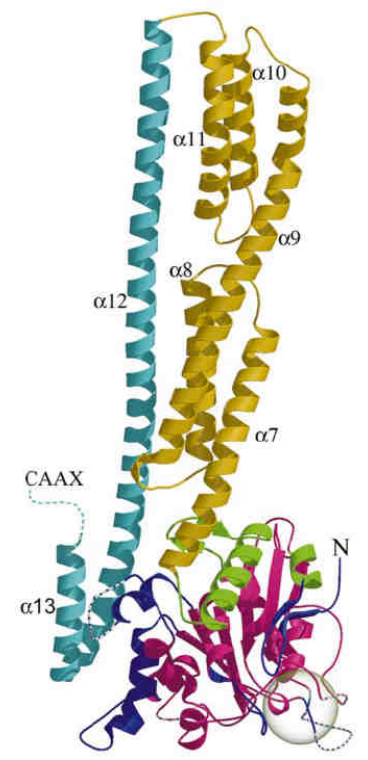

Abb. 7: Schematische Darstellung der Tertiärstruktur von GBP-1.

Die Struktur von GBP-1 kann in zwei Domänen unterteilt werden: 1) eine N-terminale, globuläre Domäne, welche die GTPase-Aktivität beinhaltet und aus $\alpha$-Helices und $\beta$-Faltblättern aufgebaut ist (pink, blau, grün) und 2) eine C-terminale, $\alpha$-helikale Domäne (gelb, türkis). Die Bindestelle des Guaninnukleotids in der globulären Domäne ist durch eine Kugel gekennzeichnet. Das CaaX-Motiv am C-Terminus, sowie alle Verbindungsschleifen, welche mittels Röntgenstrukturanalyse nicht aufgelöst werden konnten, sind als gestrichelte Linien dargestellt. Modifizierte Abbildung nach Prakash (Prakash et al., 2000b). 


\subsubsection{Expression und transkriptionelle Regulation von GBP-1}

In vitro kann GBP-1 in unterschiedlichen Zellen nach Behandlung mit IFN- $\gamma$ exprimiert werden. Dazu gehören EZ, GMZ, Fibroblasten, Keratinozyten, B-Zellen und T-Zellen (Guenzi et al., 2001; Guenzi et al., 2003; Lubeseder-Martellato et al., 2002; Naschberger et al., 2006). Neben IFN- $\gamma$ kann GBP-1 in EZ auch durch die inflammatorischen Zytokine IL-1 $\beta$ und TNF- $\alpha$ induziert werden (Guenzi et al., 2001; Lubeseder-Martellato et al., 2002). Von allen diesen Zytokinen ist bekannt, dass sie antiangiogen wirken, da sie die Proliferation von EZ hemmen (siehe Tab. 1 und Abschnitt 2.3) (Cozzolino et al., 1990; Frater-Schroder et al., 1987; Friesel et al., 1987; Schweigerer et al., 1987). Im Gegensatz zur in vitro Situation wird GBP-1 in vivo vor allem in EZ der Blutgefäße exprimiert und seltener in anderen Zellen, wie Monozyten/Makrophagen (Lubeseder-Martellato et al., 2002). GBP-1 stellt somit einen molekularen Marker für inflammatorisch-aktivierte EZ während einer Entzündungsreaktion dar.

Die transkriptionelle Aktivierung der GBP-1-Expression in EZ erfolgt nach einer Stimulation mit IFN- $\gamma$ im Vergleich zu einer IL-1 $\beta$ - und TNF- $\alpha$-Behandlung unterschiedlich. Eine IFN- $\gamma-$ Behandlung führt zu einer Aktivierung des Transkriptionsfaktors IRF-1 (interferon regulatory factor-1), welcher an ein ISRE (interferon- $\alpha$-stimulated response element)/GAS (gammainterferon activation site)-Element im GBP-1-Promotor bindet und die Expression von GBP-1 induziert (Kroger et al., 2002). Im Gegensatz dazu ist für die Induktion der GBP-1-Expression nach einer Behandlung mit IL-1 $\beta$ und TNF- $\alpha$ neben der Aktivierung von IRF-1 die Beteiligung eines weiteren Transkriptionsfaktors notwendig. Hierbei handelt es sich um $\mathrm{NF}-\kappa \mathrm{B}(\mathrm{p} 65 / \mathrm{p} 50)$, der an ein cRel-Element im GBP-1-Promotor bindet und zusammen mit IRF-1 die GBP-1-Expression induziert (Naschberger et al., 2004).

\subsubsection{Funktionen von GBP-1}

Da die Expression von GBP-1 in EZ durch IFN- $\gamma$ induziert werden kann, wurde für GBP-1 eine antipathogene Wirkung angenommen. Es wurde gezeigt, dass GBP-1 die Replikation des vesikulären Stomatitisvirus (VSV) und des Enzephalomyokraditisvirus (EMV) in HeLaZellen reduziert, wobei die Hemmeffekte nur wenig ausgeprägt waren (Anderson et al., 1999). In Untersuchungen unserer Arbeitsgruppe konnte gezeigt werden, dass GBP-1 zwei wichtige antiangiogene Eigenschaften besitzt. GBP-1 vermittelt die durch IFN- $\gamma-$, IL-1 $\beta$ - und 
TNF- $\alpha$-induzierte Hemmung der Proliferation von EZ (Guenzi et al., 2001). Die antiproliferative Aktivität von GBP-1 wird durch die C-terminale, helikale Domäne von GBP-1 vermittelt und ist unabhängig von dessen GTPase-Aktivität (Guenzi et al., 2001). Darüber hinaus konnte gezeigt werden, dass GBP-1 die Invasionsfähigkeit von EZ hemmt (Guenzi et al., 2003). Diese antiangiogene Aktivität von GBP-1 ist auf eine Herunterregulation der MMP-1-Expression zurückzuführen, die bei der Neubildung von Blutgefäßen eine wichtige Rolle spielt (siehe Abschnitt 2.1.2). Für die Hemmung der Expression von MMP-1 ist die GTPase-Aktivität von GBP-1 notwendig (Guenzi et al., 2003). Weiterhin konnte vor kurzem nachgewiesen werden, dass GBP-1 von EZ sekretiert werden kann. Es konnte in erhöhten Konzentrationen in der Cerebrospinal-Flüssigkeit von Patienten mit bakterieller Meningitis nachgewiesen werden (Naschberger et al., 2006).

\subsection{Ziele dieser Arbeit}

GBP-1 gehört zur Familie der großen GTPasen und wird selektiv durch die inflammatorischen Zytokine IFN- $\gamma$, IL-1 $\beta$ und TNF- $\alpha$ in vitro und in vivo in EZ induziert (Guenzi et al., 2001; Lubeseder-Martellato et al., 2002). Es ist bekannt, dass GBP-1 zwei wichtige antiangiogene Aktivitäten dieser inflammatorischen Zytokine in EZ vermittelt. GBP-1 hemmt die Proliferation und die Invasionsfähigkeit von EZ (Guenzi et al., 2001; Guenzi et al., 2003).

Das extrazelluläre Matrixprotein FN ist maßgeblich an der Regulation verschiedener Teilprozesse der Angiogenese beteiligt. FN bildet beispielsweise während der Aktivierungsphase eine provisorische Matrix aus und ermöglicht so die Auswanderung der EZ in das neu zu vaskularisierende Gewebe (Jin and Varner, 2004; Ruegg and Mariotti, 2003). Im Rahmen der vorliegenden Arbeit sollte untersucht werden, ob GBP-1 neben seinen antiproliferativen und antiinvasiven Eigenschaften noch weitere, unbekannte antiangiogene Effekte der inflammatorischen Zytokine vermittelt. Hierzu zählt die Reduktion der endothelialen Lamellipodienbildung bzw. die damit einhergehende Hemmung der Migration von EZ auf FN-beschichteten Oberflächen. Folgende Fragestellungen sollten im Rahmen dieser Arbeit genauer analysiert werden. 
- Führt die ektopisches Expression von GBP-1 in EZ zu einer Reduktion der endothelialen Lamellipodienbildung bzw. zu einer Hemmung der Migration auf FNbeschichteten Oberflächen?

- Welcher molekulare Mechanismus ist für diese inhibitorischen Eigenschaften von GBP-1 verantwortlich?

- Vermittelt auch endogenes GBP-1, dessen Expression durch die inflammatorischen Zytokine IFN- $\gamma$, IL- $1 \beta$ und TNF- $\alpha$ in EZ induziert wird, eine Hemmung der endothelialen Lamellipodienbildung bzw. Migration auf FN-beschichteten Oberflächen?

- Ist GBP-1 notwendig, um die durch IL-1 $\beta$ - und TNF- $\alpha$-induzierte Hemmung der Lamellipodienbildung und Migration auf FN-Matrizes zu vermitteln? 


\section{$3 \quad$ Material und Methoden}

\subsection{Material}

Alle gängigen Chemikalien und Lösungen wurden von den Firmen Carl Roth (Karlsruhe), Merck (Darmstadt) oder Sigma (München) bezogen und waren von analytischem Reinheitsgrad.

\subsubsection{Spezielle Chemikalien}

\begin{tabular}{ll}
\hline Acrylamid/N,N-Methylenbisacrylamid & BioRad \\
Accutase & PAA \\
Desoxyribonukleosidtriphosphat Set (dNTP) & Peqlab \\
fötales Kälberserum (FKS) & PAA \\
Formalin $10 \%$ (PBS gepuffert) & Sigma \\
Gelatine & Sigma \\
humanes Fibronektin & BD Biosciences \\
humanes Fibronektin; $\alpha$-chymotryptisches Fragment & Chemicon/Millipore \\
(120 kDa) & \\
IFN- $\gamma$ & Roche \\
IL-1 $\beta$ & Roche \\
Kristallviolett & Carl Roth \\
L-Glutamin & PAA \\
Mineralöl & Sigma \\
PBS-Pulver & Biochrom \\
Polybren & Sigma \\
Proteaseinhibitoren-Cocktail CompleteMini & Roche \\
Puromyzin & Sigma \\
RNAsin & Promega \\
Roti-Phenol & Roth \\
SuperFect & Qiagen \\
TNF- $\alpha$ & Roche \\
Triton X-100 & Sigma \\
&
\end{tabular}

\subsubsection{Spezielle Verbrauchsmittel}

\begin{tabular}{|ll}
\hline Gel-Blot-Filterpapier & Schleicher und Schuell \\
Hybond P-Membran (PVDF) & Amersham Pharmacia \\
Röntgenfilme & Fuji Film \\
Sterilfilter $(0,45 \mu \mathrm{m}$ Porengröße) & Schleicher und Schuell \\
Tris-Borat-Harnstoff-Gele & Anamed \\
Zeta-Probe $G T$ Membran & BioRad
\end{tabular}

\subsubsection{Kommerzielle Reagenziensätze}

\begin{tabular}{|ll}
\hline Big Dye Terminator Mix & Perkin Elmer \\
Chemilumineszenz-Detektions-Kit & Pierce \\
DC-Protein-Assay & BioRad \\
ECL-Nachweisreagenzien & Pierce \\
Gel-Extraktions-Kit (QIAQuick) & Qiagen \\
In vitro Transcription Kit (RiboQuant) & BD Biosciences \\
\hline
\end{tabular}




\begin{tabular}{|ll}
\hline Multiprobe Human Integrin Template Set (RiboQuant) & BD Biosciences \\
Plasmid-Maxi-Präparations-Kit (HiPure) & Invitrogen \\
Plasmid-Mini-Präparations-Kit (peqGOLD) & PeqLab \\
RNA-Isolierungs-Kit (RNeasy Mini) & Qiagen \\
RNase Protection Assay-Kit (RiboQuant) & BD Biosciences \\
QIAshredder Säulchen & Qiagen \\
\hline
\end{tabular}

\subsubsection{Enzyme}

\begin{tabular}{|ll|}
\hline DNase I & Qiagen \\
„Klenow“-Fragment der DNA-Polymerase I & New England Biolabs \\
Platinum-Taq-DNA-Polymerase & Invitrogen \\
Restriktionsendonukleasen & New England Biolabs \\
Shrimp-Alkalische-Phosphatase & Roche \\
Superscript III reverse Transkriptase & Invitrogen \\
T4-DNA Ligase & Fermentas \\
Trypsin/EDTA & PAA \\
\hline
\end{tabular}

\subsubsection{Primärantikörper}

Tab. 2: Primärantikörper und ihre Verwendung.

\begin{tabular}{llll}
\hline Primäre Antikörper & Spezies & Verwendung & Herkunft \\
\hline monoklonaler $\alpha$-GBP-1 (1B1) & Ratte & $\begin{array}{l}\text { WB: } 1: 500 \text { (Hybridom } \\
\text { Überstand) }\end{array}$ & (Lubeseder-Martellato et al., 2002) \\
& & $\begin{array}{l}\text { FACS: } 1: 1.000 \\
\text { (aufgereinigt) }\end{array}$ & \\
monoklonaler $\alpha$-GAPDH & Maus & WB: $1: 70.000$ & Chemicon/Millipore \\
monoklonaler $\alpha$-ITGA4 (HP2/1) & Maus & FACS: $1: 400$ & Chemicon/Millipore \\
monoklonaler $\alpha$-ITGB1 & Maus & FACS: $1: 8.000$ & Prof. Hannes Stockinger, Wien \\
monoklonaler $\alpha$-GFP & Maus & WB: $1: 1.000$ & Roche
\end{tabular}

WB: Westernblot; FACS: fluorescence activated cell sorting

\subsubsection{Sekundärantikörper}

Tab. 3: Sekundärantikörper und ihre Verwendung.

\begin{tabular}{llll}
\hline Sekundäre Antikörper & Spezies & Verwendung & Herkunft \\
\hline$\alpha$-Maus-IgG-HRP & Schaf & WB: 1:5.000 & Amersham Biosciences \\
$\alpha$-Ratte-IgG-HRP & Ziege & WB: $1: 5.000$ & Amersham Biosciences \\
$\alpha$-Maus AlexaFluor 488-IgG & Ziege & FACS: $1: 350$ & Molecular Probes \\
$\alpha$-Maus R-PE-IgG & Ziege & FACS: $1: 300$ & Jackson Immuno Research \\
$\alpha$-Ratte R-PE-IgG & Ziege & FACS: $1: 300$ & Jackson Immuno Research
\end{tabular}

WB: Westernblot; FACS: fluorescence activated cell sorting; HRP: horseradish peroxidase; R-PE: R-Pycoerythrin 


\subsubsection{Plasmide}

Alle Plasmide tragen ein Ampizillin-Resistenzgen als selektierbaren Marker und einen Replikationsstartpunkt für E. coli.

Tab. 4: Übersicht der verwendeten Plasmide.

\begin{tabular}{|c|c|c|c|}
\hline Plasmidname & relevante Eigenschaften & Verwendung & Referenz \\
\hline pBabePuro $(5,1 \mathrm{~kb})$ & Leerplasmid, Puromyzin-Resistenzgen & $\begin{array}{l}\text { retrovirale } \\
\text { Transduktion }\end{array}$ & $\begin{array}{l}\text { (Morgenstern and Land, } \\
\text { 1990) }\end{array}$ \\
\hline $\begin{array}{l}\text { pBabePuro-GBP-1 } \\
(6,9 \mathrm{~kb})\end{array}$ & $\begin{array}{l}\text { exprimiert humanes GBP-1; Puromyzin- } \\
\text { Resistenzgen }\end{array}$ & $\begin{array}{l}\text { retrovirale } \\
\text { Transduktion }\end{array}$ & (Guenzi et al., 2001) \\
\hline $\begin{array}{l}\text { pBabePuro-GFP } \\
(5,8 \mathrm{~kb})\end{array}$ & $\begin{array}{l}\text { exprimiert GFP; Puromyzin- } \\
\text { Resistenzgen; dient als Kontrolle }\end{array}$ & $\begin{array}{l}\text { retrovirale } \\
\text { Transduktion }\end{array}$ & diese Arbeit \\
\hline $\begin{array}{l}\text { pBabePuro-GBP-1- } \\
\text { D184N }(6,9 \mathrm{~kb})\end{array}$ & $\begin{array}{l}\text { exprimiert humanes GBP-1-D184N; } \\
\text { Puromyzin-Resistenzgen }\end{array}$ & $\begin{array}{l}\text { retrovirale } \\
\text { Transduktion }\end{array}$ & (Guenzi et al., 2001) \\
\hline $\begin{array}{l}\text { pBabePuro-GBP-1- } \\
\text { K51A }(6,9 \mathrm{~kb})\end{array}$ & $\begin{array}{l}\text { exprimiert humanes GBP-1-K51A; } \\
\text { Puromyzin-Resistenzgen }\end{array}$ & $\begin{array}{l}\text { retrovirale } \\
\text { Transduktion }\end{array}$ & diese Arbeit \\
\hline $\begin{array}{l}\text { pLKOPuro-GBP-1- } \\
\text { shRNA }(7,0 \mathrm{~kb})\end{array}$ & $\begin{array}{l}\text { exprimiert shRNA gegen GBP-1 (5'-GG- } \\
\text { TTGAGGATTCAGCTGACttcaagagaGT } \\
\text { CAGCTGAATCCTCAACCTTTTTG- } \\
\text { 3'); Puromyzin-Resistenzgen }\end{array}$ & $\begin{array}{l}\text { lentivirale } \\
\text { Transduktion }\end{array}$ & H. Stockinger, Wien \\
\hline $\begin{array}{l}\text { pLKOPuro-GFP- } \\
\text { shRNA }(7,0 \mathrm{~kb})\end{array}$ & $\begin{array}{l}\text { exprimiert shRNA gegen GFP (5'-GC- } \\
\text { AAGCTGACCCTGAAGTTCttcaagagaG } \\
\text { AACTTCAGGGTCAGCTTGCTTTTTG } \\
\text {-3'); Puromyzin-Resistenzgen }\end{array}$ & $\begin{array}{l}\text { lentivirale } \\
\text { Transduktion }\end{array}$ & H. Stockinger, Wien \\
\hline $\begin{array}{l}\text { pBabePuro-GBP-1- } \\
\text { shRNA }(5,4 \mathrm{~kb})\end{array}$ & $\begin{array}{l}\text { shRNA gegen GBP-1 (5'-GGTTGAGG- } \\
\text { ATTCAGCTGACttcaagagaGTCAGCTG } \\
\text { AATCCTCAACCTTTTTG-3'); } \\
\text { Puromyzin-Resistenzgen }\end{array}$ & $\begin{array}{l}\text { retrovirale } \\
\text { Transduktion }\end{array}$ & diese Arbeit \\
\hline $\begin{array}{l}\text { pBabePuro-GFP- } \\
\text { shRNA }(5,4 \mathrm{~kb})\end{array}$ & $\begin{array}{l}\text { exprimiert shRNA gegen GFP (5'-GGT- } \\
\text { TGAGGATTCAGCTGACttcaagagaGTC } \\
\text { AGCTGAATCCTCAACCTTTTTG-3'); } \\
\text { Puromyzin-Resistenzgen; dient als } \\
\text { Kontrolle (Ktrl-shRNA) }\end{array}$ & $\begin{array}{l}\text { retrovirale } \\
\text { Transduktion }\end{array}$ & diese Arbeit \\
\hline phCMV-G $(6,4 \mathrm{~kb})$ & exprimiert VSV-Glykoprotein & $\begin{array}{l}\text { Hilfsplasmid } \\
\text { für retrovirale } \\
\text { Transduktion }\end{array}$ & (Yee et al., 1994) \\
\hline pGag-PolGp (12,2 kb) & exprimiert gag- und pol-Gene des MLV & $\begin{array}{l}\text { Hilfsplasmid } \\
\text { für retrovirale } \\
\text { Transduktion }\end{array}$ & (Markowitz et al., 1988) \\
\hline
\end{tabular}




\subsubsection{Biologisches Material}

\subsubsection{Bakterienstamm}

\section{Escherichia coli XL1-Blue (Stratagene):}

recAl endA1 gyrA96 thi-1 hsdR17 supE44 relA1 lac [F' proAB lacl ${ }^{q}$ ZMM15 Tn10 (Tetr)]

\subsubsection{Eukaryontische Zellen}

\section{Primäre Endothelzellen:}

HUVEC: humane Nabelschnurvenen-Endothelzellen;

HUVEC-Kultur 1 (HUVEC1): gepoolte EZ von zwei Donoren (PromoCell)

HUVEC-Kultur 2 (HUVEC2): gepoolte EZ von drei Donoren (Cambrex)

\section{Zelllinien:}

HEK293T: humane embryonale Nierenzellen transformiert mit dem large T Antigen des SV40 Virus [American Type Culture Collection (ATCC)]

PG13: retrovirale Verpackungszelllinie, NIH/3T3-basierend (murine Fibroblasten) [American Type Culture Collection (ATCC)]

\subsubsection{Medien}

\subsubsection{Bakterien-Nährmedium}

LB-Medium

$$
\begin{array}{ll}
1 \% & \text { Trypton } \\
0,5 \% & \text { Hefeextrakt } \\
0,5 \% & \mathrm{NaCl} \\
\text { pH 7,0 } & \text { mit } \mathrm{HCl} \text { eingestellt }
\end{array}
$$

Dem LB-Medium wurde bei der Herstellung von Festmedium 1,2\% Bacto-Agar zugesetzt. Zur positiven Selektion plasmidhaltiger Bakterien wurde dem Kulturmedium nach Abkühlung auf ca. $50{ }^{\circ} \mathrm{C}$ Ampizillin (Endkonzentration: $100 \mu \mathrm{g} / \mathrm{ml}$ ) beigefügt. 


\subsubsection{Zellkultur-Nährmedien}

Für HUVEC-Kultur 1 (HUVEC1) von PromoCell:

Endothelzellwachstumsmedium

(ECGM) von PromoCell

Endothelzellmangelmedium

(ECBM-0,5\% FKS) von PromoCell
$500 \mathrm{ml} \quad$ Endothelzellbasalmedium

$1 \times \quad$ Supplement-Mix (enthält 2\% FKS

und Wachstumsfaktoren)

$500 \mathrm{ml} \quad$ Endothelzellbasalmedium

$0,5 \%$ fötales Kälberserum (FKS)

Für HUVEC-Kultur 2 (HUVEC2) von Cambrex:

Endothelzellwachstumsmedium

(EGM) von Cambrex

Endothelzellmangelmedium

(EBM-0,5\% FKS) von Cambrex
$500 \mathrm{ml} \quad$ Endothelzellbasalmedium 2\% fötales Kälberserum (FKS)

je 1 Aliquot aus EGM-BulletKit (Bovine Brain Extract, Hydrocortison, GA-1000, hEGF)

$500 \mathrm{ml} \quad$ Endothelzellbasalmedium

$0,5 \%$ fötales Kälberserum (FKS)

Für HEK293T und PG13:

DMEM-Wachstumsmedium

Ultraculture-Medium

(zur Herstellung viraler Partikel)
$500 \mathrm{ml}$

$10 \%$

$2 \mathrm{mM}$

$500 \mathrm{ml}$

$2 \mathrm{mM}$
DMEM-Medium mit High Glucose (4,5 g/l) (PAA)

fötales Kälberserum (FKS)

L-Glutamin

Ultraculture-Medium (Cambrex)

L-Glutamin

Zum Ansetzen der Medien wurden alle Komponenten bei Raumtemperatur (RT) aufgetaut und unter der Sterilbank zusammenpipettiert. Alle Medien wurden bei $4{ }^{\circ} \mathrm{C}$ unter Lichtausschluss gelagert. 


\subsection{Zellbiologische Methoden}

Alle Arbeiten erfolgten unter einer Sterilbank. Die verwendeten Materialien und Lösungen wurden bereits steril vom Hersteller bezogen oder vor Gebrauch autoklaviert bzw. sterilfiltriert.

\subsubsection{Kultivierung von Säugerzellen}

Die primären HUVEC-Kulturen wurden von PromoCell (HUVEC1) und Cambrex (HUVEC2) bezogen und in ihrem jeweiligen Wachstumsmedium [ECGM (PromoCell) oder EGM (Cambrex)] bei $37{ }^{\circ} \mathrm{C}$ und $5 \% \mathrm{CO}_{2}$ kultiviert. Die routinemäßige Kultivierung der primären HUVEC-Kultur 2 (Cambrex) erfolgte in gelatinisierten Zellkulturflaschen, wohingegen die HUVEC-Kultur 1 (PromoCell) in Flaschen ohne Gelatinebeschichtung kultiviert wurde. Zum Gelatinisieren wurde 1,5\%ige Gelatine verwendet, die in den Zellkulturflaschen verteilt wurde. Nach 2 h bei $37{ }^{\circ} \mathrm{C}$ wurde überschüssige Gelatine entfernt und die Flaschen zur Passagierung der Zellen verwendet. Hierzu wurden die konfluenten EZ mit PBS gewaschen, für 3 min bei $37^{\circ} \mathrm{C}$ mit Trypsin/EDTA vom Flaschenboden abgelöst und mit frischem, vorgewärmten Wachstumsmedium maximal 1:4 verdünnt und erneut ausgebracht. Eine Passage entspricht einer Verdünnung der Zellen von 1:4.

$\begin{array}{lll}1,5 \% \text { Gelatine } & 7,5 \mathrm{~g} & \text { Gelatine } \\ & 500 \mathrm{ml} & \text { PBS }\end{array}$

Die Gelatine wurde unter ständigem Rühren für $1 \mathrm{~h}$ bei $65^{\circ} \mathrm{C}$ gelöst. Anschließend autoklaviert, sterilfiltriert und bei $4{ }^{\circ} \mathrm{C}$ gelagert.

HEK293T und PG13-Verpackungszellen wurden in DMEM-Wachstumsmedium bei $37{ }^{\circ} \mathrm{C}$ und $8,5 \% \mathrm{CO}_{2}$ kultiviert. Zur Passagierung wurden die Zellen mit PBS gewaschen, mit Trypsin/EDTA abgelöst und maximal 1:10 verdünnt in frischem, vorgewärmtem Wachstumsmedium ausgesät. 


\subsubsection{Stimulierung von primären Endothelzellen mit inflammatorischen Zytokinen}

Zur Stimulierung beider HUVEC-Kulturen mit inflammatorischen Zytokinen wurden die Zellen in Zellkulturflaschen ausgebracht, welche vorher mit Gelatine beschichtet wurden. Die Zellen wurden im jeweiligen Wachstumsmedium bis $\mathrm{zu}$ einer Dichte von ca. $70-80 \%$ kultiviert und zur Synchronisierung des Zellzyklus in Mangelmedium über Nacht inkubiert. Die Stimulierung mit Zytokinen erfolgte in Mangelmedium. Für Untersuchungen von Änderungen der mRNA-Spiegel verschiedener Gene wurden die Zellen $24 \mathrm{~h}$ nach Stimulation, für die Analyse der Proteinexpression $48 \mathrm{~h}$ nach Stimulation geerntet. Zur Stimulierung wurden alle verwendeten Pipettenspitzen mit PBS/0,1\% BSA beschichtet.

Die Zytokine wurden in folgenden Konzentrationen eingesetzt:

$\begin{array}{ll}\text { IFN- } \gamma & 100 \mathrm{U} / \mathrm{ml} \\ \text { IL-1 } \beta & 200 \mathrm{U} / \mathrm{ml} \\ \text { TNF- } \alpha & 300 \mathrm{U} / \mathrm{ml}\end{array}$

\subsubsection{Herstellung retroviraler Partikel}

Primäre Endothelzellen lassen sich nur mit geringer Effizienz transfizieren und die Selektion stabil exprimierender Klone ist durch das Eintreten von altersbedingten Zellveränderungen (Seneszenz) nicht möglich. Aus diesen Gründen wurden rekombinante Proteine und shRNAs in primären Endothelzellen mittels retroviraler Transduktion konstitutiv exprimiert.

\subsubsection{Produktion von infektiösen PG13-Überständen}

Zur ektopischen Expression von rekombinantem GBP-1, GFP, GBP-1-D184N und GBP-1K51A in HUVEC wurden Zellen der Verpackungszelllinie PG13 (Miller et al., 1991) mit retroviralen pBabePuro Plasmiden (Morgenstern and Land, 1990) transfiziert. Dazu wurde in das retrovirale Plasmid pBabePuro zunächst die cDNA von GBP-1, GFP, GBP-1-D184N und GBP-1-K51A kloniert. Die Transfektion der PG13 Zellen erfolgte durch Lipofektion mit SuperFect (Qiagen) nach Angaben des Herstellers. Die Verpackungszellen $\left(3 \times 10^{5}\right)$ wurden dazu in T25-Zellkulturflaschen ausgesät und bei einer Dichte von $60-80 \%$ mit $10 \mu \mathrm{g}$ Plasmid-DNA transfiziert. $48 \mathrm{~h}$ nach Transfektion erfolgte die Selektion der Zellen mit 
Puromyzin (4 $\mu \mathrm{g} / \mathrm{ml})$ für weitere 10 Tage. Nach der Puromyzin-Selektion standen die Zellen zur Produktion retroviraler Partikel zur Verfügung. Dazu wurden die stabil transfizierten PG13-Verpackungszellen bis zu einer Dichte von $80 \%$ in T75-Zellkulturflaschen kultiviert, einmal mit PBS gewaschen und mit $4 \mathrm{ml}$ frischem, vorgewärmten DMEMWachstumsmedium ohne Puromyzin überschichtet. Nach weiteren $24 \mathrm{~h}$ wurden die viralen Zellkulturüberstände abgenommen, filtriert $(0,45 \mu \mathrm{m})$ und mit $8 \mu \mathrm{g} / \mathrm{ml}$ Polybren gemischt. Die viralen Überstände wurden sofort zur Infektion von HUVEC eingesetzt.

\subsubsection{Produktion infektiöser Partikel in HEK293T-Zellen}

Zur Produktion infektiöser, VSV-G-pseudotypisierter Viruspartikel, welche shRNAs kodieren, wurden HEK293T-Zellen verwendet. Die Expression des G-Proteins von VSV wird nur kurzfristig von Zellen toleriert, so dass alle für die Produktion der retroviralen Partikel benötigten Gene transient exprimiert wurden. Die Zellen wurden hierfür in $10 \mathrm{~cm}$ Kulturschalen mittels Kalziumphosphat-Präzipitation (Chen and Okayama, 1988) bei einer Dichte von ca. $60 \%$ transfiziert. Je $10 \mathrm{~cm}$-Kulturschale wurden 2,5 $\mu \mathrm{g}$ phCMV-G (Yee et al., 1994), $10 \mu \mathrm{g}$ pGag-PolGp (Markowitz et al., 1988) und $10 \mu \mathrm{g}$ der auf pBabePuro (Morgenstern and Land, 1990) basierenden, proviralen Konstrukte eingesetzt. Die PlasmidDNA wurde in $500 \mu 10,25 \mathrm{M} \mathrm{CaCl}_{2}$ und $500 \mu 12 \times \mathrm{HBS}(\mathrm{pH} 7,0)$ aufgenommen, gründlich gemischt und 15 min bei RT inkubiert. Anschließend wurde der Transfektionsansatz auf die Zellen (in $10 \mathrm{ml}$ DMEM) getröpfelt. $8 \mathrm{~h}$ nach der Transfektion wurde das DMEM-Medium für die Virusproduktion durch Ultraculture-Medium ersetzt. Weitere $36 \mathrm{~h}$ später wurde das nun virushaltige Medium abgenommen, sterilfiltriert $(0,45 \mu \mathrm{m})$ und die Viren $2 \mathrm{~h}$ bei $4{ }^{\circ} \mathrm{C}$ und $48.400 \mathrm{~g}$ gesammelt. Das virale Pellet wurde in 1/100 des Ausgangsvolumens in HUVEC-Wachstumsmedium aufgenommen und direkt zur Infektion von HUVEC eingesetzt oder bei $-80{ }^{\circ} \mathrm{C}$ gelagert.

\subsubsection{Retrovirale Transduktion von HUVEC}

Für die retrovirale Transduktion wurden HUVEC (Passage 3,0 - 4,5) bis zu einer Zelldichte von 40 - 50\% in T25-Zellkulturflaschen kultiviert. 


\subsubsection{Infektion mit PG13-Überständen}

Die Infektion mit $3 \mathrm{ml}$ der filtrierten, viralen PG13-Überstände erfolgte für $4 \mathrm{~h}$ bei $37{ }^{\circ} \mathrm{C}$. Anschließend wurde das virale Medium abgenommen und durch frisches Endothelzellwachstumsmedium ersetzt. Nach weiteren $4 \mathrm{~h}$ erfolgte eine zweite 4-stündige Infektion der HUVEC mit darauffolgendem Mediumwechsel. Um die Transduktionseffizienz zu erhöhen, wurde am nächsten Tag der gleiche Infektionsprozess (2 x 4 h Infektion) wiederholt.

\subsubsection{Infektion mit viralen Partikeln aus HEK293T}

Für die Infektion mit den konzentrierten Viren aus HEK293T-Verpackungszellen wurden $3,9 \mathrm{ml}$ Wachstumsmedium mit $100 \mu \mathrm{l}$ virushaltigem Medium und Polybren (Endkonzentration: $8 \mu \mathrm{g} / \mathrm{ml}$ ) versetzt und die Zellen damit für $24 \mathrm{~h}$ inkubiert. Anschließend wurde das virushaltige Medium durch frisches Medium ersetzt.

$24 \mathrm{~h}$ nach den jeweiligen Infektionen wurde zur Selektion stabiler Transduktanden das Endothelzellwachstumsmedium mit $0,3 \mu \mathrm{g} / \mathrm{ml}$ Puromyzin versetzt und die transduzierten HUVEC für 10 Tage selektioniert. Alle 1,5 Tage erfolgte ein Mediumwechsel.

\subsubsection{Untersuchungen zur Bildung endothelialer Lamellipodien}

Um die Bildung endothelialer Lamellipodien untersuchen zu können, wurden die Löcher einer 96-Loch-Platte mit jeweils $5 \mu \mathrm{g} / \mathrm{cm}^{2}$ FN oder einem $120 \mathrm{kDa}$ großen Fragment von FN (FN-120) für $1 \mathrm{~h}$ bei $37^{\circ} \mathrm{C}$ beschichtet. Unspezifische Bindestellen wurden mit 1\% BSA in PBS über Nacht bei $4{ }^{\circ} \mathrm{C}$ abgesättigt. Nach der Blockierung wurden die zu untersuchenden HUVEC mit PBS gewaschen und mittels Accutase-Behandlung abgelöst. $5 \times 10^{3}$ Zellen wurden pro Loch in Serum-freiem Endothelzellbasalmedium (SFM) ausgesät. Nach einer Inkubation der Zellen für 20 min bei $37^{\circ} \mathrm{C}$ in $5 \% \mathrm{CO}_{2}$ wurde das Medium abgesaugt und die Zellen einmal mit $100 \mu \mathrm{PBS} / 0,1 \%$ BSA gewaschen. Alle adhärenten Zellen wurden mit 10\% Formalin (PBS gepuffert) für 15 min bei RT fixiert und anschließend mit 0,5\% Kristallviolett in 2\% Ethanol für $10 \mathrm{~min}$ bei RT gefärbt. Überschüssiges Kristallviolett wurde durch mehrmaliges Waschen mit $\mathrm{H}_{2} \mathrm{O}$ entfernt und die Zellen an der Luft getrocknet. Bilder der gefärbten Zellen wurden mit Hilfe einer Digitalkamera (Olympus) und einem AxiovertMikroskop (Zeiss) erstellt. 
Um die Anzahl an Zellen mit ausgebildeten Lamellipodien quantitativ ermitteln zu können, wurde von je 100 Zellen pro Zelltyp die Größe der Zelloberfläche (in $\mu^{2}{ }^{2}$ ) mit Hilfe der OPTIMAS 6.0 Software (Optimas Corporation) bestimmt und die Zellen anhand dieser Größe in 15 Inkremente mit steigender Oberflächengröße eingeteilt (d.h. Gruppe 1: 0 - $400 \mu \mathrm{m}^{2}$; Gruppe 2: $400-800 \mu \mathrm{m}^{2} ; \ldots$; Gruppe 15: $5.600-6.000 \mu \mathrm{m}^{2}$ ). Zellen, welche eine größere Oberfläche als $1.200 \mu \mathrm{m}^{2}$ bzw. $1.600 \mu \mathrm{m}^{2}$ aufwiesen, wurden als Zellen mit ausgebildeten Lamellipodien definiert.

\subsubsection{In vitro Wundheilungstest}

Um das Migrationsverhalten von HUVEC auf FN- oder FN-120-beschichteten Oberflächen $\mathrm{zu}$ analysieren, wurde die Methode des in vitro Wundheilungstest verwendet. Für den Versuch wurden die Zellen in FN oder FN-120-beschichteten (je $5 \mu \mathrm{g} / \mathrm{cm}^{2}$ ) $35 \mathrm{~mm}$-Schälchen bis zu einer Konfluenz von 90 - 100\% kultiviert und über Nacht in Mangelmedium inkubiert. Am nächsten Tag wurde mit Hilfe einer sterilen 1 ml-Pipettenspitze ein definierter zellfreier Bereich in den konfluenten Zellrasen gekratzt. Lose Zellen wurden entfernt, indem die Zellen zweimal mit SFM gewaschen wurden. Anschließend erfolgte eine weitere Zellkultivierung für $10 \mathrm{~h}$ in SFM. shRNA-transduzierte Zellen wurden vor dem Abkratzen für $48 \mathrm{~h}$ mit Zytokinen stimuliert (siehe 3.2.2). Aufgrund einer erhöhten Sterberate während der Kultivierung in SFM, wurde bei diesen Zellen der Wundheilungstest in Mangelmedium durchgeführt. Mit Hilfe einer Digitalkamera (Olympus) und einem Axiovert-Mikroskop (Zeiss) wurden die zellfreien Bereiche sofort nach dem Abkratzen der Zellen (Zeitpunkt 0 h) und alle weiteren zwei Stunden aufgenommen. Der Abstand zwischen den Zellfronten wurde zu jedem Zeitpunkt bestimmt und als relativer Prozentanteil des Abstandes zu Beginn des Versuches $(100 \%)$ dargestellt.

\subsubsection{Durchflusszytometrie (FACS)}

Die Durchflusszytometrie ist ein Verfahren, bei dem Zellen in einem Flüssigkeitsstrom phänotypisch charakterisiert und quantifiziert werden können. Mit Hilfe von Fluorochromgekoppelten Sekundärantikörpern können definierte Zelloberflächenstrukturen oder intrazelluläre Proteine markiert und detektiert werden.

Zur Detektion von ITGA4 und ITGB1 an der Zelloberfläche wurden die zu untersuchenden HUVEC mit PBS gewaschen, mit Accutase abgelöst und in $10 \mathrm{ml}$ kaltem PBS aufgenommen. 
$1 \times 10^{5}$ Zellen wurden abzentrifugiert $\left(300 \mathrm{~g}, 5 \mathrm{~min}, 4^{\circ} \mathrm{C}\right)$ und das Zellpellet in $150 \mu \mathrm{l}$ monoklonalen Primärantikörper ( $\alpha$-ITGA4-Antikörper 1:400 in FACS-Puffer; $\alpha$-ITGB1Antikörper 1:8.000 in FACS-Puffer) resuspendiert. Nach der Inkubation der Primärantikörper für 45 min bei $4{ }^{\circ} \mathrm{C}$ wurden $800 \mu$ PBS zugegeben und die Zellen erneut abzentrifugiert (350 g, $\left.5 \mathrm{~min}, 4^{\circ} \mathrm{C}\right)$. Das Zellpellet wurde in $100 \mu \mathrm{l} \alpha$-Maus-AlexaFluor $488-\operatorname{IgG}(1: 350$ in FACS-Puffer) aufgenommen und für 30 min unter Lichtausschluss bei $4{ }^{\circ} \mathrm{C}$ inkubiert. Nach der Inkubation mit dem Sekundärantikörper wurden die Zellen zweimal mit $800 \mu \mathrm{PBS}$ gewaschen, bei $350 \mathrm{~g}, 4{ }^{\circ} \mathrm{C}$ für 5 min zentrifugiert und das Pellet zur Analyse an einem FACS-Calibur-Durchflusszytometer (BD Biosciences) in $300 \mu 1$ FACS-Puffer aufgenommen. Als Negativkontrolle wurden die Zellen anstelle des spezifischen Primärantikörpers mit einem irrelevanten Antikörper gleichen Isotyps (R\&D Systems) in der entsprechenden Konzentration inkubiert. Zur Analyse von ITGA4 und ITGB1 auf GFP-exprimierenden Zellen wurde ein $\alpha$-Maus-R-PE-IgG (1:350 in FACS-Puffer) als Sekundärantikörper eingesetzt. Mit Hilfe dieses rot-fluoreszierenden Antikörpers lassen sich ITGA4- und ITGB1-Signale von den grünen GFP-Signalen unterscheiden.

Zur Detektion von intrazellulärem GBP-1 bzw. dem mutierten GBP-1-D184N und GBP-1K51A wurden $3 \times 10^{5}$ Zellen in $100 \mu 180 \%$ igem Methanol für $30 \mathrm{~min}$ bei $-20{ }^{\circ} \mathrm{C}$ fixiert. Die fixierten Zellen wurden abzentrifugiert (400 g, $4{ }^{\circ} \mathrm{C}, 5 \mathrm{~min}$ ), mit $800 \mu \mathrm{lPBS} / 0,1 \%$ EDTA gewaschen und erneut zentrifugiert $\left(400 \mathrm{~g}, 4{ }^{\circ} \mathrm{C}, 5 \mathrm{~min}\right)$. Das Zellpellet wurde in $100 \mu \mathrm{l}$ monoklonalem Primärantikörper ( $\alpha$-GBP-1-Antikörper $1: 1.000$ in PBS/0,1\% Triton X100/0,5\% BSA) resuspendiert und für $30 \mathrm{~min}$ bei RT inkubiert. Nach der Inkubation des Primärantikörpers wurden $800 \mu \mathrm{l}$ PBS/0,1\% EDTA zugegeben und die Zellen erneut abzentrifugiert (350 g, $\left.5 \mathrm{~min}, 4^{\circ} \mathrm{C}\right)$. Das Zellpellet wurde in $100 \mu 1 \alpha$-Ratte-R-PE-IgG (1:300 in PBS $/ 0,1 \%$ Triton X-100/0,5\% BSA) aufgenommen und für 30 min unter Lichtausschluss bei RT inkubiert. Nach der Inkubation mit dem Sekundärantikörper wurden die Zellen erneut mit $800 \mu \mathrm{PBS} / 0,1 \%$ EDTA gewaschen, bei $400 \mathrm{~g}, 4{ }^{\circ} \mathrm{C}$ für 5 min zentrifugiert und das Pellet zur Analyse in $300 \mu \mathrm{l}$ FACS-Puffer aufgenommen. Zur Bestimmung des nicht-spezifischen Färbehintergrunds wurden die Zellen ausschließlich mit dem sekundären Antikörper inkubiert.

$\begin{array}{lll}\text { FACS-Puffer } & 250 \mathrm{ml} & \text { PBS } \\ & 5 \% & \text { FKS } \\ & 0,05 \% & \mathrm{NaN}_{3}\end{array}$




\subsection{Molekularbiologische Methoden}

\subsubsection{Isolierung von Plasmid-DNA aus E. coli}

Zur Isolierung von ca. 20 - $50 \mu \mathrm{g}$ DNA wurde der peqGOLD Plasmid Miniprep-Kit I (PeqLab) und von ca. 200 - $500 \mu \mathrm{g}$ DNA der PureLink Hipure Plasmid Maxiprep-Kit (Invitrogen) verwendet. Es wurden $250 \mathrm{ml}$ (ergibt 200 - $500 \mu \mathrm{g}$ DNA) bzw. $5 \mathrm{ml}$ LB-Medium (ergibt 20 - $50 \mu \mathrm{g}$ DNA) inkl. Ampizillin $(100 \mu \mathrm{g} / \mathrm{ml})$ mit einer Einzelkolonie der plasmidhaltigen Bakterien angeimpft. Die Kulturen wurden bei $37^{\circ} \mathrm{C}$ über Nacht geschüttelt und die Bakterien durch Zentrifugation (6.000 g, 10 min, RT) gesammelt. Die Präparation der Plasmid-DNA erfolgte nach Empfehlung des Herstellers.

\subsubsection{Bestimmung von Nukleinsäurekonzentrationen}

Die Bestimmung von RNA- und DNA-Konzentrationen erfolgte photometrisch bei einer Anregung mit $260 \mathrm{~nm}$ an einem Spektralphotometer (GeneQuant, Amersham). In einer Quarzküvette mit einer Schichtdicke von $1 \mathrm{~cm}$ entspricht ein Extinktionswert $\left(\mathrm{A}_{260} \mathrm{~nm}\right)$ von 1,0 dem Gehalt von $50 \mu \mathrm{g}$ dsDNA/ml oder $40 \mu \mathrm{g}$ ssDNA/ml bzw. RNA $/ \mathrm{ml}$. Proteine und aromatische Verbindungen absorbieren bei $280 \mathrm{~nm}\left(\mathrm{~A}_{280} \mathrm{~nm}\right)$. Daher wird zur Bestimmung der Reinheit von präparierter RNA oder DNA der Quotient aus $\mathrm{A}_{260} \mathrm{~nm} / \mathrm{A}_{280} \mathrm{~nm}$ gebildet. Reine RNA-Lösungen liefern einen Wert $\geq 2,0$, wohingegen reine DNA-Lösungen einen Wert $\geq 1,8$ liefern. Kontaminationen mit Proteinen verringern den Quotienten $\mathrm{A}_{260} \mathrm{~nm} / \mathrm{A}_{280} \mathrm{~nm}$. Die in dieser Arbeit verwendeten DNA- und RNA-Präparationen hatten einen Wert $\geq 2,0$ für RNA und $\geq 1,8$ für DNA.

\subsubsection{Restriktionsspaltungen von DNA}

Restriktionsenzyme binden und spalten an spezifischen, palindromischen Erkennungsstellen doppelsträngiger DNA-Moleküle. Die Enzyme hydrolysieren dabei Phosphodiesterbindungen zwischen je zwei Basen in beiden Strängen der DNA. Aufgrund der Lage der Spaltstellen entstehen DNA-Fragmente definierter Größe, die mittels Gelelektrophorese aufgetrennt werden können. 
Die in dieser Arbeit beschriebenen Restriktionsspaltungen wurden mit Enzymen der Firma New England Biolabs in mitgelieferten Inkubationspuffern durchgeführt. Es wurden 2 - $3 \mu \mathrm{g}$ gelöste DNA und 5 - 10 Einheiten (U) des jeweiligen Restriktionsenzyms verwendet. Die Inkubation erfolgte bei $37{ }^{\circ} \mathrm{C}$ für mindestens $2 \mathrm{~h}$ in einem Thermoblock. Für präparative DNA-Spaltungen wurden entsprechend größere Mengen an DNA und Restriktionsenzymen eingesetzt.

\subsubsection{Agarose-Gelelektrophorese}

Nukleinsäuren bewegen sich in Abhängigkeit von ihrer Molekülmasse und Molekülstruktur unterschiedlich im elektrischen Feld. Mit Hilfe von Agarosegelen mit definierter Porengröße können DNA-Fragmente und RNA von einander getrennt werden. Zur Größenabschätzung, zur präparativen Auftrennung von Nukleinsäuren, sowie zur Überprüfung der RNA-Integrität wurden Gelelektrophoresen durchgeführt.

Zur Herstellung der Gele wurde die Agarose in Konzentrationen zwischen 1 und 1,5\% verwendet. Die Agarose wurde in $1 \mathrm{x}$ Tris-Acetat-EDTA (TAE)-Puffer aufgekocht und vollständig gelöst. Nach Abkühlen wurde Ethidiumbromid (Endkonzentration 0,5 $\mu \mathrm{g} / \mathrm{ml}$ ) zugegeben und die Agarose in die vorgesehene Gelapparatur gegossen. Nach dem Aushärten wurde das Gel mit TAE-Puffer überschichtet, die DNA- bzw. RNA-Proben wurden mit 1/6 Volumen Auftragspuffer versetzt und in die Geltaschen pipettiert. Die angelegte Spannung lag bei $100 \mathrm{~V}$. Während der elektrophoretischen Auftrennung interkalierte das Ethidiumbromid mit der DNA bzw. RNA und die Nukleinsäuren konnten im UV-Durchlicht $(302 \mathrm{~nm})$ kontrolliert und fotografiert werden.

$\begin{array}{lll}50 \times \text { TAE-Puffer } & 2 \mathrm{M} & \text { Tris } \\ & 1 \mathrm{M} & \text { Eisessig } \\ & 0,1 \mathrm{M} & \text { EDTA pH 8,0 } \\ & \mathrm{pH} 8,5 & \\ \text { Auftragspuffer } & 0,15 \% & \text { Orange G } \\ & 40 \% & \text { Glycerol }\end{array}$




\subsubsection{Größenstandards für die Agarose-Gelelektrophorese}

Zur Größenbestimmung der Nukleinsäuren wurde bei der Gelelektrophorese ein Molekulargewichtstandard aufgetragen.

Molekulargewichtstandard für größere DNA-Fragmente (Fermentas, Generuler, 1 kb DNA Ladder):

10.000 bp, 8.000 bp, 6.000 bp, 5.000 bp, 4.000 bp, 3.500 bp, 3.000 bp, 2.500 bp, 2.000 bp, $1.500 \mathrm{bp}, 1.000 \mathrm{bp}, 750 \mathrm{bp}, 500 \mathrm{bp}, 250 \mathrm{bp}$

Molekulargewichtstandard für kleinere DNA-Fragmente (Fermentas, Generuler, 100 bp DNA Ladder):

1.000 bp, 900 bp, 800 bp, 700 bp, 600 bp, 500 bp, 400 bp, 300 bp, 200 bp, 100 bp

\subsubsection{Elution von DNA aus Agarosegelen}

Die Elution von DNA-Fragmenten aus 1 - 1,5\%igen Agarosegelen wurde mittels QIAquick Gel Extraction Kit (Qiagen) durchgeführt. Die gewünschte DNA-Bande wurde mit einem sterilen Skalpell unter möglichst kurzzeitiger UV-Bestrahlung aus dem Gel ausgeschnitten und in ein Reaktionsgefäß überführt. Die DNA-Elution erfolgte entsprechend der Anleitung des Herstellers.

\subsubsection{Auffüllen von 5'-Überhängen mit dem „Klenow“-Fragment der DNA- Polymerase I}

Um für die Fusion nicht-kompatibler Enden aus 5'-Überhängen „glatte“ DNA-Enden zu erzeugen, wurde die DNA mit dem „Klenow“-Fragment der DNA-Polymerase I behandelt. Hierzu wurde $1 \mu \mathrm{g}$ linearisierte DNA mit dem entsprechenden Puffer (nach Angaben des Herstellers), $33 \mu \mathrm{M}$ freien Desoxynukleotiden (dNTPs) und $1 \mathrm{U}$ „Klenow“-Fragment der DNA-Polymerase I für 30 min bei $25{ }^{\circ} \mathrm{C}$ inkubiert. Zur Inaktivierung des Enzyms wurden 10 mM EDTA (pH 8,0) zugegeben und der Ansatz für 20 min auf $75^{\circ} \mathrm{C}$ erhitzt. 


\subsubsection{Dephosphorylierung von DNA-Fragmenten}

Alkalische Phosphatasen katalysieren die Abspaltung von 5'-Phosphatgruppen der DNAEnden unter Bildung freier 5'-Hydroxylgruppen. Sie werden eingesetzt, um die Religation von linearisierter Vektor-DNA zu vermeiden. Die zur Ligation notwendigen Phosphatgruppen werden von anderen DNA-Molekülen (Insert) zur Verfügung gestellt. Zur Dephosphorylierung von Vektor-DNA wurde 1 U Shrimp-Alkalische-Phosphatase (Roche) und 100 ng linearisierte Vektor-DNA eingesetzt. Der Dephosphorylierungsansatz wurde 45 min bei $37^{\circ} \mathrm{C}$ inkubiert. Zur Inaktivierung des Enzyms wurde der Ansatz anschließend für $20 \mathrm{~min}$ auf $65^{\circ} \mathrm{C}$ erhitzt.

\subsubsection{Ligation von DNA-Fragmenten}

DNA-Fragmente mit zueinander kompatiblen Enden können mit Hilfe der ATP-abhängigen T4-DNA-Ligase kovalent verknüpft werden. Es wurden 100 ng Vektor-DNA und ein 3- bis 6facher molarer Überschuss der $\mathrm{zu}$ inserierenden DNA eingesetzt. Die Ligationsansätze wurden nach Anleitung des Herstellers (Fermentas) pipettiert und über Nacht bei $16{ }^{\circ} \mathrm{C}$ inkubiert. Parallel zu den jeweiligen Reaktionen wurde eine Vektorligation ohne Insert durchgeführt, um die Effizienz der in Abschnitt 3.3.6 beschriebenen Phosphatasebehandlung abschätzen zu können.

\subsubsection{Transformation von kompetenten $E$. coli-Zellen}

Die Transformation stellt eine Methode zur Einschleusung und Vervielfältigung von PlasmidDNA in kompetenten E. coli-Zellen dar. Zu $4 \mu 1$ Plasmid-DNA (1/4 Ligationsansatz) wurden $50 \mu$ chemokompetente E. coli (XL1-Blue) gegeben und der Ansatz für $30 \mathrm{~min}$ auf Eis inkubiert. Die Zellen wurden $45 \mathrm{sec}$ bei $42{ }^{\circ} \mathrm{C}$ einem Hitzeschock unterzogen, auf Eis für 2 min abgekühlt und nach Zugabe von $500 \mu \mathrm{S}$ SOC-Medium 60 min bei $37^{\circ} \mathrm{C}$ unter Schütteln inkubiert. Diese Zeit diente der Regeneration der Bakterienzellen. Anschließend wurden $100 \mu \mathrm{l}$ der Bakterien auf LB-Platten mit Ampizillin $(100 \mu \mathrm{g} / \mathrm{ml})$ ausplattiert und über Nacht bei $37{ }^{\circ} \mathrm{C}$ inkubiert. Am folgenden Tag wurden Einzelkolonien entnommen, mittels Restriktionsspaltung analysiert und positive Klone weiter verwendet. 


$\begin{array}{lll}\text { SOC-Medium } & 0,5 \% & \text { Hefeextrakt } \\ 2 \% & \text { Trypton } \\ 0,2 \% & \mathrm{MgCl}_{2} \\ 0,25 \% & \mathrm{MgSO}_{4} \\ 0,36 \% & \text { Glucose }\end{array}$

\subsubsection{Sequenzierung von DNA}

Grundlage des angewendeten Verfahrens ist die Kettenabbruchreaktion nach Sanger (Sanger et al., 1977). Als Terminatoren der Sequenzierreaktion dienten unterschiedlich fluoreszenzmarkierte Didesoxynukleotide (ddNTPs), die als Big Dye Terminator Mix (Perkin Elmer) bezogen wurden. Die Durchführung der Sequenzierreaktion erfolgte nach den Empfehlungen des Herstellers. Analysiert wurden die Produkte am Lehrstuhl für Humangenetik des Universitätsklinikums Erlangen.

Tab. 5: Übersicht der Oligonukleotide, welche als Primer zur Sequenzierung eingesetzt wurden.

\begin{tabular}{lll}
\hline Komplementär zu & Primer & Sequenz $\left(\mathbf{5}^{\prime} \rightarrow \mathbf{3}^{\prime}\right)$ \\
\hline pBabePuro & pBabe-for-sequencing fwd & TCCTCCCTTTATCCAGCCCTCACTCCTTCT \\
& pBabe-for-sequencing rev & ACTAATTGAGATGCATGCTTTGCATACTTC
\end{tabular}

fwd: Sinnstrang; rev: Gegenstrang

\subsubsection{Isolierung von zellulärer Gesamt-RNA}

Die Isolierung von zellulärer Gesamt-RNA aus HUVEC erfolgte mit Hilfe des RNeasy MiniKit von Qiagen. Nach dem Ablösen mit Trypsin/EDTA wurden die Zellen $\left(1 \times 10^{6}-5 \times 10^{6}\right)$ durch Zentrifugation ( $300 \mathrm{~g}, 5 \mathrm{~min}, 4{ }^{\circ} \mathrm{C}$ ) gesammelt und zur Lyse das Zellpellet in $350 \mu 1$ RLT-Puffer (im Kit enthalten) aufgenommen. Zum Scheren der chromosomalen DNA wurden die Lysate auf eine QIAshredder-Säule (Qiagen) pipettiert und weiter nach Angaben des Herstellers verfahren. Um die zelluläre RNA vollständig von genomischen DNA-Resten zu trennen, wurde während der RNA-Isolation zusätzlich ein Verdau mit DNase I (Qiagen) durchgeführt. Die Arbeiten wurden zügig und unter Ribonuklease-freien Bedingungen durchgeführt. Abschließend wurde die Konzentration und die Reinheit der isolierten RNA photometrisch bestimmt (Abschnitt 3.3.2) und die Integrität der RNA mittels AgaroseGelelektrophorese überprüft (Abschnitt 3.3.4). 


\subsubsection{Microarray-Analyse}

Das Verfahren der Microarray-Analyse erlaubt es, durch den Einsatz individueller GeneChips, in einem einzigen Experiment eine Vielzahl von Genen gleichzeitig auf ihr Expressionsniveau hin zu untersuchen. Eine Übersicht über den Ablauf einer MicroarrayAnalyse ist in Abbildung 8 schematisch dargestellt. Zunächst wird die zelluläre Gesamt-RNA (5 - $10 \mu \mathrm{g}$ ) durch reverse Transkription in cDNA umgeschrieben. Zur cDNA-Synthese werden Oligo(dT)-Oligonukleotide (5'-TTTTTTTTTTTTTTTTTT-3') eingesetzt, die am 5'Ende die Sequenz des bakteriophagen T7-RNA-Polymerase-Promotors tragen. Da das Oligo(dT)-Oligonukleotid spezifisch an den PolyA-Schwanz von mRNA bindet, wird selektiv mRNA der zellulären Gesamt-RNA in komplementäre, doppelsträngige DNA (cDNA) umgeschrieben. Nach Aufreinigung der cDNA-Proben werden bei der nachfolgenden in vitro Transkription unter Verwendung einer T7-RNA-Polymerase Biotin-markierte Nukleotide (UTP oder CTP) in die neu synthetisierte cRNA eingebaut. Im letzten Schritt erfolgt die Fragmentierung der cRNA und die dabei entstandenen Biotin-markierten RNA-Fragmente werden auf einem sogenannten Gene-Chip hybridisiert. Die hybridisierten Chips werden mit

Hilfe eines Streptavidin-Phycoerythrin-Konjugates gefärbt und anschließend die Fluoreszenzemission nach Anregung mit Laserlicht bei $488 \mathrm{~nm}$ bestimmt. Computergestütz werden die einzelnen Signalintensitäten, welche ein Maß für die Genexpression darstellen, registriert und ausgewertet.

In dieser Arbeit wurden HG-U133 Plus 2.0 Chips von Affymetrix verwendet. Die Herstellung von cDNA, die Fragmentierung, das Hybridisieren und Färben, sowie das Einscannen wurden nach Angaben des Herstellers (Affymetrix) am Institut für Zellbiologie (Tumorforschung) des Universitätsklinikums Essen unter der Leitung von Dr. Ludger Klein-Hitpass durchgeführt. Die Normalisierung und die Ermittlung der Signalintensitäten wurden mit Hilfe der Software Affymetrix Microarray Suite Version 5.0 durchgeführt. Um unterschiedlich exprimierte Gene identifizieren zu können, erfolgte die weitere Auswertung nach folgenden Kriterien: Gene wurden als signifikant hochreguliert eingestuft, wenn ein Anstieg der Expression (dargestellt als „,I“), eine Expressionsänderung $>1$ (dargestellt als ,,signal log ratio“), ein p-Wert $\leq 0,001$ und eine Signalintensität über 300 ermittelt werden konnte. Gene wurden als signifikant herunterreguliert eingestuft, wenn eine Abnahme der Expression (dargestellt als „D“), eine Expressionsänderung $<-1$ (dargestellt als ,signal log ratio“), ein p-Wert $\geq 0,999$ und eine Signalintensität über 300 vorlag. 


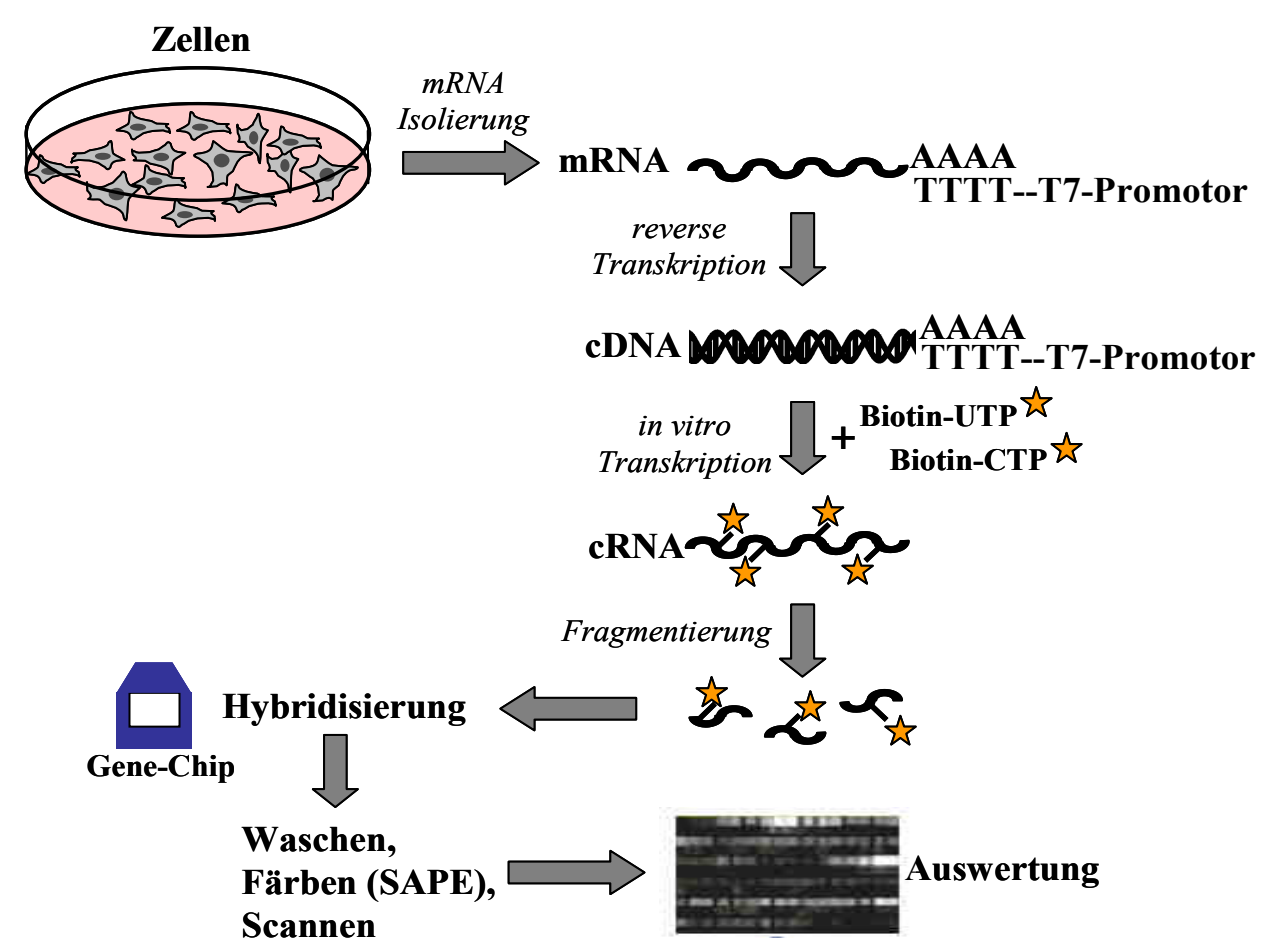

Abb. 8: Schematische Übersicht über die Methode der Microarray-Analyse (Affymetrix)

Bei der Methode der Microarray-Analyse wird zunächst Gesamt-RNA aus Zellen isoliert. Nach Isolierung wird die zelluläre Gesamt-RNA mit Hilfe von Oligo(dT)-Oligonukleotiden und der reversen Transkriptase in cDNA umgeschrieben. Es erfolgt dann eine in vitro Transkription der cDNA in Biotin-markierte cRNA. Nach Fragmentierung der Biotin-markierten cRNA, werden die Fragmente auf einen Gene-Chip (Affymetrix) hybridisiert. Nach dem Waschen, Färben und Scannen erfolgt abschließend die Auswertung des Chips. SAPE: Streptavidin-Phycoerythrin-Konjugat

\subsubsection{Reverese Transkriptase-Polymerasekettenreaktion (RT-PCR)}

\subsubsection{1 cDNA-Synthese}

Protein-kodierende mRNA wurde mittels reverser Transkriptase in cDNA umgeschrieben. Hierfür wurden pro Ansatz $1 \mu \mathrm{g}$ Gesamt-RNA, $10 \mathrm{mM}$ Dithiothreitol (DTT), 40 U RNAsin, 0,5 mM dNTPs, 0,1 $\mu \mathrm{M}$ Oligo(dT)-Oligonukleotide, $5 \mathrm{x}$ First strand buffer (Invitrogen) und 200 U reverse Transkriptase (Superscript III, Invitrogen) eingesetzt. Um Sekundärstrukturen der mRNA aufzulösen, wurden zunächst die RNA, der Oligo(dT)-Primer und die dNTPs gemischt, mit $\mathrm{H}_{2} \mathrm{O}$ auf $12 \mu \mathrm{l}$ aufgefüllt und für $5 \mathrm{~min}$ auf $65^{\circ} \mathrm{C}$ erhitzt. Anschließend wurde die Mischung kurz abzentrifugiert und auf Eis 5 x First strand buffer, RNAsin und DTT zugegeben. Nach einer 2-minütigen Inkubation bei $42{ }^{\circ} \mathrm{C}$ wurde die reverse Transkriptase zugegeben und die cDNA-Synthese bei steigenden Temperaturen durchgeführt (50 min bei $42{ }^{\circ} \mathrm{C}, 10 \mathrm{~min}$ bei $50^{\circ} \mathrm{C}, 10 \mathrm{~min}$ bei $60^{\circ} \mathrm{C}, 10 \mathrm{~min}$ bei $70^{\circ} \mathrm{C}$ ). 


\subsubsection{Polymerasekettenreaktion (PCR)}

Die PCR stellt eine in vitro Methode zur exponentiellen Vervielfältigung einer bestimmten DNA-Zielsequenz aus einem DNA-Gemisch dar. Erstmalig wurde diese Methode von Mullis beschrieben (Mullis and Faloona, 1987). Mit Hilfe einer thermostabilen DNA-Polymerase aus Thermophilus aquaticus (Taq-Polymerase) und dNTPs wird ein DNA-Fragment (Matrize) zwischen zwei definierten, an Sinnstrang bzw. Gegenstrang hybridisierenden Oligonukleotiden („Primer“) exponentiell vervielfältigt. Die Reaktionsabfolge besteht aus wiederholter, Hitze-induzierter Trennung des DNA-Doppelstrangs, OligonukleotidHybridisierung und der DNA-Synthese.

Zur Amplifizierung von spezifischen DNA-Fragmenten aus einem komplexen cDNAGemisch wurde die cDNA zunächst unterschiedlich verdünnt $(1: 10,1: 100,1: 1.000)$ und folgender PCR-Ansatz pipettiert:

\section{PCR-Ansatz:}

$\begin{array}{ll}100 \mathrm{pmol} & \text { Sinnstrang-Oligonukleotid } \\ 100 \mathrm{pmol} & \text { Gegenstrang-Oligonukleotid } \\ 1 \mu \mathrm{l} & \text { cDNA-Verdünnung } \\ 2,5 \mu \mathrm{l} & \text { Polymerase-Puffer }(10 \mathrm{x}) \\ 200 \mu \mathrm{M} & \mathrm{dNTPs} \\ 1,5 \mathrm{mM} & \mathrm{MgCl}_{2} \\ 0,125 \mu \mathrm{l} & \text { Taq-Polymerase }(5 \mathrm{U} / \mu \mathrm{l})_{\text {ad } 25 \mu \mathrm{l}} \\ & \mathrm{H}_{2} \mathrm{O}_{\text {Millipore }}\end{array}$

\section{PCR-Lauf:}

$\left.\begin{array}{ll}94{ }^{\circ} \mathrm{C} & 5 \mathrm{~min} \\ 94{ }^{\circ} \mathrm{C} & 30 \mathrm{sec} \\ 51-60{ }^{\circ} \mathrm{C} & 30 \mathrm{sec} \\ 72{ }^{\circ} \mathrm{C} & 30 \mathrm{sec}-2 \mathrm{~min} \\ 72{ }^{\circ} \mathrm{C} & 7 \mathrm{~min} \\ 4{ }^{\circ} \mathrm{C} & \infty\end{array}\right\} 35$ Zyklen

Variationen des PCR-Laufs hinsichtlich Hybridisierungstemperatur und Synthesedauer wurden in Abhängigkeit von der Schmelztemperatur des Primerpaares sowie der Länge der zu amplifizierenden DNA-Sequenz vorgenommen. 
Tab. 6: Übersicht der Oligonukleotide, welche als Primer in der RT-PCR eingesetzt wurden.

\begin{tabular}{llll}
\hline Genname & Oligonukleotid & Sequenz $\left(\mathbf{5}^{\prime} \rightarrow \mathbf{3}^{\prime}\right)$ & Größe des Produkts \\
\hline \multirow{2}{*}{ GBP-1 } & GBP-1 fwd & ATGGCATCAGAGATCCACAT & $1,8 \mathrm{~kb}$ \\
& GBP-1 rev & TTCGCTTATGGTACATGCCTTTC & $595 \mathrm{bp}$ \\
ITGA4 & ITGA4 fwd & TTCGGAGCCAGCATACTACC & $460 \mathrm{bp}$ \\
& ITGA4 rev & GCAGAATCAGACCGAAAAGC & \\
\hline
\end{tabular}

fwd: Sinnstrang; rev: Gegenstrang

\subsubsection{RNase Protection Assay (RPA)}

Der RNase Protection Assay (RPA) ist eine sensitive Methode zur Detektion und Quantifizierung eines spezifischen mRNA-Transkripts aus einem komplexen Gesamt-RNAGemisch (Zinn et al., 1983). Hierbei wird eine RNA-Sonde mittels in vitro Transkription synthetisiert. Diese Sonde ist komplementär zur Sequenz des Zielgens und ist entweder radioaktiv- oder Biotin-markiert. Damit die markierte Sonde mit der komplementären Sequenz der Ziel-mRNA hybridisieren kann, wird sie mit der zu untersuchenden GesamtRNA in Lösung gemischt. Nach der Hybridisierung wird das Gemisch aus ungebundener, einzelsträngiger RNA und doppelsträngigem Sonde/mRNA-Hybrid mit Ribonuklease (RNase) A verdaut, welche ausschließlich einzelsträngige RNA erkennt und abbaut. Als Resultat bleibt nur das doppelsträngige Sonde/mRNA-Hybrid zurück. Die Probe wird anschließend in einem denaturierenden Tris-Borat-Harnstoff-Gel elektrophoretisch aufgetrennt, auf eine positiv geladene Nylonmembran transferiert und detektiert.

Neben einer Markierung müssen die RNA-Sonden weitere wichtige Kriterien erfüllen. RNASonden werden meist so synthetisiert, dass sie an jeder Seite ihrer Zielsequenz ca. 15 irrelevante Nukleotide zusätzlich tragen. Wenn solch eine Sonde mit ihrer komplementären Ziel-mRNA hybridisiert, können diese äußeren Nukleotide nicht an die Ziel-mRNA binden, bleiben einzelsträngig und werden während des RNAse A-Verdaus abgebaut. Trennt man die unverdauten RNA-Sonden in einem Tris-Borat-Harnstoff-Gel zusammen mit den verdauten Proben auf, so laufen die unverdauten RNA-Sonden aufgrund der zusätzlichen Nukleotide höher und dienen als Kontrolle, ob ein vollständiger RNAse A-Verdau stattfand.

Im hier beschriebenen RPA wurden mit Hilfe des RiboQuant Multiprobe Human Integrin Template Set (BD Biosciences) mehrere verschiedene RNA-Sonden unterschiedlicher Länge 
in einem Versuch gleichzeitig eingesetzt, wodurch viele unterschiedliche Ziel-mRNAs aus einer Gesamt-RNA-Probe simultan detektiert, quantifiziert und miteinander verglichen werden konnten.

\subsubsection{In vitro Transkription zur Herstellung Biotin-markierter RNA-Sonden}

Die in vitro Transkription mit Hilfe der T7-RNA-Polymerase diente zur Herstellung Biotinmarkierter RNA-Sonden. Als DNA-Matrize wurde das RiboQuant Multiprobe Human Integrin Template Set (BD Biosciences), welches neben zehn DNA-Matrizes für unterschiedliche Integrine auch zwei DNA-Matrizes für zwei Haushaltsgene (L32, GAPDH) beinhaltet (siehe Tab. 7), verwendet. Die RNA-Sonden wurden mit Hilfe des RiboQuant In Vitro Transcription Kits (BD Biosciences) nach Angaben des Herstellers synthetisiert. Nach ihrer Synthese wurden die RNA-Sonden bis zur weiteren Verwendung bei $-80{ }^{\circ} \mathrm{C}$ gelagert.

Tab. 7: Übersicht der verschiedenen DNA-Matrizes des RiboQuant Multiprobe Human Integrin Template Sets.

\begin{tabular}{lll}
\hline DNA-Matrize & Größe der unverdauten Sonde & $\begin{array}{l}\text { Größe der geschützten Sonde nach } \\
\text { RNase A-Verdau }\end{array}$ \\
\hline ITGA1 & $459 \mathrm{bp}$ & $430 \mathrm{bp}$ \\
ITGA2 & $417 \mathrm{pb}$ & $388 \mathrm{bp}$ \\
ITGA3 & $378 \mathrm{bp}$ & $349 \mathrm{bp}$ \\
ITGA4 & $342 \mathrm{bp}$ & $313 \mathrm{bp}$ \\
ITGA5 & $309 \mathrm{bp}$ & $280 \mathrm{bp}$ \\
ITGA6 & $279 \mathrm{bp}$ & $250 \mathrm{bp}$ \\
ITGA7 & $252 \mathrm{bp}$ & $223 \mathrm{bp}$ \\
ITGA8 & $228 \mathrm{bp}$ & $199 \mathrm{bp}$ \\
ITGA9 & $207 \mathrm{bp}$ & $178 \mathrm{bp}$ \\
ITGAv & $189 \mathrm{bp}$ & $160 \mathrm{bp}$ \\
L32 & $141 \mathrm{bp}$ & $113 \mathrm{bp}$ \\
GAPDH & $124 \mathrm{bp}$ & $96 \mathrm{bp}$ \\
\hline
\end{tabular}

\subsubsection{RNA-Probenvorbereitung und Hybridisierung}

Um die zu untersuchende mRNA mit den spezifischen RNA-Sonden hybridisieren zu können, wurden $10 \mu \mathrm{g}$ der präparierten Gesamt-RNA (siehe 3.3.1) durch Zugabe von einem entsprechendem Volumen an $4 \mathrm{M}$ Ammoniumacetat und 2,5 Volumen an kaltem Ethanol (100\%) für mindestens $30 \mathrm{~min}$ bei $-80{ }^{\circ} \mathrm{C}$ gefällt. Die RNA wurde für $30 \mathrm{~min}$ bei $12.000 \mathrm{~g}$ und $4{ }^{\circ} \mathrm{C}$ zentrifugiert und das Pellet mit 90\%igem Ethanol gewaschen. Nach dem Trocknen 
wurde das Pellet in $8 \mu$ l Hybridisierungspuffer (BD Biosciences) aufgenommen und $2 \mu 1$ der in Abschnitt 3.3.12.1 hergestellten RNA-Sonden (1:50 in Hybridisierungspuffer verdünnt) dazu pipettiert. Nach dem Überschichten der Reaktionsansätze mit einem Tropfen Mineralöl wurden die Proben in einen Thermoblock gestellt, welcher auf $90{ }^{\circ} \mathrm{C}$ vorgeheizt war. Die Proben wurden langsam auf $56^{\circ} \mathrm{C}$ abgekühlt und bei dieser Temperatur über Nacht inkubiert.

\subsubsection{RNase A-Behandlung}

Die RNase A-Behandlung der RNA-Proben, sowie deren anschließende Inaktivierung durch die Proteinase $\mathrm{K}$ erfolgte mit Hilfe des RiboQuant RNase Protection Assay-Kits (BD Biosciences) nach Empfehlung des Herstellers.

\subsubsection{Tris-Borat-Harnstoff-Gelelektrophorese und Membrantransfer}

Die RNase A-behandelten, Biotin-markierten doppelsträngigen RNA-Moleküle wurden für 3 min bei $90{ }^{\circ} \mathrm{C}$ erhitzt und anschließend in Abhängigkeit ihrer Größe in einem Tris-BoratHarnstoff-Gel (Anamed) aufgetrennt. Der Gellauf erfolgte für $90 \mathrm{~min}$ bei $140 \mathrm{~V}$. Als Laufpuffer wurde 1 x Tris-Borat-EDTA (TBE)-Puffer verwendet. Zur Größenbestimmung der RNA-Moleküle wurde bei der Gelelektrophorese $4 \mu 1$ der unverdauten RNA-Sonden (1:1.000 in Hybridisierungspuffer verdünnt) aufgetragen. Nach dem Gellauf wurden die aufgetrennten RNA-Moleküle mit Hilfe einer Tankblot-Apparatur (BioRad) auf eine positiv geladene Nylonmembran (Zeta-Probe GT Membran; BioRad) übertragen. Dazu wurden drei auf Gelgröße zugeschnittene und in TBE-Puffer getränkte, Gel-Blot-Filterpapiere übereinander positioniert. Die mit TBE-Puffer befeuchtete Nylonmembran wurde aufgelegt und anschließend das RNA-Gel luftblasenfrei darauf platziert. Abschließend wurde das Gel mit drei in TBE-Puffer geschwenkten Gel-Blot-Filterpapieren überschichtet und in die BlotApparatur eingesetzt. Der Transfer erfolgte elektrophoretisch für $1 \mathrm{~h}$ bei $25 \mathrm{~V}$. Nach dem Blotten wurde die Membran an der Luft getrocknet. Um die immobilisierte RNA mit der Nylonmembran zu vernetzen, wurde die Membran mit UV-C-Licht $\left(1.200 \mathrm{~J} / \mathrm{m}^{2}\right) \mathrm{mit}$ Hilfe eines UV-Stratalinkers 1800 (Stratagene) bestrahlt. 


$\begin{array}{lll}10 \times \text { TBE-Puffer } & 1 \mathrm{M} & \text { Tris } \\ & 1 \mathrm{M} & \text { Borsäure } \\ & 20 \mathrm{mM} & \text { EDTA pH 8,0 } \\ & \mathrm{pH} 8,3 & \end{array}$

\subsubsection{Proben-Detektion}

Streptavidin wird aus dem Bakterium Streptomyces avidinii isoliert und besitzt eine hohe Affinität zu Biotin. Biotin-markierte RNA-Moleküle, welche auf eine Nylonmembran übertragen worden sind, wurden mit Hilfe eines Chemilumineszenz-Detektions-Kits (Pierce) nach Angaben des Herstellers detektiert. Dazu wurde die Nylonmembran zunächst mit Streptavidin-Meerrettich-Peroxidase-Konjugaten inkubiert, welche an die Biotin-markierten RNA-Moleküle binden. Der Nachweis der RNA-Moleküle erfolgte anschließend über eine von Peroxidase katalysierte Oxidation von Luminol. Um die Reaktion zu starten, wurde die Nylonmembran mit ECL-Nachweisreagenzien (im Kit enthalten) für 5 min inkubiert und die bei dieser Katalyse entstehende Chemilumineszenz anschließend durch Exposition mit einem Röntgenfilm nachgewiesen.

\subsubsection{Quantifizierung und Normalisierung von Bandensignalen}

Der quantitative Vergleich von DNA-, RNA- oder Protein-Bandenintensitäten erfordert die densitometrische Bestimmung der Signalstärke. Zur Bestimmung von DNABandenintensitäten wurden digitale Aufnahmen der zu quantifizierenden Agarosegele bei 302 nm UV-Anregung gemacht. Zur Bestimmung von RNA- oder Protein-Bandenintensitäten wurden die Röntgenfilme eingescannt und als Bilddatei gespeichert. Die Quantifizierung aller Bandenintensitäten erfolgte mit Hilfe der AIDA Software (Raytest). Um mögliche Unterschiede in den aufgetragenen Probenmengen auszugleichen, wurden die erhaltenen Signalstärken mit den Werten der entsprechenden Banden von Haushaltsgenen, wie Glycerinaldehyd-3-Phosphatdehydrogenase (GAPDH) oder L32 normalisiert. Da die Haushaltsgene GAPDH und L32 unabhängig von der Behandlung der Zellen immer gleich stark exprimiert werden, eignen sie sich als interner Standard, um die Menge der eingesetzten Probe anzuzeigen. 


\subsection{Proteinbiochemische Methoden}

\subsubsection{Herstellung von Gesamtproteinzellextrakten}

Zur Herstellung von Gesamtproteinzellextrakten wurden die Zellen mit PBS gewaschen und mit Trypsin/EDTA vom Boden der Zellkulturschale abgelöst. Nach Aufnahme in $2 \mathrm{ml}$ kaltem Medium wurden die Zellen abzentrifugiert $\left(300 \mathrm{~g}, 5 \mathrm{~min}, 4{ }^{\circ} \mathrm{C}\right)$ und der Überstand verworfen. Das Zellpellet wurde zweimal mit je $2 \mathrm{ml}$ kaltem PBS gewaschen, in RIPA-Puffer, entsprechend der Zellzahl, aufgenommen und für $10 \mathrm{~min}$ auf Eis lysiert. Abschließend wurden die Zelllysate für $10 \mathrm{~min}$ bei $10.000 \mathrm{~g}, 4^{\circ} \mathrm{C}$ abzentrifugiert, der Überstand, bestehend aus löslichen Proteinen, aufbewahrt und das Pellet verworfen. Die Lagerung der Proteinextrakte erfolgte bis zur weiteren Analyse bei $-20^{\circ} \mathrm{C}$.

$\begin{array}{lll}\text { RIPA-Puffer } & 50 \mathrm{mM} & \text { Tris-HCl, } \mathrm{pH} 7,5 \\ 150 \mathrm{mM} & \mathrm{NaCl} \\ 1 \% & \text { Igepal } \\ 0,5 \% & \text { Natriumdesoxycholat } \\ 0,1 \% & \text { SDS } \\ 1 \mathrm{Tablette} & \text { Proteaseinhibitoren-Cocktail CompleteMini } \\ \text { ad } 10 \mathrm{ml} & \mathrm{H}_{2} \mathrm{O}_{\text {Millipore }}\end{array}$

\subsubsection{Bestimmung von Gesamtproteinkonzentrationen}

Die Gesamtproteinkonzentration von Zelllysaten wurde mit Hilfe des DC-Protein-Assays (BioRad) ermittelt. Diese kolorimetrische Messung basiert auf der Methode nach Lowry (Legler et al., 1985) und wurde nach Angaben des Herstellers durchgeführt.

\subsubsection{SDS-Polyacrylamid-Gelelektrophorese}

Die diskontinuierliche SDS-Polyacrylamid-Gelelektrophorese (SDS-PAGE) nach Laemmli (Laemmli, 1970) dient dazu, Proteine aus einem Gemisch nach ihrem Molekulargewicht aufzutrennen, um die Größe eines Proteins zu bestimmen oder um die Reinheit eines Proteins zu überprüfen. Die elektrophoretische Beweglichkeit von Proteinen in einer Polyacrylamid (PAA)-Gelmatrix ist von ihrer Größe und Form abhängig und wird durch die Nettoladung des Proteins bestimmt. Sodiumdodecylsulfat (SDS) ist ein anionisches Detergenz, welches die Eigenladung von Proteinen so effektiv überdeckt, dass Micellen mit konstanter negativer Ladung pro Masseneinheit entstehen. Durch ihre negative Ladung wandern die Proteine im 
elektrischen Feld zur Anode. Proteine würden im porenfreien Gel gleich schnell wandern, im porösen Gel jedoch wird die Wanderungsgeschwindigkeit und somit die Laufstrecke pro Zeiteinheit durch die Molekülgröße bestimmt. Als Referenz zur Bestimmung der Proteingröße dienen Markerproteine mit bekanntem Molekulargewicht.

Die Elektrophorese erfolgte in einer vertikalen mighty small Gel-Apparatur (Amersham Pharmacia). Die Gele wurden in einer Gießkammer gegossen, wobei Acrylamidkonzentrationen von 5\% für das Sammelgel und 10\% für das Trenngel verwendet wurden. Zunächst wurde zwischen die mit Abstandshaltern getrennten Gelplatten das Trenngel gegossen, welches anschließend mit Isopropanol überschichtet wurde. Nach der Polymerisation der Trenngelmatrix wurde das Isopropanol entfernt, der Kamm eingesetzt und das Sammelgel gegossen. Bei der Vorbereitung der Proben wurde mit einem Überschuss an SDS (im 6 x SDS-Probenpuffer enthalten) für 5 min auf $95{ }^{\circ} \mathrm{C}$ erhitzt, um so Tertiär- und Sekundärstrukturen der Proteine aufzulösen. Schwefelbrücken zwischen Cysteinen wurden durch Zugabe von reduzierendem DTT aufgespalten. Die Gelelektrophorese erfolgte bei $20 \mathrm{~mA}$ pro Gel in SDS-Tris/Glycin-Laufpuffer (10 x SDS-Tris/Glycin-Laufpuffer; BioRad), bis die Bromphenolblau-Bande das gesamte Gel durchwandert hatte.

$\begin{array}{lll}6 \text { x SDS-Probenpuffer } & 7 \mathrm{ml} & 0,5 \mathrm{M} \text { Tris-HCl/0.4\% SDS, pH 6,8 } \\ & 3 \mathrm{ml} & \text { Glycerol } \\ 1 \mathrm{~g} & \text { SDS } \\ 0,93 \mathrm{~g} & \text { DTT } \\ 1,2 \mathrm{mg} & \text { Bromphenolblau } \\ & & \\ & & \\ \text { Trenngel }(10 \%) & 1,65 \mathrm{ml} & 30 \% \text { Acrylamid/N,N-Methylenbisacrylamid } \\ & 1,25 \mathrm{ml} & 1,5 \mathrm{M} \text { Tris-HCl, pH } 8,8 \\ & 2 \mathrm{ml} & \mathrm{H}_{2} \mathrm{O}_{\text {Millipore }} \\ & 50 \mu 1 & 10 \% \text { SDS } \\ & 50 \mu 1 & 10 \% \text { APS } \\ 2 \mu 1 & \text { TEMED }\end{array}$

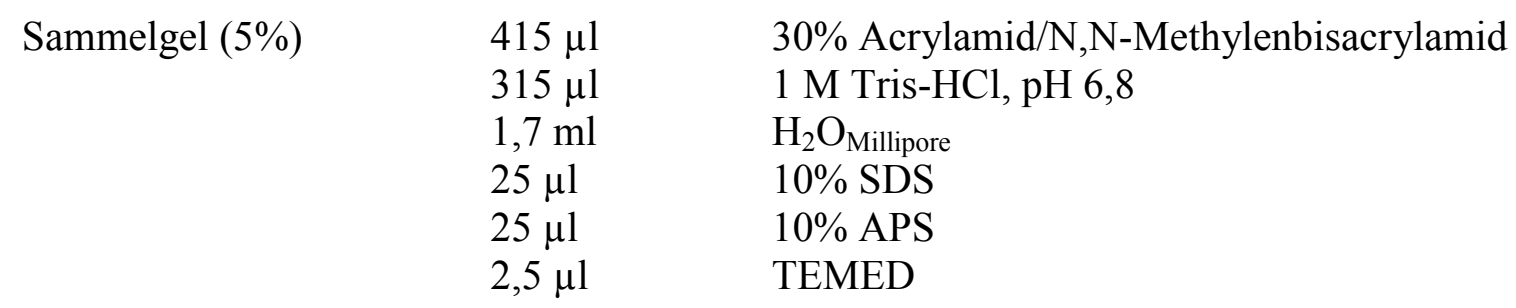


Als Referenz zur Größenbestimmung denaturierter Proteine dienten Markerproteine mit bekanntem Molekulargewicht.

Molekulargewichtsstandard für denaturierte Proteine (peqGOLD Protein-Marker IV, PeqLab):

$170 \mathrm{kDa}, 130 \mathrm{kDa}, 95 \mathrm{kDa}, 72 \mathrm{kDa}, 55 \mathrm{kDa}, 43 \mathrm{kDa}, 34 \mathrm{kDa}, 26 \mathrm{kDa}, 17 \mathrm{kDa}, 11 \mathrm{kDa}$

\subsubsection{Westernblot-Analyse}

Nach der SDS-PAGE wurden die aufgetrennten Proteine mit Hilfe einer Tankblot-Apparatur (Amersham Pharmacia) auf eine Polyvinylidenfluorid (PVDF)-Membran übertragen. Dazu wurden zwei, auf Gelgröße zugeschnittene und in Transferpuffer getränkte Gel-BlotFilterpapiere übereinander positioniert. Die durch Methanol aktivierte und mit Transferpuffer befeuchtete PVDF-Membran wurde aufgelegt und anschließend das Proteingel luftblasenfrei darauf platziert. Abschließend wurde das Gel mit zwei in Transferpuffer geschwenkten GelBlot-Filterpapieren überschichtet und in die Blot-Apparatur eingesetzt. Der Transfer erfolgte elektrophoretisch für $2 \mathrm{~h}$ bei $250 \mathrm{~mA}$.

$\begin{array}{lll}\text { Transferpuffer } & 5,8 \mathrm{~g} & \text { Tris } \\ 2,9 \mathrm{~g} & \text { Glycin } \\ 3,7 \mathrm{ml} & 10 \% \mathrm{SDS} \\ 200 \mathrm{ml} & \text { Methanol } \\ & \text { ad } 1000 \mathrm{ml} & \mathrm{H}_{2} \mathrm{O}_{\text {Millipore }}\end{array}$

\subsubsection{Immunfärbung des Westernblots}

Proteine (Antigene), die auf PVDF-Membranen übertragen worden sind, können durch spezifische Primärantikörper und gegen die Primärantikörper gerichtet Sekundärantikörper detektiert werden. Vor der Antigen-Detektion wurde die PVDF-Membran für $2 \mathrm{~h}$ bei RT in 5\% Magermilch (in PBS/0,1\% Tween20) geschwenkt, um unspezifische Immunreaktionen zu vermeiden. Die Inkubation mit dem in 2,5\% Magermilch verdünnten antigenspezifischen Primärantikörper erfolgte über Nacht bei $4{ }^{\circ} \mathrm{C}$ unter ständigem Schütteln. Der Antikörper wurde wieder abgenommen und die PVDF-Membran mit PBS/0,1\% Tween20 dreimal für je $10 \mathrm{~min}$ gewaschen. Es folgte ein weiterer Waschschritt für $10 \mathrm{~min}$ mit $\mathrm{PBS} / 0,1 \%$ Tween20/2,5\% Magermilch und anschließend die Inkubation des Zweitantikörpers (in PBS/0,1\% Tween20/2,5\% Magermilch verdünnt) für 45 min bei RT. Als Sekundärantikörper 
wurden Meerrettich-Peroxidase (horseradish peroxidase) gekoppelte Antikörper verwendet, so dass der Nachweis der Proteine nach weiteren vier Waschschritten mit PBS/0,1\% Tween20 für jeweils 10 min über eine von Peroxidase katalysierte Oxidation von Luminol erfolgte. Um die Reaktion zu starten wurde die PVDF-Membran mit ECL-Nachweisreagenzien (Pierce) für 1 min inkubiert und die bei dieser Katalyse entstehende Chemilumineszenz durch Exposition mit einem Röntgenfilm nachgewiesen.

\subsection{Statistik}

Zur Berechnung der statistischen Signifikanz wurde der t-Test nach Student unter Zuhilfenahme der SPSS 14.0 Software angewendet. Ein $p$-Wert $\leq 0.05$ wurde als signifikant angesehen. 


\section{Ergebnisse}

\subsection{Die ektopische Expression von GBP-1 hemmt die Bildung} stabiler Lamellipodien und die Migration von Endothelzellen auf FN

Während der Angiogenese ist FN eines der am häufigsten vorkommenden Proteine der EZM und maßgeblich an der Regulation der Angiogenese beteiligt (Jin and Varner, 2004; Ruegg and Mariotti, 2003). Im Gegensatz dazu lässt sich in der EZM ausgereifter, ,alter“ Blutgefäße kein FN nachweisen.

\subsubsection{Ektopische Expression und Nachweis von GBP-1 in HUVEC}

Um die Wirkung von GBP-1 auf die Bildung endothelialer Lamellipodien auf FNbeschichteten Oberflächen untersuchen zu können, wurde GBP-1 mit Hilfe der retroviralen Transduktion in HUVEC stabil exprimiert. Zur Herstellung von GBP-1-kodierenden Retroviren wurden PG13-Verpackungszellen (Miller et al., 1991) verwendet, welche stabil mit dem retroviralen Expressionsplasmid pBabePuro-GBP-1 (GBP-1) und zur Kontrolle mit dem Leerplasmid pBabePuro (KV) (Morgenstern and Land, 1990) transfiziert waren. Nach der retroviralen Transduktion und anschließender Puromyzin-Selektion (10 Tage) der HUVEC wurde die GBP-1-Expression mittels Westernblot-Analyse überprüft. Im Vergleich zu KV-HUVEC konnte in GBP-1-HUVEC eine hohe GBP-1-Expression nachgewiesen werden (Abb. 9).

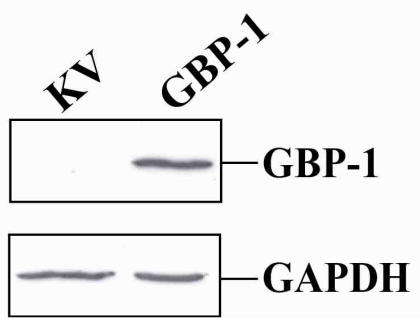

\section{Abb. 9: Ektopische Expression von GBP-1 in HUVEC mittels retroviraler Transduktion.}

HUVEC (HUVEC1) wurden mit den retroviralen Plasmiden pBabePuro-GBP-1 (GBP-1) oder pBabePuro (KV) transduziert und nach 10 Tagen Puromyzin-Selektion die GBP-1-Expression der Zellen untersucht. Dazu wurden KV- und GBP-1-HUVEC lysiert, jeweils $10 \mu \mathrm{g}$ der Gesamtzellextrakte in einem 10\% PAA-Gel aufgetrennt und auf eine PVDF-Membran übertragen. Die GBP-1-Expression wurde anschließend mit dem monoklonalen, GBP-1-spezifischen Antikörper 1B1 im Westernblot detektiert. Der Nachweis von GAPDH diente als Ladekontrolle. 


\subsubsection{Die ektopische Expression von GBP-1 hemmt die Bildung endothelialer Lamellipodien auf FN-beschichteten Oberflächen}

Mit Hilfe der stabil GBP-1-exprimierenden Zellen wurde der Einfluss von GBP-1 auf die Bildung endothelialer Lamellipodien auf FN-beschichteten Oberflächen untersucht. Dazu wurden KV- und GBP-1-HUVEC auf FN-Matrizes in SFM ausgesät und bei $37^{\circ} \mathrm{C}$ für 20 min kultiviert. Anschließend wurden die Zellen fixiert, mit Kristallviolett angefärbt und fotografiert. Es konnte gezeigt werden, dass ein Großteil der KV-HUVEC innerhalb dieser Zeit stabile Lamellipodien ausgebildet hatte (Abb. 10A; KV; Pfeile), wohingegen GBP-1exprimierende Zellen eine kleine, runde Zellmorphologie aufwiesen (Abb. 10A; GBP-1). Zur Quantifizierung wurde von jeweils 100 der KV- und GBP-1-HUVEC mit Hilfe der OPTIMAS 6.0 Software die Größe der Zellfläche bestimmt und die Zellen je nach Fläche 15 Inkrementen zugeordnet (Inkrement 1: 0 - $400 \mu \mathrm{m}^{2}$; Inkrement 2: $400-800 \mu \mathrm{m}^{2} ; \ldots$; Inkrement 15: $5.600-6.000 \mu \mathrm{m}^{2}$ ). KV- und GBP-1-HUVEC zeigten dabei deutliche Unterschiede in ihrer Größenverteilung (Abb. 10B). Während die meisten GBP-1exprimierenden Zellen ein Flächenmaß zwischen $0 \mu \mathrm{m}^{2}$ und $1.600 \mu \mathrm{m}^{2}$ (Inkrement 1 - 4) aufwiesen, lagen die Flächen von KV-HUVEC meist in einem Bereich zwischen $800 \mu \mathrm{m}^{2}$ und $3.200 \mu \mathrm{m}^{2}$ (Inkrement 3 - 9). Definiert man eine Zelle mit ausgebildeten Lamellipodien mit größer als $1.200 \mu \mathrm{m}^{2}$ (Inkrement 4 - 15), so weisen GBP-1-exprimierende Zellen $(27 \pm 5,6 \%)$ signifikant $(\mathrm{p} \leq 0,001)$ weniger Lamellipodien auf im Vergleich zu KV-HUVEC $(87,8 \pm$ 5,6\%) (Abb. 10C; $\geq 1.200 \mu \mathrm{m}^{2}$ ). Auch bei einer stringenteren Definition einer Zelle mit ausgebildeten Lamellipodien (Inkrement 5 - 15 oder $\geq 1.600 \mu \mathrm{m}^{2}$ ) war die Anzahl an GBP-1HUVEC $(13,3 \pm 3,5 \%)$ mit ausgebildeten Lamellipodien signifikant $(\mathrm{p} \leq 0,001)$ unterschiedlich zu KV-HUVEC (74,3 $\pm 7,1 \%$ ) (Abb. 10C; $\left.\geq 1.600 \mu \mathrm{m}^{2}\right)$. 
A
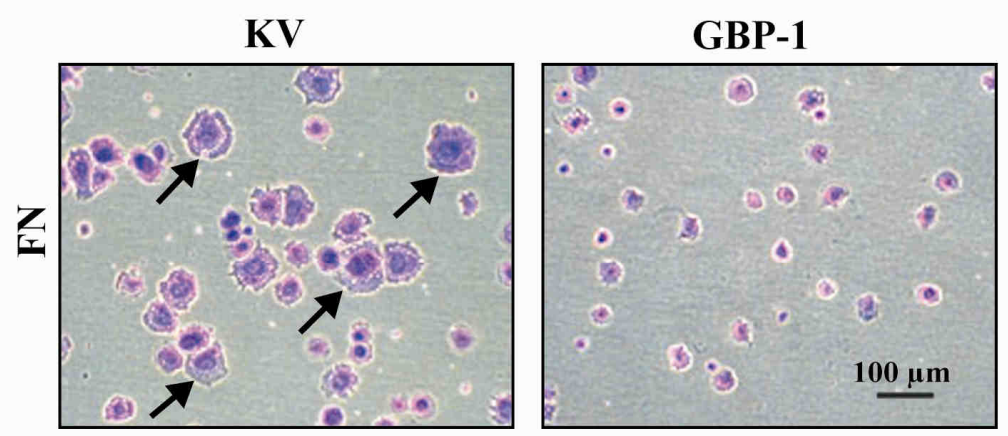

B

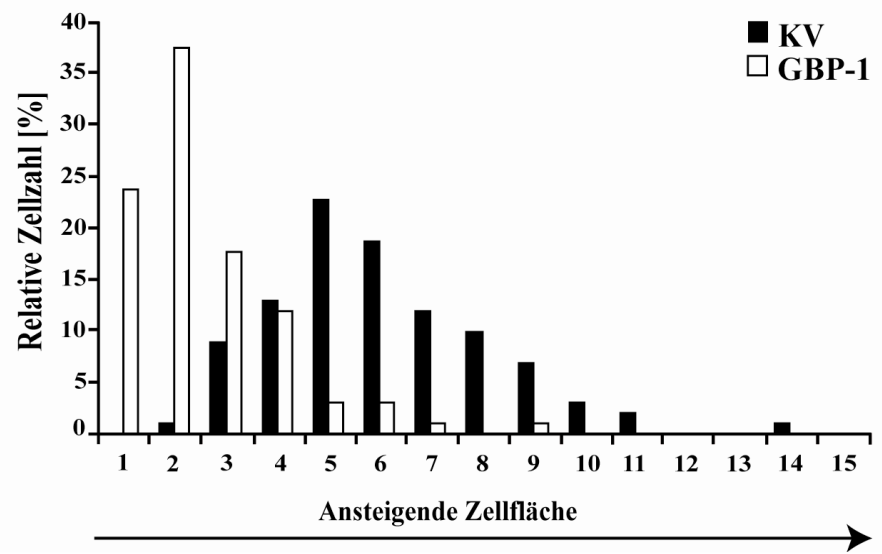

C

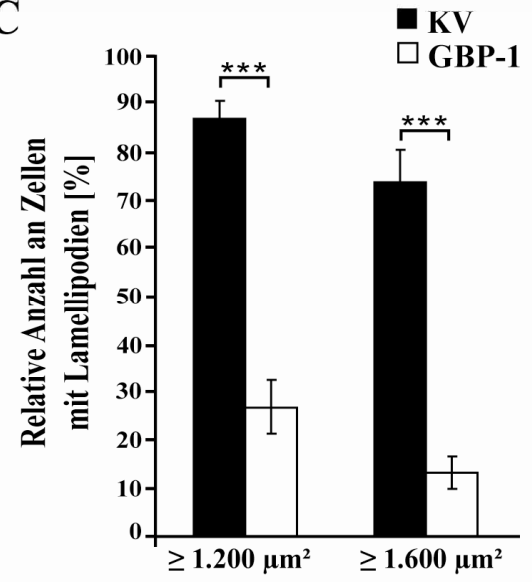

\section{Abb. 10: GBP-1 hemmt die Lamellipodienbildung auf FN-beschichteten Oberflächen.}

(A) Es wurden jeweils $5 \times 10^{3}$ der KV- und GBP-1-HUVEC (HUVEC1) pro Loch in einer mit FN-beschichteten $\left(5 \mu \mathrm{g} / \mathrm{cm}^{2}\right)$ 96-Loch-Platte ausgesät. Die Zellen wurden 20 min nach Anheftung in 10\% Formalin fixiert und mit 0,5\% Kristallviolett angefärbt. GBP-1-exprimierende Zellen wiesen im Vergleich zu KV-HUVEC eine kleine, runde Zellmorphologie auf. Schwarze Pfeile verweisen auf ausgebildete Lamellipodien. (B) Die Fläche von jeweils 100 der in (A) dargestellten Zellen wurde mit Hilfe der OPTIMAS 6.0 Software bestimmt. Die Zellen wurden je nach Flächenmaß 15 Inkrementen zugeordnet, wobei ein Inkrement einer Größe von $400 \mu \mathrm{m}^{2}$ entspricht. Die Größenverteilung der Zellen eines repräsentativen Experiments ist im Diagramm dargestellt. (C) Die relative Anzahl (\%) an KV- und GBP-1-HUVEC mit ausgebildeten Lamellipodien definiert über eine Fläche $\geq 1.200 \mu \mathrm{m}^{2}$ (linke Säulen; Inkremente 4 - 15) oder $\geq 1.600 \mu \mathrm{m}^{2}$ (rechte Säulen; Inkremente 5 - 15) ist im Diagramm dargestellt. Die Mittelwerte \pm Standardabweichungen von vier unabhängigen Experimenten sind gezeigt $(* * *=\mathrm{p} \leq 0,001)$. 


\subsubsection{Die ektopische Expression von GBP-1 hemmt die Migration von Endothelzellen auf FN-beschichteten Oberflächen}

Eine wichtige Vorraussetzung für die zelluläre Migration ist die Bildung stabiler Lamellipodien am Vorderende einer Zelle (siehe auch Abschnitt 2.2.2) (Lauffenburger and Horwitz, 1996; Ridley et al., 2003). Deshalb wurde angenommen, dass GBP-1 aufgrund seiner Hemmwirkung auf die Lamellipodienbildung auch die Migrationsfähigkeit von Zellen auf FN-beschichteten Oberflächen verändert. Das Migrationsverhalten von GBP-1- und KVHUVEC auf FN-Matrizes wurde mit Hilfe eines in vitro Wundheilungstests untersucht. Mit Hilfe dieses Tests kann die Wanderungsgeschwindigkeit von Zellen in einen definierten, zellfreien Bereich (Verwundung) aus einer intakten, konfluenten Zellschicht bestimmt werden. Dazu wurden die transduzierten HUVEC auf FN-beschichteten Oberflächen ausgesät und bis zu einer Konfluenz von 90 - 100\% kultiviert. Mit Hilfe einer sterilen 1 mlPipettenspitze wurde der Zellrasen abgekratzt, so dass ein definierter, zellfreier Bereich entstand. Anschließend wurden die Zellen für $10 \mathrm{~h}$ in SFM kultiviert (Abb. 11A). Zur Bestimmung des Migrationsverhaltens wurde der Abstand zwischen den Zellfronten und somit die Fähigkeit der Zellen in den verwundeten, zellfreien Bereich zu migrieren, zu Beginn des Versuches (Zeitpunkt $0 \mathrm{~h}$ ) und alle weiteren $2 \mathrm{~h}$ bestimmt. Innerhalb eines Zeitraums von $10 \mathrm{~h}$ wiesen GBP-1-exprimierende Zellen ein signifikant $(\mathrm{p} \leq 0,05)$ langsameres Migrationsverhalten im Vergleich zu den Kontrollzellen auf (Abb. 11A, B). Die Breite des zellfreien Bereichs bei GBP-1-HUVEC betrug nach $10 \mathrm{~h} \mathrm{81,2} \pm 2,0 \%$ des initialen Abstandes, wohingegen KV-HUVEC den anfänglichen Abstand zwischen den Zellfronten auf 45,6 \pm $13,5 \%$ reduzierten $(\mathrm{Abb} .11 \mathrm{~B})$. 
A

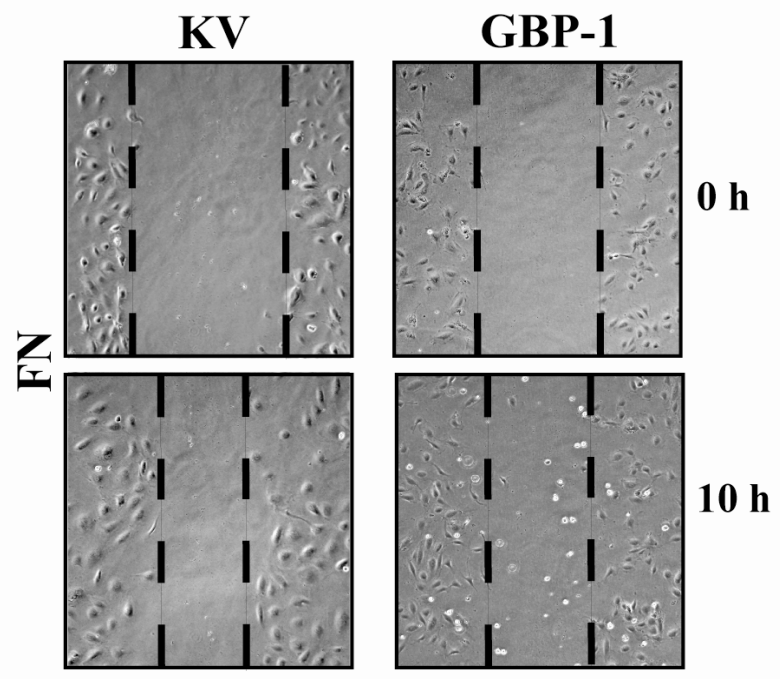

B

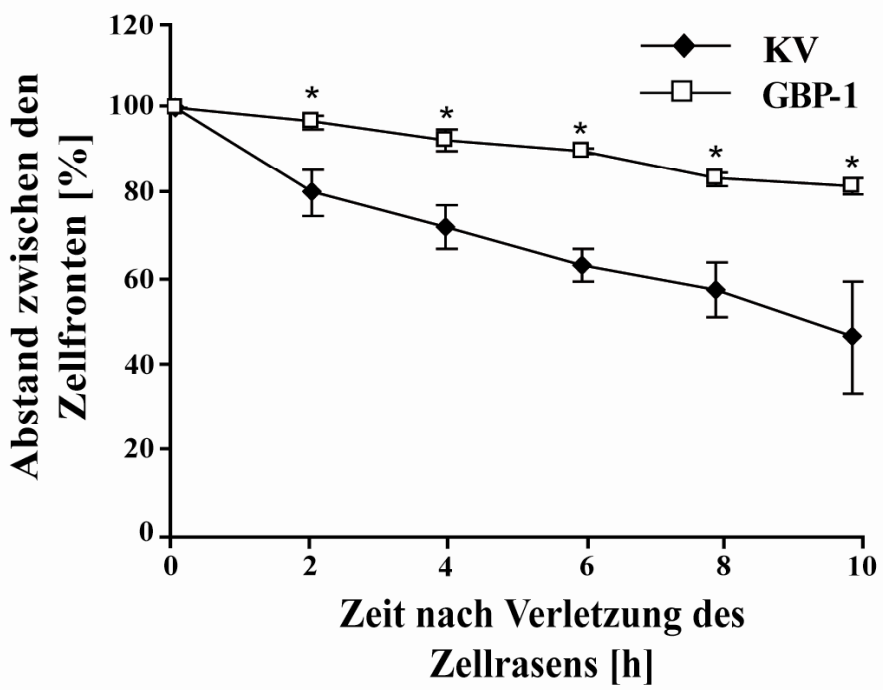

Abb. 11: GBP-1 hemmt die Migration von HUVEC auf FN-beschichteten Oberflächen.

(A) Zur Bestimmung der Migrationsfähigkeit von KV- und GBP-1-HUVEC (HUVEC1) wurde ein in vitro Wundheilungstest durchgeführt. Dazu wurden die Zellen auf FN-beschichteten Oberflächen ausgesät und bis zu einer Konfluenz von 90 - 100\% kultiviert. Mit Hilfe einer sterilen 1 ml-Pipettenspitze wurde ein definierter, zellfreier Bereich in den konfluenten Zellrasen gekratzt. Die Zellen wurden anschließend für $10 \mathrm{~h}$ in SFM kultiviert. Sowohl zu Beginn des Versuches (Zeitpunkt $0 \mathrm{~h}$ ), als auch nach $10 \mathrm{~h}$ wurden von den zellfreien Bereichen Bilder aufgenommen. (B) Der Abstand zwischen den Zellfronten wurde alle $2 \mathrm{~h}$ bestimmt und prozentual zum Abstand zum Zeitpunkt $0 \mathrm{~h}$ berechnet. Die Ergebnisse sind als Mittelwerte \pm Standardabweichungen von drei unabhängigen Experimenten in einem Diagramm abgebildet $(*=\mathrm{p} \leq 0,05)$. 


\subsection{GBP-1 induziert die Expression von Integrin $\alpha_{4}$ in Endothel- zellen}

\subsubsection{Identifizierung von GBP-1-regulierten Genen mittels Microarray-Analyse}

Um den molekularen Mechanismus der inhibitorischen Aktivität von GBP-1 bezüglich der Lamellipodienbildung und der Migration von $\mathrm{EZ} \mathrm{zu}$ identifizieren, wurde das Genexpressionsprofil von GBP-1- und KV-HUVEC verglichen. Es wurde mit zwei unterschiedlichen HUVEC-Kulturen (HUVEC1 und HUVEC2) gearbeitet, um Zellkulturspezifische Variationen ausschließen zu können. Zusätzlich zur HUVEC-Kultur 1 (Abb. 9) wurde eine zweite Kultur mit dem retroviralen Expressionsplasmid pBabePuro-GBP-1 (GBP-1) und zur Kontrolle mit dem Leerplasmid pBabePuro (KV) transduziert. Nach 10 Tagen Puromyzin-Selektion wurde die GBP-1-Expression mittels Westernblot-Analyse überprüft. Es zeigte sich, dass auch in diesem Fall GBP-1-HUVEC im Vergleich zu KVHUVEC eine hohe GBP-1-Expression aufwiesen (Abb. 12).

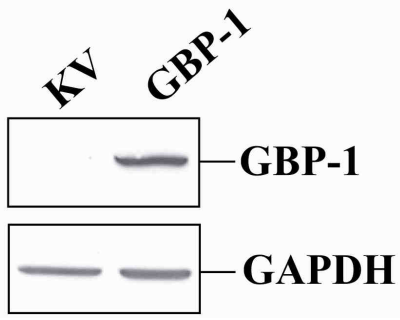

Abb. 12: Ektopische Expression von GBP-1 in HUVEC mittels retroviraler Transduktion.

HUVEC (HUVEC2) wurden mit den retroviralen Plasmiden pBabePuro-GBP-1 (GBP-1) oder pBabePuro (KV) transduziert und nach 10 Tagen Puromyzin-Selektion die GBP-1-Expression der Zellen untersucht. Dazu wurden GBP-1- und KV-HUVEC lysiert, jeweils $10 \mu \mathrm{g}$ der Gesamtzellextrakte in einem 10\% PAA-Gel aufgetrennt und auf eine PVDF-Membran übertragen. Die GBP-1-Expression wurde anschließend mit dem monoklonalen, GBP-1-spezifischen Antikörper 1B1 im Westernblot detektiert. Der Nachweis von GAPDH diente als Ladekontrolle.

Nach Überprüfung der GBP-1-Expression wurde aus den beiden verschiedenen GBP-1- und KV-HUVEC-Kulturen (HUVEC1, HUVEC2) die Gesamt-RNA isoliert. Um das Genexpressionsprofil vergleichen zu können, wurden je $10 \mu \mathrm{g}$ Gesamt-RNA zur Analyse mittels Oligonukleotid-basierter Microarray-Technologie eingesetzt. Mit Hilfe dieser Methode konnte die Transkription von 38.500 Genen simultan untersucht werden. Insgesamt konnten sechs Gene identifiziert werden, welche durch GBP-1 in beiden HUVEC-Kulturen hoch signifikant $(\mathrm{p} \leq 0,001)$ reguliert waren (Tab. 8). 
Tab. 8: GBP-1-regulierte $(p \leq 0,001)$ Gene in stabil transduzierten HUVEC-Kulturen.

\begin{tabular}{|c|c|c|c|c|c|}
\hline \multirow{2}{*}{$\begin{array}{l}\text { Proben- } \\
\text { nummer }\end{array}$} & \multirow[b]{2}{*}{$\begin{array}{c}\text { Akzessions- } \\
\text { nummer }\end{array}$} & \multirow[b]{2}{*}{ Genname } & \multirow[b]{2}{*}{$\begin{array}{c}\text { Gen- } \\
\text { symbol }\end{array}$} & \multicolumn{2}{|c|}{ x-fache Induktion } \\
\hline & & & & HUVEC1 & HUVEC2 \\
\hline 213416_at & BG532690 & integrin, alpha 4 & ITGA4 & 3,4 & 3,8 \\
\hline 244741_s_at & BE855713 & $\begin{array}{c}\text { hypothetical protein } \\
\text { MGC9913 }\end{array}$ & MGC9913 & 2,8 & 2,5 \\
\hline$\overline{2} 0 \overline{3} 8 \overline{6} 8$ _at & $\overline{\mathrm{N}} \overline{\mathrm{M}} \_\overline{0} 0 \overline{10} \overline{78}$ & $\begin{array}{c}-\overline{-}-\overline{-} \overline{-} \bar{c} \bar{l} \\
\text { vascular cell adhesion } \\
\text { molecule } 1\end{array}$ & $\overline{\mathrm{V}} \overline{\mathrm{CA}} \overline{\mathrm{M}} \overline{1}-$ & $-\overline{-2, \overline{1}}$ & $-\overline{-2}, \overline{1}$ \\
\hline 206942_s_at & NM_002674 & $\begin{array}{l}\text { pro-melanin- } \\
\text { concentrating hormone }\end{array}$ & $\mathrm{PMCH}$ & $-2,4$ & $-2,4$ \\
\hline 219685_at & NM_021637 & $\begin{array}{l}\text { transmembrane protein } \\
35\end{array}$ & TMEM35 & $-3,5$ & $-2,1$ \\
\hline 205433_at & NM_000055 & $\begin{array}{l}\text { butyrylcholin } \\
\text { esterase }\end{array}$ & BCHE & $-5,1$ & $-2,0$ \\
\hline
\end{tabular}

$\uparrow$ durch GBP-1 hochregulierte Gene

$\downarrow$ durch GBP-1 herunterregulierte Gene

Integrin $\alpha_{4}$ (itga4) war in beiden GBP-1-exprimierenden HUVEC-Kulturen das am stärksten hochregulierte Gen (Tab. 8; fett gedruckt). Es ist bereits bekannt, dass ITGA4 spezifisch mit den Integrin $\beta_{1}$ - und $\beta_{7}$-Untereinheiten heterodimerisiert. Interessanterweise wurde auch gezeigt, dass die Expression von ITGA4 sowohl die Bildung zellulärer Lamellipodien reduziert (Chan et al., 1992; Goldfinger et al., 2003; Kassner et al., 1995; Liu et al., 1999), als auch die Invasion und Migration von Zellen auf FN hemmt (Ignatoski et al., 2000; Jia et al., 2004; White et al., 2003; Zhang et al., 2004). Andere Integrine, wie beispielsweise $\alpha_{5} \beta_{1}$ oder $\alpha_{\mathrm{v}} \beta_{3}$, induzieren diese Prozesse (Kim et al., 2000b; Stupack and Cheresh, 2004).

\subsubsection{GBP-1 erhöht die mRNA-Transkription von itga4 in Endothelzellen}

Die Ergebnisse der Microarray-Analysen wurden zunächst auf RNA-Ebene mittels semiquantitativer RT-PCR und RNase Protection Assay (RPA) überprüft.

Zum Vergleich der Transkription von itga4 in GBP-1- und KV-HUVEC mittels semiquantitativer RT-PCR wurde je $1 \mu \mathrm{g}$ der gesamtzellulären mRNA in cDNA umgeschrieben. Jeweils vier verschiedene cDNA-Verdünnungen [unverdünnt (1), 1:10, 1:100, 1:1.000] 
wurden anschließend mittels PCR amplifiziert. Zusätzlich zur spezifischen Amplifikation der itga4-cDNA, wurde auch die Transkription der $g b p-1$-mRNA und als Kontrolle die Transkription des Hauhaltsgens gapdh mit Hilfe spezifischer Oligonukleotide überprüft. Es konnte ein deutlicher Anstieg der Transkription des itga4-Gens in GBP-1-HUVEC im Vergleich zu Kontrollzellen in beiden untersuchten HUVEC-Kulturen mittels RT-PCR nachgewiesen werden (Abb. 13A; ITGA4). Darüber hinaus konnte auch eine erhöhte gbp-1Expression in GBP-1-exprimierenden Zellen im Vergleich zu KV-HUVEC gezeigt werden (Abb. 13A; GBP-1). Die Amplifikation des Haushaltsgens gapdh führte bei gleichen Verdünnungen zu Banden ähnlicher Intensität und bestätigte somit die Vergleichbarkeit der eingesetzten Probenmengen (Abb. 13A; GAPDH). Zur quantitativen Bestimmung der relativen itga4-Expression wurden die Banden der PCR-Produkte, welche nicht im Sättigungsbereich lagen (cDNA-Verdünnung 1:100), densitometrisch analysiert und mit dem jeweiligen, für gapdh erhaltenen Signal (cDNA-Verdünnung 1:100) normalisiert. Ein Vergleich der so normalisierten Signale zeigte, dass die Transkription von itga4 in GBP-1HUVEC beider Kulturen hochreguliert war (3,4-fach HUVEC1; 2,3-fach HUVEC2) (Abb. 13B).

Neben der semi-quantitativen RT-PCR-Analyse wurde zum Vergleich der itga4-mRNATranskription in GBP-1- und KV-HUVEC auch ein RPA durchgeführt. Zum simultanen Nachweis von zehn verschiedenen Integrin $\alpha$-Untereinheiten in einer Probe wurden jeweils $10 \mu \mathrm{g}$ Gesamt-RNA mit zehn Integrin-spezifischen, Biotin-markierten Sonden unterschiedlicher Länge inkubiert. Zusätzlich zu den zehn verschiedenen Integrin-Sonden wurden zur Kontrolle auch zwei Biotin-markierte Sonden für die Haushaltsgene 132 und gapdh mitgeführt. 132 codiert ein essentielles Protein, welches Bestandteil der 60S ribosomalen Untereinheit ist. Auch mittels RPA ließ sich in GBP-1-HUVEC beider Kulturen eine gesteigerte Transkription an itga4 im Vergleich zu KV-HUVEC nachweisen (Abb. 13C). Zur quantitativen Bestimmung der relativen itga4-Expression wurden die itga4-Banden densitometrisch analysiert, mit den jeweiligen Signalen für $l 32$ normalisiert und in einem Balkendiagramm dargestellt (Abb. 13D). Ein Vergleich der so normalisierten Signale bestätigte eine erhöhte Expression an itga4-mRNA in GBP-1-Transduktanden beider HUVEC-Kulturen im Vergleich zu den jeweiligen Kontrollzellen (2,4-fach HUVEC1; 1,8fach HUVEC2) (Abb. 13D). Mit Hilfe des RPA konnte neben der Expression von itga4 auch die Expression anderer Integrin $\alpha$-Untereinheiten in EZ nachgewiesen werden. Für die Transkription der Integrine itga2, itga3, itga5 und itga6 konnte keine Beeinflussung durch 
GBP-1 festgestellt werden und auch die mRNA-Transkription von itgav wies keine einheitliche Veränderung durch GBP-1 in den beiden untersuchten HUVEC-Kulturen auf (Abb. 13C). Eine Expression der Integrine itgal, itga7, itga8 und itga9 konnte in EZ nicht nachgewiesen werden.

A

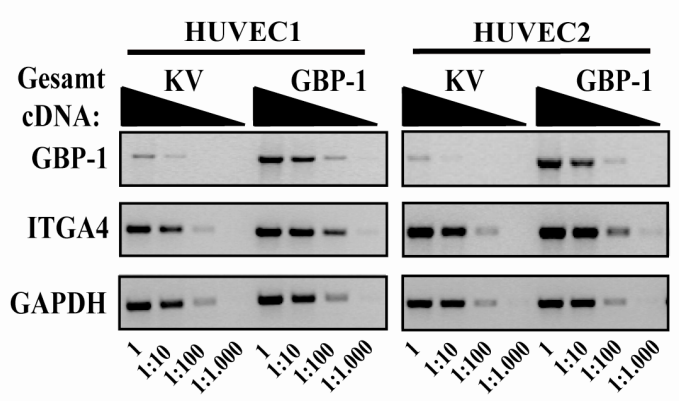

C

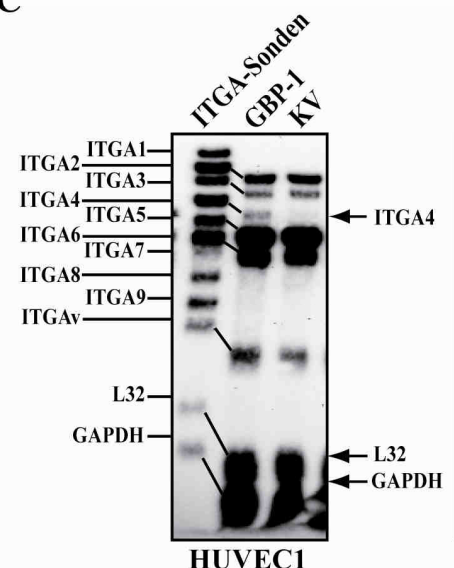

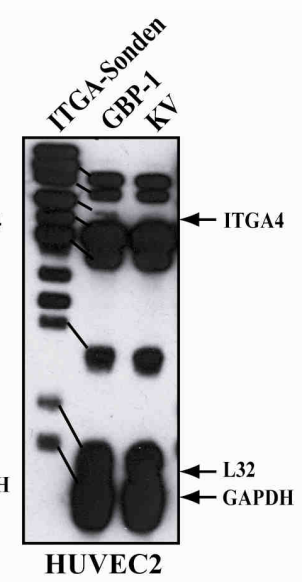

B

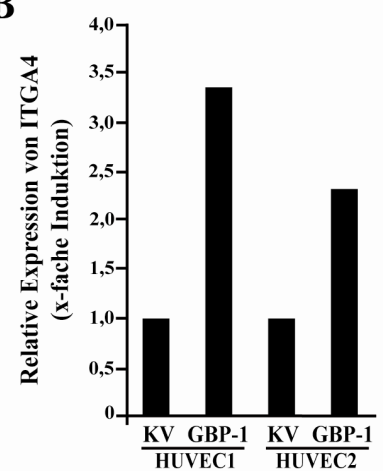

D

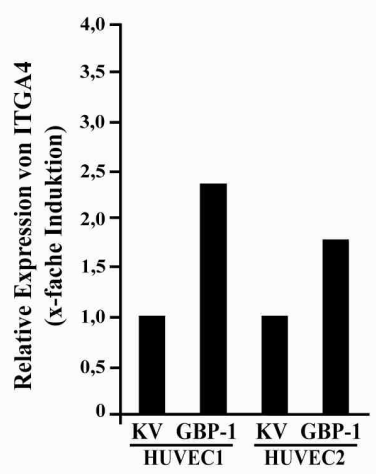

Abb. 13: GBP-1 induziert die mRNA-Transkription von itga 4 in HUVEC.

(A) RT-PCR-Analyse zum Vergleich der gbp-1-, itga4- und gapdh-mRNA-Transkription in KV- und GBP-1HUVEC-Kulturen (HUVEC1 und HUVEC2). Je $1 \mu \mathrm{g}$ der isolierten gesamtzellulären RNA wurde durch reverse Transkription in cDNA umgeschrieben. Für die PCR wurde die cDNA in verschiedenen Konzentrationen eingesetzt [unverdünnt (1), 1:10, 1:100 und 1:1.000]. GAPDH diente als Kontrolle, ob gleiche Mengen an Gesamt-RNA amplifiziert wurden. Die PCR-Produkte wurden bei $100 \mathrm{~V}$ für $1 \mathrm{~h}$ in einem $1 \%$ igen Agarosegel elektrophoretisch aufgetrennt, mit Ethidiumbromid angefärbt und durch UV-Anregung $(302 \mathrm{~nm})$ nachgewiesen. (B) Zur Quantifizierung der itga4-Expressionsstärken aus (A) wurden die Banden, welche sich nicht in der Farbtonsättigung befanden (cDNA-Verdünnung 1:100) densitometrisch analysiert. Variationen bei der cDNASynthese wurden durch Normalisierung mit dem entsprechenden gapdh-Signal ausgeglichen (cDNA Verdünnung 1:100). Die relative Induktion der itga4-Expression in GBP-1-exprimierenden Zellen im Vergleich zu KVHUVEC ist als Balkendiagramm dargestellt. (C) Je $10 \mu \mathrm{g}$ gesamtzelluläre RNA von KV- und GBP-1-HUVECKulturen (HUVEC1 und HUVEC2) wurden mittels RPA untersucht. Zur simultanen Synthese von 12 verschiedenen Biotin-markierten Sonden wurde das RiboQuant Multiprobe Human Integrin Template Set (BD Biosciences) eingesetzt. Nach RNase A-Behandlung wurden die RNA-Proben in einem Tris-Borat-Harnstoff-Gel bei $25 \mathrm{~V}$ für $1 \mathrm{~h}$ aufgetrennt und auf eine Nylonmembran übertragen. Als Größenstandard und zur Kontrolle, ob der RNase A-Verdau vollständig war, wurden $4 \mu \mathrm{l}$ der unverdauten RNA-Sonden (1:1.000 verdünnt) im Gel aufgetrennt. Die Detektion der RNA erfolgte mit Hilfe von Streptavidin-Meerrettich-Peroxidase-Konjugaten und ECL-Nachweisreagenzien. (D) Zur Quantifizierung der itga4-Expression aus (C) wurden die Banden densitometrisch analysiert und auf das entsprechende 132 -Signal normalisiert. Die relative Induktion der itga4Expression in GBP-1-exprimierenden Zellen im Vergleich zu KV-HUVEC ist in einem Balkendiagramm dargestellt. 


\subsubsection{GBP-1 induziert die Exposition von ITGA4 an der Oberfläche von Endothelzellen}

Nachdem die Ergebnisse der Microarray-Analysen auf RNA-Ebene sowohl mittels semiquantitativer RT-PCR, als auch mittels RPA bestätigt werden konnten, wurde die Proteinexpression von ITGA4 an der Oberfläche von GBP-1- und KV-HUVEC mittels Durchflusszytometrie untersucht (Abb. 14; ITGA4). Neben der Expression von ITGA4 wurde zur Kontrolle auch die Oberflächenexpression von Integrin $\beta_{1}$ (ITGB1) analysiert (Abb 14; ITGB1). ITGB1 bildet zusammen mit ITGA4 Heterodimere an der Zelloberfläche aus und gehört zur selben Proteinfamilie wie ITGA4. In Übereinstimmung mit den Ergebnissen der Microarray-Analyse, der semi-quantitativen RT-PCR und des RPA konnte auch mittels Durchflusszytometrie eine erhöhte ITGA4-Exposition an der Zelloberfläche von GBP-1exprimierenden Zellen (2,8 \pm 0,7-fach HUVEC1; 2,2 \pm 0,2-fach HUVEC2) im Vergleich zu den Kontrollzellen nachgewiesen werden (Abb. 14; ITGA4). ITGB1 wurde an der Oberfläche aller untersuchten Zellen exprimiert, zeigte jedoch im Gegensatz zu ITGA4 keine Expressionsunterschiede (Abb. 14; ITGB1). Darüber hinaus zeigen diese Ergebnisse auch, dass die Methode der retroviralen Transduktion die Regulation der endogenen IntegrinExpression per se nicht beeinflusst.
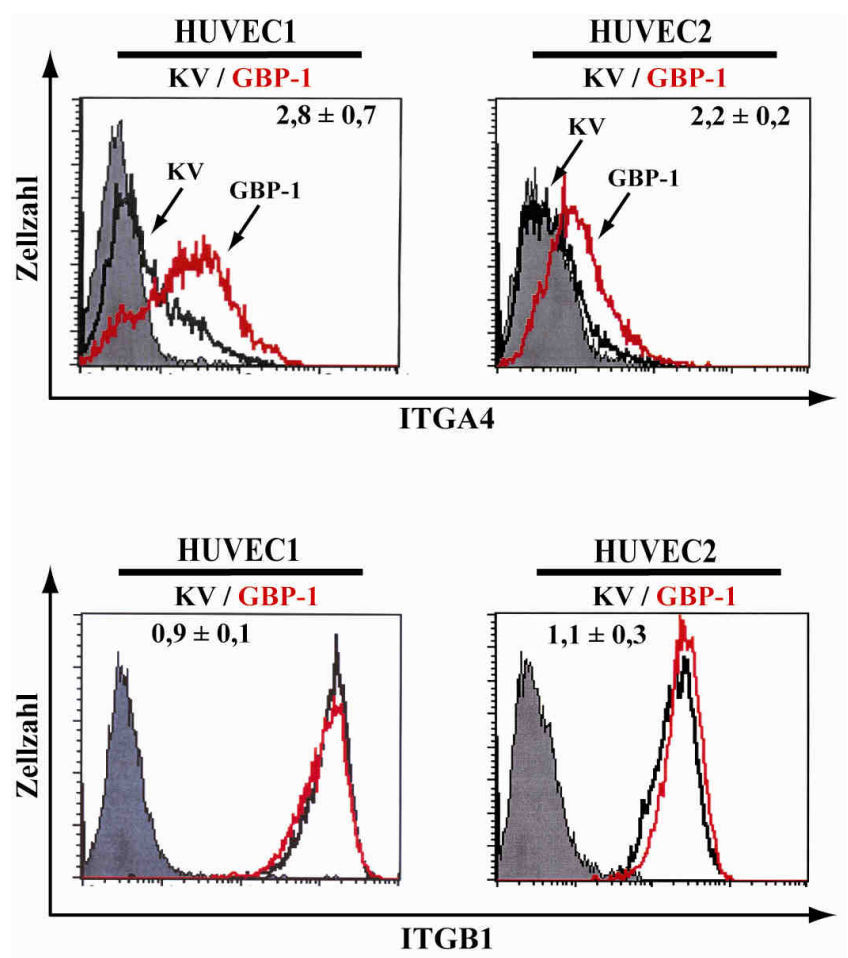
Abb. 14: GBP-1 bewirkt die Exposition von ITGA4 an der Oberfläche von HUVEC.

Zur Analyse der Oberflächenexpression von ITGA4 und ITGB1 wurden jeweils 1 x $10^{5}$ der GBP-1- (rot) und KVHUVEC (schwarz) mit dem monoklonalen, ITGA4-spezifischen Antikörper HP2/1 (obere Reihe) oder einem monoklonalen, ITGB1-spezifischen Antikörper (untere Reihe) angefärbt. Als Sekundärantikörper wurde ein an AlexaFluor 488-gekoppelter Antikörper verwendet. Zur Bestimmung des Färbehintergrunds wurden die Zellen anstelle des Erstantikörpers mit einem irrelevanten Antikörper des gleichen Isotyps in den entsprechenden Konzentrationen inkubiert (grau schattiert). Die Analyse der gefärbten Zellen erfolgte mittels Durchflusszytometrie an einem FACS-Calibur-Gerät (BD Biosciences). Die Durchschnittsfluoreszenzintensitäten von ITGA4- und ITGB1-gefärbten Zellen wurden mit den entsprechenden Werten der Isotypkontrollen normalisiert. Mit Hilfe der normalisierten Durchschnittsfluoreszenzintensitäten wurde die relative ITGA4- und ITGB1-Oberflächenexpression (x-fache Induktion) von GBP-1-HUVEC im Vergleich zu den jeweiligen Kontrollzellen bestimmt. Dieser Wert ist in jedem Bild als Mittelwert \pm Standardabweichung aus drei unabhängigen Experimenten angegeben.

\subsection{Die GTPase-Aktivität von GBP-1 ist an der Hochregulation der ITGA4-Expression beteiligt}

Um zu überprüfen, ob die GTPase-Aktivität von GBP-1 für die Induktion der ITGA4Expression notwendig ist, wurden die Effekte von zwei unterschiedlichen Mutanten (GBP-1K51A und GBP-1-D184N) des GBP-1-Proteins untersucht. Im GBP-1-K51A-Protein wurde eine Aminosäure an der Position +51 von GBP-1 mutiert (Lysin zu Alanin), was zu einer fast vollständigen Hemmung der GTP-Bindung und der GTPase-Aktivität führt (Praefcke et al., 2004). In der Mutante GBP-1-D184N wurde die Aminosäure Asparaginsäure an Position +184 zu Asparagin ausgetauscht, wodurch ein mutiertes GBP-1-Protein entsteht, welches nicht mehr in der Lage ist GTP zu binden (Guenzi et al., 2001; Praefcke et al., 1999). Die cDNAs beider Mutanten wurden nach Klonierung in das retrovirale Expressionsplasmid pBabePuro zusammen mit dem GBP-1-Wildtyp-Protein mittels retroviraler Transduktion in HUVEC (HUVEC1) ektopisch exprimiert. Darüber hinaus wurde zur Kontrolle neben dem Leerplasmid pBabePuro, GFP als ein heterologes Protein überexprimiert. Nach 10 Tagen Puromyzin-Selektion wurde die Expression des Wildtyp-GBP-1 und der Mutanten, sowie von GFP mittels Westernblot-Analyse (Abb. 15A, GBP-1 und GFP) und Durchflusszytometrie überprüft (Abb. 15B; Bilder a-c, h). Die Oberflächenexpression von ITGA4 war in GBP-1K51A- und GBP-1-D184N-HUVEC (3,0 \pm 1,0-fach GBP-1-K51A; 2,0 \pm 0,3-fach GBP-1D184N) im Vergleich zu GBP-1-HUVEC (7,2 \pm 1,0-fach) deutlich vermindert (Abb. 15B; Bilder i-k). Ein Vergleich der ITGA4-Expression nach Normalisierung auf den entsprechenden GBP-1-Proteingehalt verdeutlichte, dass die Induktion der ITGA4-Expression durch die beiden Mutanten statistisch signifikant $(\mathrm{p} \leq 0,01)$ niedriger war, als die in Anwesenheit des Wildtyp-Proteins beobachtete Induktion (Abb. 15C). Diese Ergebnisse zeigen, dass die GTPase-Aktivität von GBP-1 für die Hochregulation von ITGA4 wichtig ist. 
Die Expression von ITGB1 war in allen untersuchten Zellkulturen identisch (Abb. 15B; Bilder m-o).

A

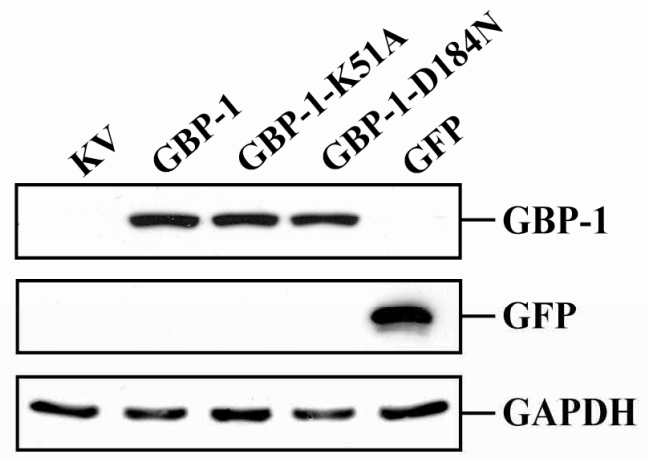

C

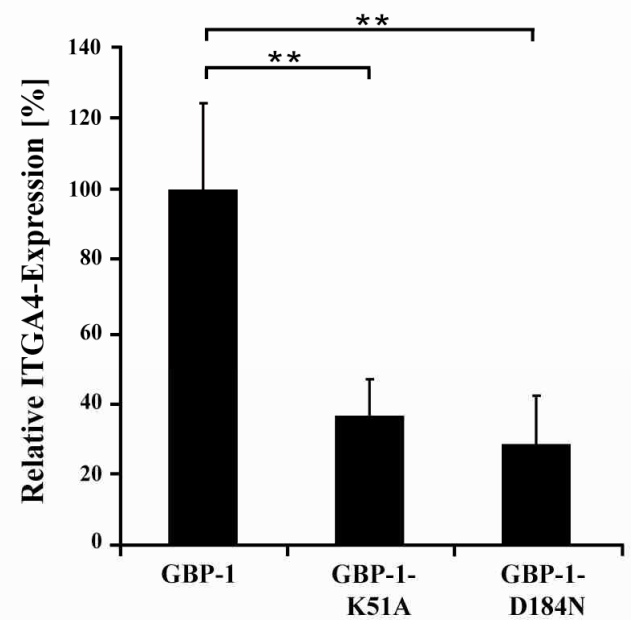

B

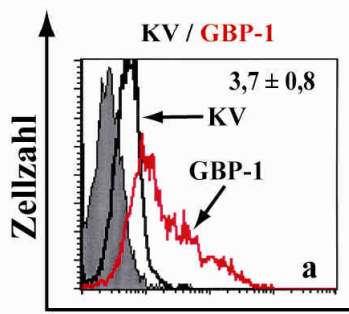

KV / GBP-1 K51A

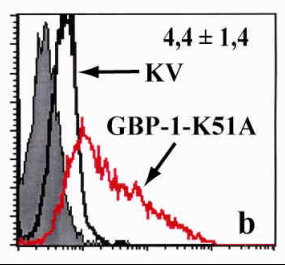

KV/ GBP-1-D184N

KV / GFP
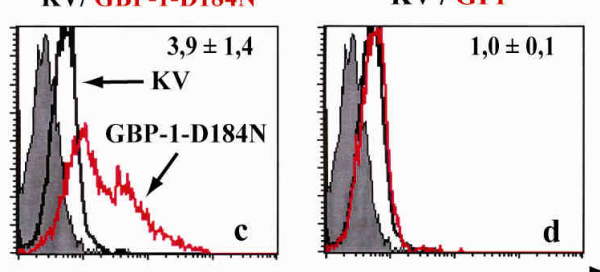

GBP-1
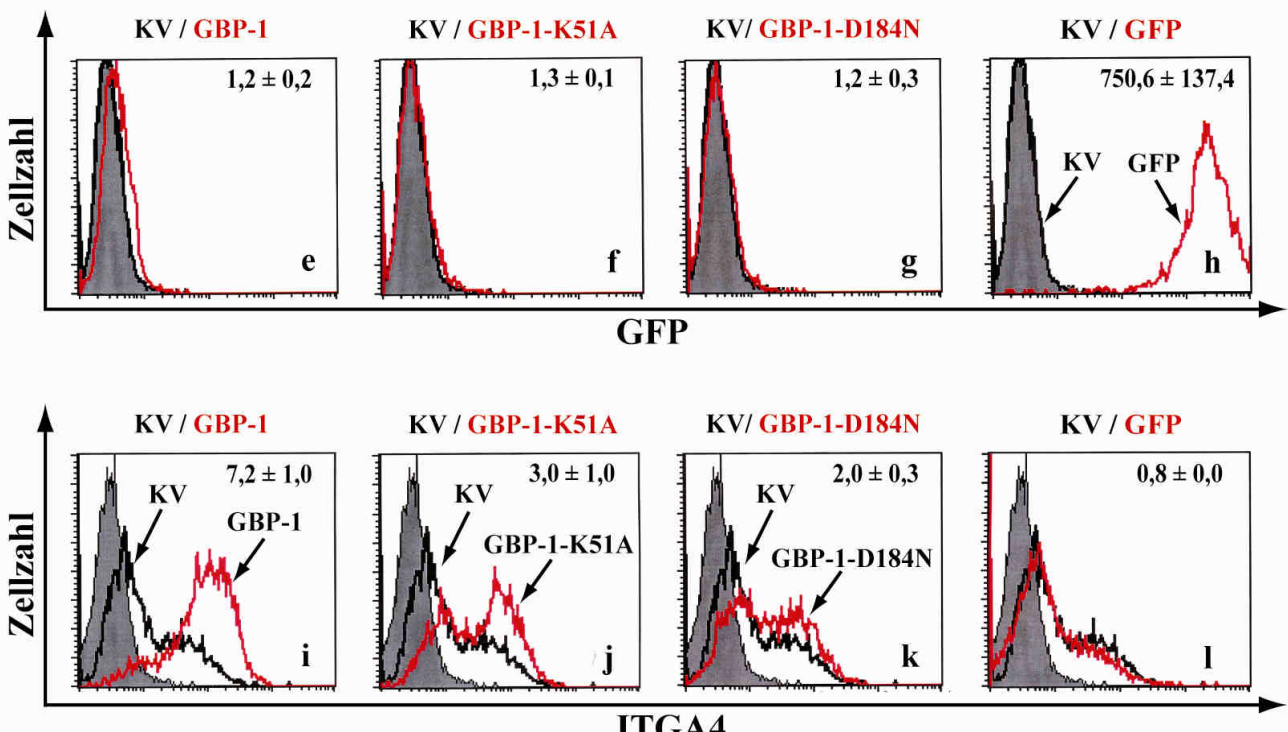

ITGA4
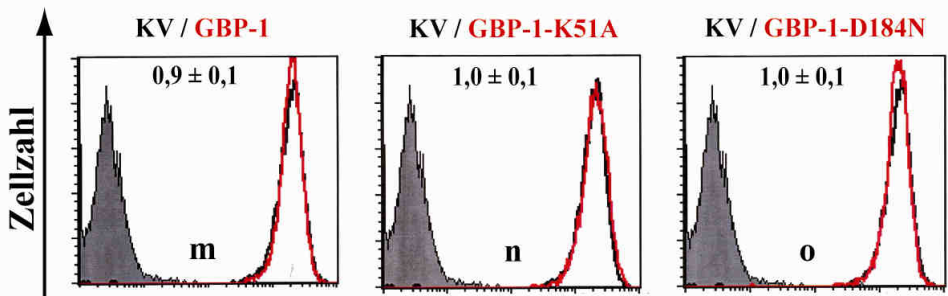

KV / GFP

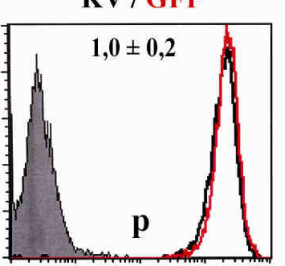


Abb. 15: Die GTPase-Aktivität von GBP-1 ist an der Induktion der ITGA4-Expression beteiligt.

(A) HUVEC (HUVEC1) wurden mit den retroviralen Expressionsplasmiden pBabePuro (KV), pBabePuroGBP-1 (GBP-1), pBabePuro-GBP-1-K51A (GBP-1-K51A), pBabePuro-GBP-1-D184N (GBP-1-D184N) oder pBabePuro-GFP (GFP) transduziert und nach 10 Tagen Puromyzin-Selektion die Expression der GBP-1Mutanten, sowie die GBP-1- und GFP-Expression der Zellen untersucht. Dazu wurden die Zellen lysiert, jeweils $10 \mu \mathrm{g}$ der Gesamtzellextrakte in einem 10\% PAA-Gel aufgetrennt und auf eine PVDF-Membran übertragen. Die GBP-1-Expression wurde anschließend mit dem monoklonalen GBP-1-spezifischen Antikörper 1B1 und die GFP-Expression mit einem monoklonalen GFP-spezifischen Antikörper im Westernblot detektiert. Der Nachweis von GAPDH diente als Ladekontrolle. (B) Zum Nachweis von GBP-1 wurden jeweils 3 x $10^{5}$ der GBP-1-, GBP-1-K51A-, GBP-1-D184N-, GFP- (alle in rot) und KV-HUVEC (schwarz) für 30 min bei $-20^{\circ} \mathrm{C}$ in eiskaltem 80\%igen MetOH fixiert und permeabilisiert, um das zytoplasmatische Antigen detektieren zu können. Die Zellen wurden anschließend mit dem aufgereinigten, monoklonalen, GBP-1-spezifischen Antikörper 1B1 angefärbt (Bilder a-d). Als Sekundärantikörper wurde ein an R-PE-gekoppelter Antikörper verwendet. Zur Bestimmung des Färbehintergrunds wurden Zellen ausschließlich mit dem Sekundärantikörper inkubiert (grau schattiert). Zur Analyse der Oberflächenexpression von ITGA4 und ITGB1 wurden jeweils 1 x $10^{5}$ Zellen mit dem monoklonalen, ITGA4-spezifischen Antikörper HP2/1 (Bilder i-1) oder einem monklonalen ITGB1spezifischen Antikörper (Bilder m-p) angefärbt. Als Sekundärantikörper wurde ein rot-fluoreszierender an R-PEgekoppelter Antikörper verwendet, um die Integrin-Signale von GFP-Signalen (Bilder e-h) unterscheiden zu können. Zur Bestimmung des Färbehintergrunds wurden die Zellen anstelle des Erstantikörpers mit einem irrelevanten Antikörper des gleichen Isotyps in den entsprechenden Konzentrationen inkubiert (grau schattiert). Die Analyse der gefärbten Zellen erfolgte mittels Durchflusszytometrie an einem FACS-Calibur-Gerät (BD Biosciences). Die Durchschnittsfluoreszenzintensitäten von GBP-1-, ITGA4- und ITGB1-gefärbten Zellen, sowie von GFP-exprimierenden Zellen wurden mit den Werten der jeweiligen Färbekontrollen normalisiert. Mit Hilfe der normalisierten Durchschnittsfluoreszenzintensitäten wurde die relative GBP-1-, GFP-, ITGA4- und ITGB1-Expression (x-fache Induktion) der Zellen im Vergleich $\mathrm{zu}$ den jeweiligen Kontrollzellen (KV) bestimmt. Dieser Wert ist in jedem Bild als Mittelwert \pm Standardabweichung aus mindestens drei unabhängigen Experimenten angegeben. (C) Die relative ITGA4-Expression von GBP-1-K51A und GBP-1-D184N-HUVEC im Vergleich zu GBP-1-HUVEC (100\%) nach Normalisierung auf den jeweiligen GBP-1-Proteingehalt ist im Diagramm dargestellt $(* *=\mathrm{p} \leq 0,01)$.

Untersuchungen zur ITGA4- und ITGB1-Expression an der Oberfläche von GFPexprimierenden HUVEC mittels Durchflusszytometrie zeigten, dass ITGA4 in diesen Zellen im Vergleich zu KV-HUVEC nicht erhöht war (Abb. 15B; Bild 1). Auch die Expression von ITGB1 wurde durch das heterologe Kontrollprotein GFP nicht beeinflusst (Abb. 15B; Bild p). Dies verdeutlicht, daß die ITGA4-Expression spezifisch durch GBP-1 hochreguliert wird.

\subsection{Die GBP-1-vermittelte Hemmung der Lamellipodienbildung und der Migration ist abhängig von der Bindung zwischen ITGA4 und FN}

Die durch GBP-1-vermittelte Hochregulation von ITGA4 könnte in enger Korrelation mit der Inhibierung der Lamellipodienbildung und der Migration von EZ auf FN stehen. ITGA4 ist die einzige Integrinuntereinheit, die FN über eine C-terminale Bindestelle (Typ III Modul 14 IIICS) erkennt, welche auch die CS-1- und CS-5-Domänen beinhaltet (Abb. 16; FN). Andere Integrine, wie beispielsweise $\alpha_{v} \beta_{3}$ oder $\alpha_{5} \beta_{1}$, binden FN über die zentrale Integrin-Bindestelle (Typ III Modul 9 - 10) (Abb. 16; FN) (Pankov and Yamada, 2002; Plow et al., 2000). FN-120 
ist ein $120 \mathrm{kDa}$ schweres Fragment von FN, dem die C-terminale ITGA4-Bindestelle fehlt, aber die zentrale Integrinbindestelle aufweist (Abb. 16; FN-120). Bei einer ITGA4vermittelten Hemmung der zellulären Lamellipodienbildung und der Migration sollten beide Effekte auf FN-120-beschichteten Oberflächen aufgehoben sein.

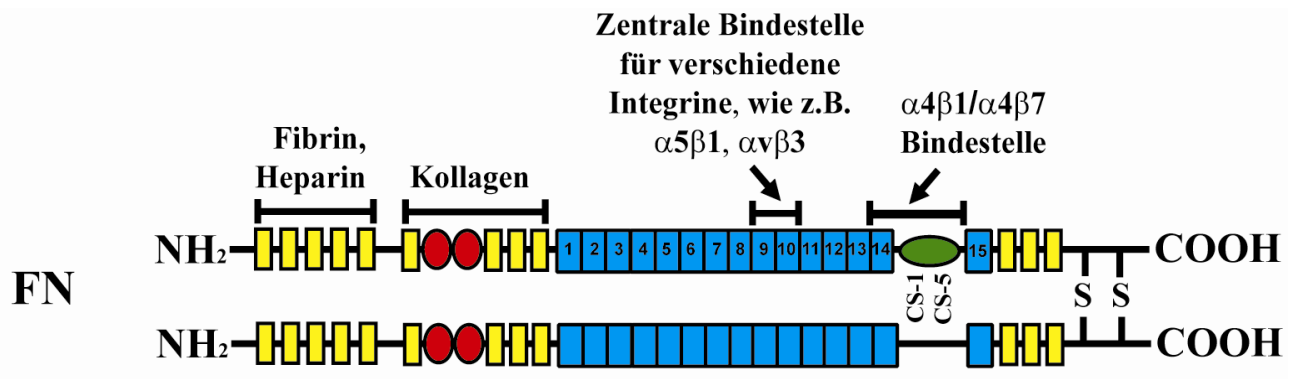

FN-120

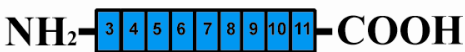

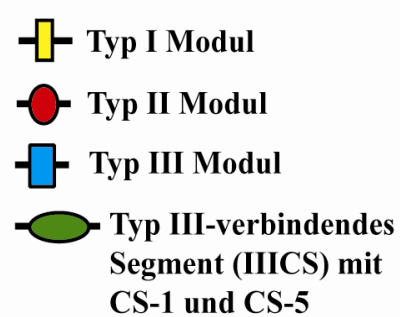

Abb. 16: Schematische Darstellung von FN und FN-120.

FN besteht aus vier verschiedenen Modulen, welche als Typ I (gelb), Typ II (rot), Typ III (blau) und Typ IIIverbindendes Segment (IIICS) (grün) bezeichnet werden. Neben einer Fibrin/Heparin- und einer KollagenBindestelle am N-Terminus besitzt FN auch zwei Bindestellen für Integrine: (1) eine zentrale Integrinbindestelle, an die viele verschiedene Integrine binden können (Typ III Modul 9-10) und (2) eine C-terminale Bindestelle, welche ausschließlich von den Integrinen $\alpha_{4} \beta_{1}$ und $\alpha_{4} \beta_{7}$ erkannt wird (Typ III Modul 14-IIICS). FN-120 ist ein $\alpha-$ chymotryptisch verdautes, $120 \mathrm{kDa}$ schweres Fragment von FN und umfasst die Typ III Module 3 bis 11 . Diesem Fragment fehlt im Vergleich zu Gesamt-FN die C-terminale ITGA4-Bindestelle. Die zentrale Integrinbindestelle (Typ III Modul 9 - 10) ist vorhanden.

Um den Einfluss von GBP-1 auf die Bildung endothelialer Lamellipodien auf FN-120 zu untersuchen, wurden KV- und GBP-1-HUVEC auf FN-120-beschichteten Oberflächen ausgebracht, nach 20 min Inkubation bei $37^{\circ} \mathrm{C}$ fixiert und mit Kristallviolett angefärbt (Abb. 17A). Nach Bestimmung der Größe der Zellflächen von jeweils 100 Zellen konnte gezeigt werden, dass die Fähigkeit zur Lamellipodienbildung von KV- und GBP-1-HUVEC auf FN120-beschichteten Oberflächen identisch war (Abb. 17A, B). 
A

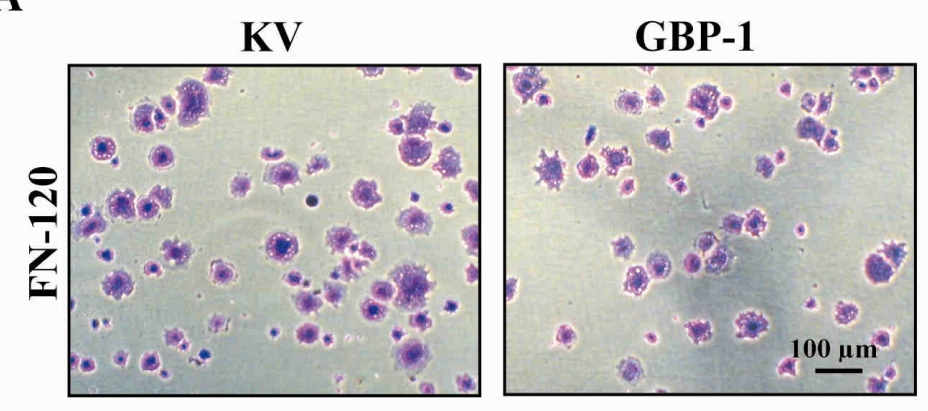

B

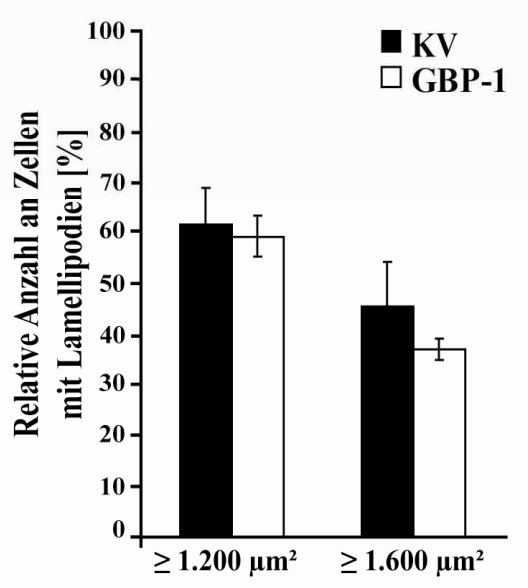

Abb. 17: Die durch GBP-1-vermittelte Hemmung der endothelialen Lamellipodienbildung ist abhängig von der Bindung zwischen ITGA4 und FN.

(A) Es wurden jeweils $5 \times 10^{3}$ der KV- und GBP-1-HUVEC (HUVEC1) pro Loch in einer mit FN-120beschichteten $\left(5 \mu \mathrm{g} / \mathrm{cm}^{2}\right)$ 96-Loch-Platte ausgesät. 20 min nach Anheftung wurden die Zellen in 10\% Formalin fixiert und mit 0,5\% Kristallviolett angefärbt. KV- und GBP-1-HUVEC wiesen eine identische Zellmorphologie auf. (B) Die Fläche von jeweils 100 der in (A) dargestellten Zellen wurde mit Hilfe der OPTIMAS 6.0 Software bestimmt. Die relative Anzahl (\%) an KV- und GBP-1-HUVEC mit ausgebildeten Lamellipodien definiert über eine Fläche $\geq 1.200 \mu \mathrm{m}^{2}$ (linke Säulen; Inkremente 4 - 15) oder $\geq 1.600 \mu \mathrm{m}^{2}$ (rechte Säulen; Inkremente 5 - 15) ist im Diagramm dargestellt. Die Mittelwerte \pm Standardabweichungen von drei unabhängigen Experimenten sind gezeigt.

Neben der Fähigkeit zur Bildung von Lamellipodien wurde auch das Migrationsverhalten von KV- und GBP-1-HUVEC auf FN-120-beschichteten Oberflächen mit Hilfe eines in vitro Wundheilungstests untersucht. Dazu wurden die Zellen auf FN-120-beschichteten Oberflächen ausgesät und bis zu einer Konfluenz von 90 - 100\% kultiviert. Mit Hilfe einer sterilen 1 ml-Pipettenspitze wurde ein definierter, zellfreier Bereich in den konfluenten Zellrasen gekratzt und anschließend die Zellen für $10 \mathrm{~h}$ in SFM kultiviert (Abb. 18A). Der Abstand zwischen den Zellfronten und somit die Fähigkeit der Zellen in den verwundeten Bereich zu migrieren, wurde zu Beginn des Versuchs (Zeitpunkt $0 \mathrm{~h}$ ) und alle weiteren $2 \mathrm{~h}$ bestimmt. In Übereinstimmung mit der Fähigkeit stabile Lamellipodien auszubilden, war auch das Migrationsverhalten der KV- und GBP-1-HUVEC auf FN-120-beschichteten Oberflächen 
identisch (Abb. 18A, B). Diese Ergebnisse verdeutlichen, dass die GBP-1-vermittelte Hemmung der Lamellipodienbildung und der Migration von der Bindung zwischen ITGA4 und $\mathrm{FN}$ abhängig ist.

A

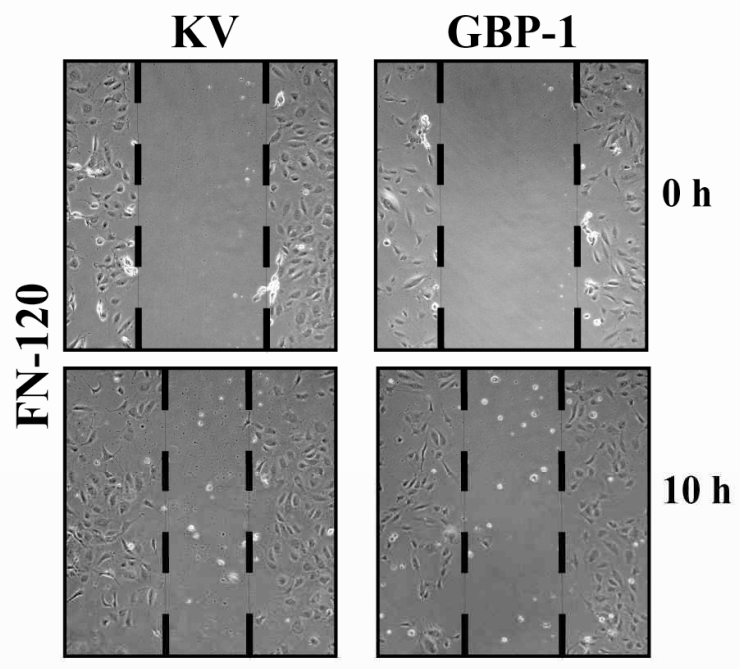

B

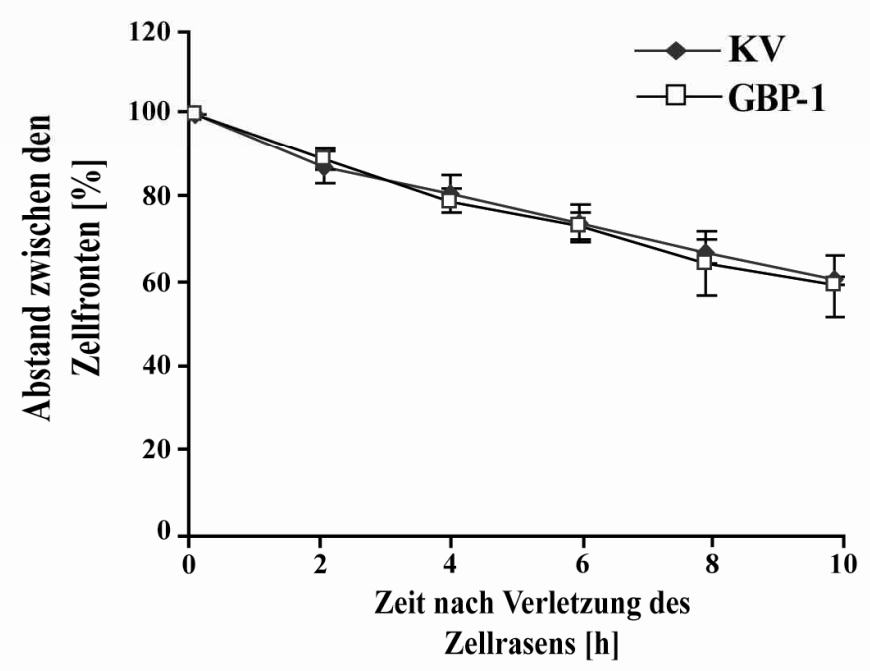

Abb. 18: Die durch GBP-1-vermittelte Hemmung der Migration ist abhängig von der Bindung zwischen ITGA4 und FN.

(A) Zur Bestimmung der Migrationsfähigkeit von KV- und GBP-1-HUVEC (HUVEC1) auf FN-120beschichteten Oberflächen wurde ein in vitro Wundheilungstest durchgeführt. Die transduzierten Zellen wurden auf FN-120-beschichteten Oberflächen ausgesät und bis zu einer Konfluenz von 90 - 100\% kultiviert. Mit Hilfe einer sterilen $1 \mathrm{ml}$-Pipettenspitze wurde ein definierter zellfreier Bereich in den konfluenten Zellrasen gekratzt. Die Zellen wurden anschließend für $10 \mathrm{~h}$ in SFM kultiviert. Sowohl zu Beginn des Versuches (Zeitpunkt $0 \mathrm{~h}$ ), als auch nach $10 \mathrm{~h}$ wurden von den zellfreien Bereichen Bilder aufgenommen. (B) Der Abstand zwischen den Zellfronten wurde alle $2 \mathrm{~h}$ bestimmt und prozentual zum Abstand zum Zeitpunkt $0 \mathrm{~h}$ berechnet. Die Ergebnisse sind als Mittelwerte \pm Standardabweichungen von vier unabhängigen Experimenten in einem Diagramm abgebildet. 


\subsection{IL-1 $\beta$ und TNF- $\alpha$ induzieren die Oberflächenexpression von} ITGA4 und hemmen die Lamellipodienbildung von HUVEC auf FN

Die inflammatorischen Zytokine IL-1 $\beta$, TNF- $\alpha$ und IFN- $\gamma$ induzieren die endogene Expression von GBP-1 (Decker et al., 1991; Guenzi et al., 2001; Lubeseder-Martellato et al., 2002; Naschberger et al., 2004). Deshalb wurden die Effekte von IL-1 $\beta$, TNF- $\alpha$ und IFN- $\gamma$ auf die ITGA4-Expression in EZ und die endotheliale Lamellipodienbildung auf FN- und FN120-beschichteten Oberflächen untersucht.

\subsubsection{Nachweis von endogenem GBP-1 in IL-1 $\beta$-, TNF- $\alpha$ - und IFN- $\gamma$ - behandelten HUVEC}

Zur Untersuchung des Einfluss von IL-1 $\beta$, TNF- $\alpha$ und IFN- $\gamma$ auf die Oberflächenexpression von ITGA4 wurden HUVEC (HUVEC1) für $48 \mathrm{~h}$ mit den jeweiligen Zytokinen behandelt. Die Zytokine wurden in Konzentrationen eingesetzt, von denen bereits bekannt ist, dass neben GBP-1 auch ein biologischer Effekt, wie z.B. die Hemmung der Proliferation, induziert wird (Lubeseder-Martellato et al., 2002). Nach Stimulierung wurden die Zellen geerntet und die GBP-1-Expression mittels Westernblot-Analyse überprüft. In den Zellen, welche mit IL-1 $\beta$, TNF- $\alpha$ oder IFN- $\gamma$ behandelt wurden, konnte im Vergleich zu den unstimulierten Zellen eine erhöhte GBP-1-Expression nachgewiesen werden (Abb. 19).

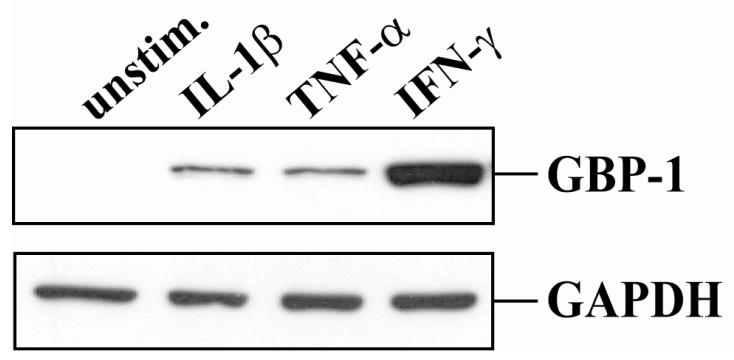

Abb. 19: Nachweis der endogenen GBP-1-Expression in HUVEC nach Stimulierung mit IL-1 $\beta$, TNF- $\alpha$ und IFN- $\gamma$.

HUVEC (HUVEC1) blieben unbehandelt (unstim.) oder wurden für $48 \mathrm{~h}$ mit IL-1 $\beta$ (200 U/ml), TNF- $\alpha$ $(300 \mathrm{U} / \mathrm{ml})$ oder IFN- $\gamma(100 \mathrm{U} / \mathrm{ml})$ stimuliert. Zur Untersuchung der GBP-1-Expression wurden die Zellen lysiert, jeweils $10 \mu \mathrm{g}$ der Gesamtzellextrakte in einem 10\% PAA-Gel aufgetrennt und auf eine PVDF-Membran übertragen. Die GBP-1-Expression wurde anschließend mit dem monoklonalen, GBP-1-spezifischen Antikörper 1B1 im Westernblot analysiert. Der Nachweis von GAPDH diente als Ladekontrolle. 


\subsubsection{IL-1 $\beta$ und TNF- $\alpha$ induzieren die Oberflächenexpression von ITGA4}

Nach Überprüfung der GBP-1-Expression in IL-1 $\beta$-, TNF- $\alpha$ - und IFN- $\gamma$-stimulierten HUVEC wurde als nächstes mittels Durchflusszytometrie die ITGA4-Oberflächenexpression dieser Zellen untersucht. Zusätzlich wurde zur Kontrolle die Expression von ITGB1 analysiert. Es konnte gezeigt werden, dass die Oberflächenexpression von ITGA4 in IL-1 $\beta$ - (2,8 $\pm 0,4$-fach) und TNF- $\alpha$-stimulierten Zellen $(2,0 \pm 0,4$-fach) nach $48 \mathrm{~h}$ im Vergleich zu unstimulierten Kontrollzellen erhöht war (Abb. 20; ITGA4; IL-1 $\beta$ und TNF- $\alpha$ ). Interessanterweise war die ITGA4-Expression an der Zelloberfläche von IFN- $\gamma$-behandelten HUVEC reduziert $(0,4 \pm$ 0,0-fach im Vergleich zu unstimulierten Kontrollzellen) (Abb. 20; ITGA4; IFN- $\gamma$ ). Die Oberflächenexpression von ITGB1 wurde dagegen weder von IL-1 $\beta$, TNF- $\alpha$ noch von IFN- $\gamma$ beeinflusst (Abb. 20; ITGB1).
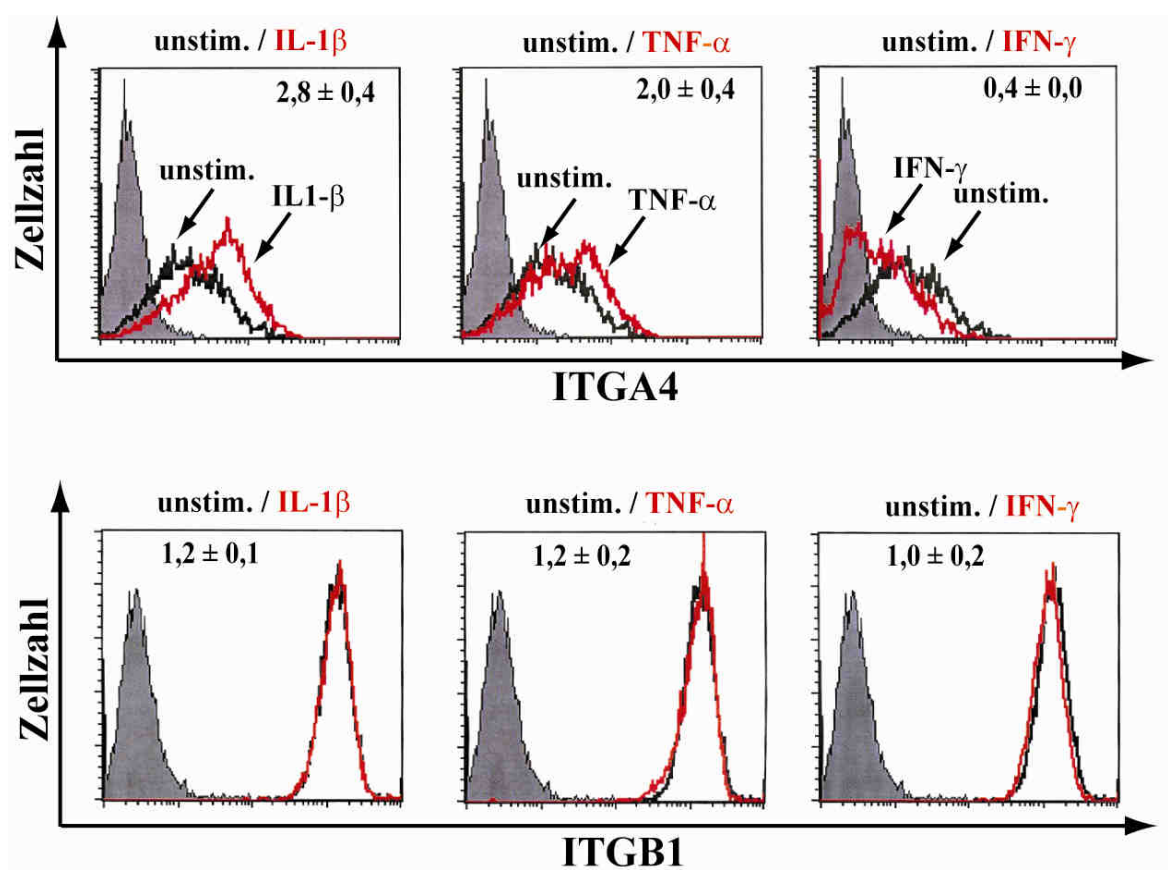

Abb. 20: IL-1 $\beta$ und TNF- $\alpha$ induzieren die Proteinexpression von ITGA4 an der Oberfläche von HUVEC.

HUVEC (HUVEC1) blieben entweder unbehandelt (unstim.) oder wurden für 48 h mit IL-1 $\beta$ (200 U/ml), TNF- $\alpha$ $(300 \mathrm{U} / \mathrm{ml})$ oder IFN- $\gamma(100 \mathrm{U} / \mathrm{ml})$ stimuliert. Zur Analyse der Oberflächenexpression von ITGA4 und ITGB1 wurden jeweils 1 x $10^{5}$ der stimulierten (rot) und unstimulierten (schwarz) Zellen mit dem monoklonalen, ITGA4spezifischen Antikörper HP2/1 (obere Reihe) oder einem monoklonalen, ITGB1-spezifischen Antikörper (untere Reihe) gefärbt. Als Sekundärantikörper wurde ein an AlexaFluor 488-gekoppelter Antikörper verwendet. Zur Bestimmung des Färbehintergrunds wurden die Zellen anstelle des Erstantikörpers mit einem irrelevanten Antikörper des gleichen Isotyps in den entsprechenden Konzentrationen inkubiert (grau schattiert). Die Analyse der gefärbten Zellen erfolgte mittels Durchflusszytometrie an einem FACS-Calibur-Gerät (BD Biosciences). Die Durchschnittsfluoreszenzintensitäten von ITGA4- und ITGB1-gefärbten Zellen wurden mit den Werten der entsprechenden Isotypkontrollen normalisiert. Mit Hilfe der normalisierten Durchschnittsfluoreszenzintensitäten wurde die relative ITGA4- und ITGB1-Oberflächenexpression (x-fache Induktion) der stimulierten HUVEC im Vergleich zu den unstimulierten Kontrollzellen bestimmt. Dieser Wert ist in jedem Bild als Mittelwert \pm Standardabweichung von drei unabhängigen Experimenten angegeben. 


\subsubsection{IL-1 $\beta$ und TNF- $\alpha$ hemmen die Bildung endothelialer Lamellipodien auf FN-beschichteten Oberflächen in Abhängigkeit von ITGA4}

Es kann angenommen werden, dass die veränderte Oberflächenexpression von ITGA4 nach Behandlung der EZ mit den Zytokinen IL-1 $\beta$, TNF- $\alpha$ bzw. IFN- $\gamma$ auch die Lamellipodienbildung beeinflusst. Aufgrund dieser Annahme wurde als nächstes die Lamellipodienbildung der stimulierten Zellen auf FN- bzw. FN-120-beschichteten Oberflächen untersucht. Dazu wurden HUVEC für $48 \mathrm{~h}$ mit IL-1 $\beta$, TNF- $\alpha$ und IFN- $\gamma$ behandelt und anschließend auf FNund FN-120-Matrizes in SFM ausgesät. Nach einer 20-minütigen Inkubation bei $37{ }^{\circ} \mathrm{C}$ wurden die Zellen fixiert und mit Kristallviolett angefärbt (Abb. 21A). Eine Größenbestimmung der Zellflächen auf FN ergab, dass die relative Anzahl an Zellen mit einer

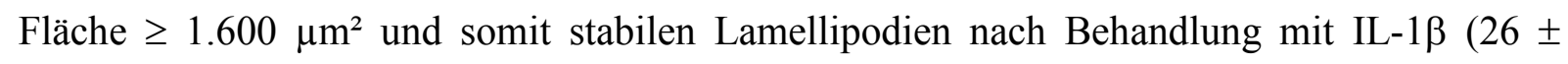
$1,7 \%)$, TNF- $\alpha(21,7 \pm 2,5 \%)$ und IFN- $\gamma(20,3 \pm 0,6 \%)$ im Vergleich zu den unstimulierten Kontrollzellen $(82,3 \pm 3,8 \%)$ signifikant $(\mathrm{p} \leq 0,001)$ reduziert war (Abb. 21B; FN; $\geq$ $1.600 \mu \mathrm{m}^{2}$ ). Im Gegensatz dazu wurde die Lamellipodienbildung auf FN-120-beschichteten Oberflächen nicht durch IL-1 $\beta$ und TNF- $\alpha$ gehemmt (Abb. 21A, B; FN-120; IL-1 $\beta$ und TNF- $\alpha$ ). Interessanterweise war jedoch die Lamellipodienbildung auch auf FN-120beschichteten Oberflächen durch IFN- $\gamma$ signifikant reduziert (Abb. 21A, B; FN-120; IFN- $\gamma$ ).

Diese Ergebnisse zeigen, dass IL-1 $\beta$ und TNF- $\alpha$ die Oberflächenexpression von ITGA4 induzieren und in Folge dessen die Bildung endothelialer Lamellipodien in Abhängigkeit von der ITGA4-Bindung an FN gehemmt ist. Weiterhin konnte beobachtet werden, dass auch IFN- $\gamma$ die Lamellipodienbildung auf FN-Matrizes hemmt, dies allerdings unabhängig von der Bindung zwischen ITGA4 und FN. In den folgenden Experimenten wurde der inhibitorische Effekt von GBP-1 auf die Lamellipodienbildung und die Migration von IL-1 $\beta$ - und TNF- $\alpha$ behandelten HUVEC genauer untersucht. 
A
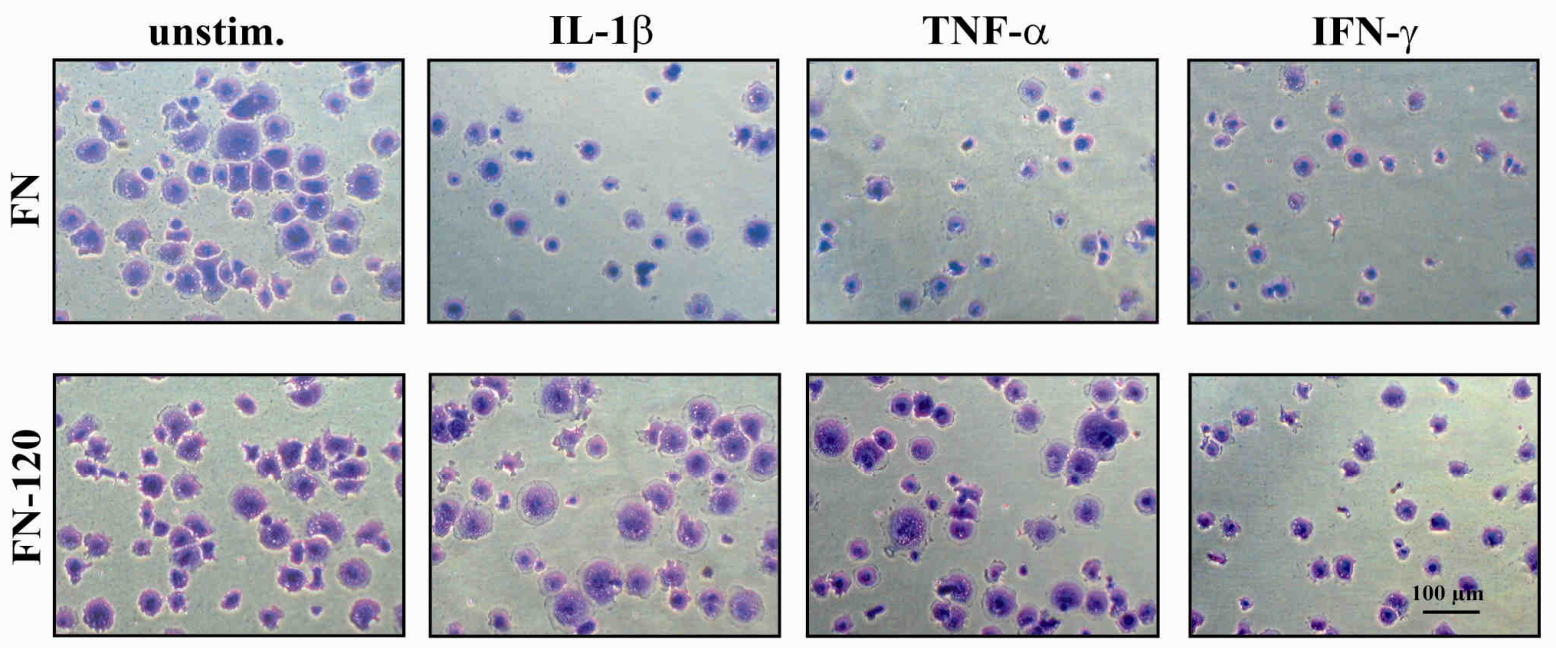

B
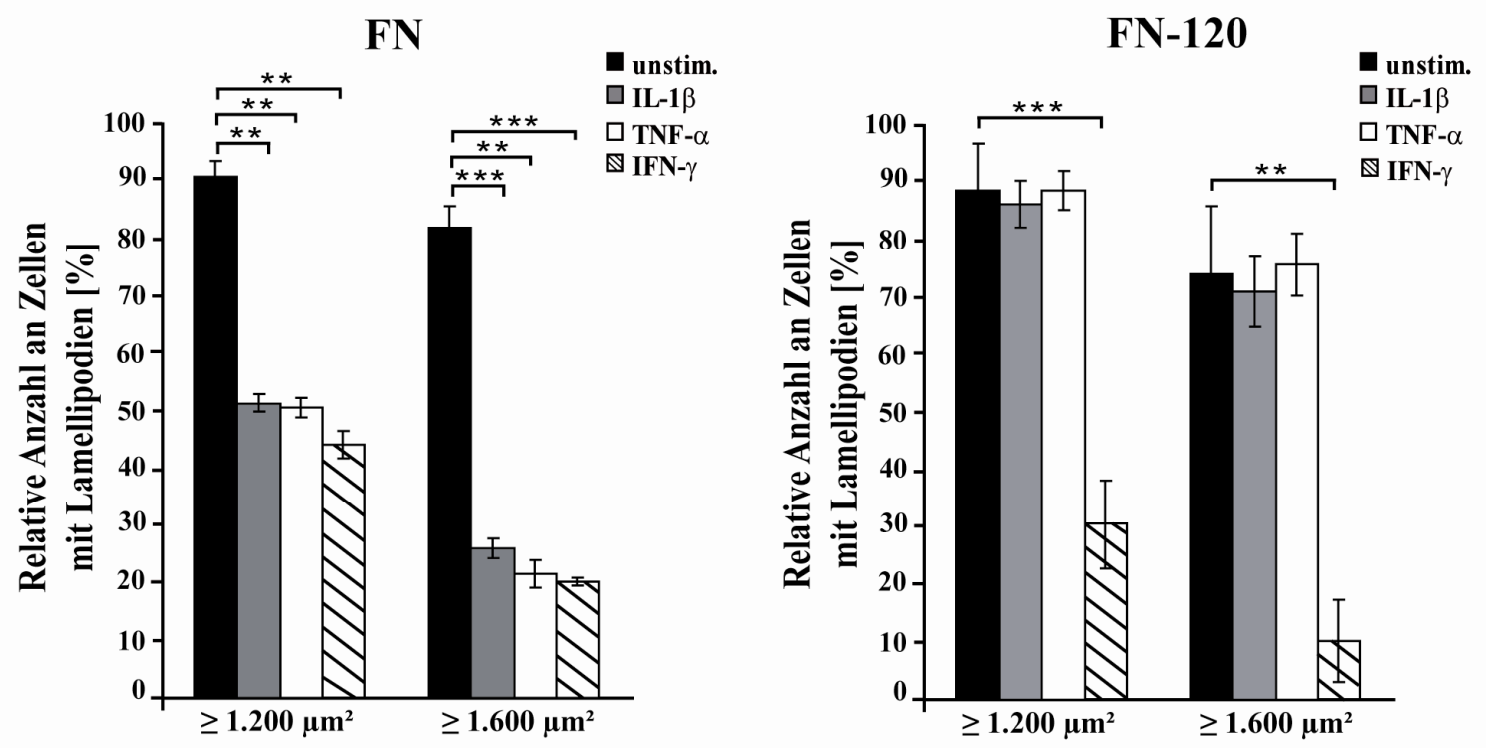

Abb. 21: IL-1 $\beta$ und TNF- $\alpha$ hemmen die Bildung endothelialer Lamellipodien auf FN in Abhängigkeit von der Bindung zwischen ITGA4 und FN.

(A) HUVEC (HUVEC1) blieben entweder unbehandelt (unstim.) oder wurden für $48 \mathrm{~h}$ mit IL-1 $\beta$ (200 U/ml), TNF- $\alpha(300 \mathrm{U} / \mathrm{ml})$ oder IFN- $\gamma(100 \mathrm{U} / \mathrm{ml})$ stimuliert. Es wurden jeweils $5 \times 10^{3}$ der unstimulierten Kontrollzellen und der stimulierten Zellen pro Loch in einer mit FN- oder FN-120-beschichteten (jeweils $5 \mu \mathrm{g} / \mathrm{cm}^{2}$ ) 96-LochPlatte ausgesät. 20 min nach Anheftung wurden die Zellen in 10\% Formalin fixiert und mit 0,5\% Kristallviolett angefärbt. (B) Die Fläche von jeweils 100 der in (A) dargestellten Zellen wurde mit Hilfe der OPTIMAS 6.0 Software bestimmt. Die relative Anzahl (\%) an KV- und GBP-1-HUVEC mit ausgebildeten Lamellipodien definiert über eine Fläche $\geq 1.200 \mu \mathrm{m}^{2}$ (linke Säulen) oder $\geq 1.600 \mu \mathrm{m}^{2}$ (rechte Säulen) ist im Diagramm dargestellt. Die Mittelwerte \pm Standardabweichungen von drei unabhängigen Experimenten sind gezeigt $(* *=\mathrm{p} \leq$ $0,01 ; * * *=\mathrm{p} \leq 0,001)$. 


\subsection{GBP-1 vermittelt die durch IL1- $\beta$ - und TNF- $\alpha$-induzierte Hemmung der Lamellipodienbildung und der Migration durch Induktion von ITGA4}

Um zu untersuchen, ob GBP-1 für die durch IL-1 $\beta$ - und TNF- $\alpha$-induzierte Hemmung der Lamellipodienbildung notwendig ist, wurden Experimente mit IL-1 $\beta$ - und TNF- $\alpha$ behandelten HUVEC durchgeführt, in denen die endogene GBP-1-Expression mittels spezifischer shRNA abgeschalten war.

\subsubsection{Klonierung der shRNAs in retrovirale Expressionsplasmide}

Um die shRNAs mittels retroviraler Transduktion in HUVEC exprimieren zu können, wurde eine shRNA gegen GBP-1 (GBP-1-shRNA) und zur Kontrolle gegen GFP (Ktrl-shRNA) aus den jeweiligen, bereits vorhandenen pLKOPuro-Plasmiden (Prof. H. Stockinger, Abteilung für Molekulare Immunologie, Wien) zusammen mit dem U6-Promotor in das retrovirale Plasmid pBabePuro kloniert (Abb. 22). Der U6-Promotor ist ein für die RNA-Polymerase III spezifischer Promotor, der für die Transkription von shRNA erforderlich ist. Die Plasmide pLKOPuro-GFP-shRNA und pLKOPuro-GBP-1-shRNA wurden mit dem Enzym XhoI verdaut. Die verdauten DNA-Fragmente wurden in einem Agarosegel aufgetrennt und die Fragmente (344 bp), welche den U6-Promotor und die jeweilige shRNA kodieren, aus dem Gel ausgeschnitten und aufgereinigt. Die 5'-Überhänge der Fragmente wurden mit Hilfe des „Klenow"-Fragments der DNA-Polymerase I mit Nukleotiden aufgefüllt, so dass DNAFragmente mit glatten Enden entstanden. Anschließend wurden die beiden DNA-Fragmente mit EcoRI verdaut und zusammen mit dem SnaBI (erzeugt glatte Enden) und EcoRI verdauten, dephosphorylierten pBabePuro-Plasmid ligiert. Chemokompetente $E$. coli wurden mit dem Ligationsansatz transformiert und anschließend die Plasmid-DNA aus selektionierten Bakterienkolonien isoliert. Zur Überprüfung des korrekten Einbaus wurden die Plasmide einem Kontrollverdau mit den Enzymen BamHI und EcoRI unterzogen. Die Plasmid-DNA, welche das erwartete Restriktionsmuster zeigte, wurde im größeren Maßstab präpariert und die inserierte DNA-Sequenz durch Sequenzierung bestätigt. Die isolierte Plasmid-DNA wurde anschließend für die Produktion retroviraler Partikel in HEK293T-Zellen verwendet. 


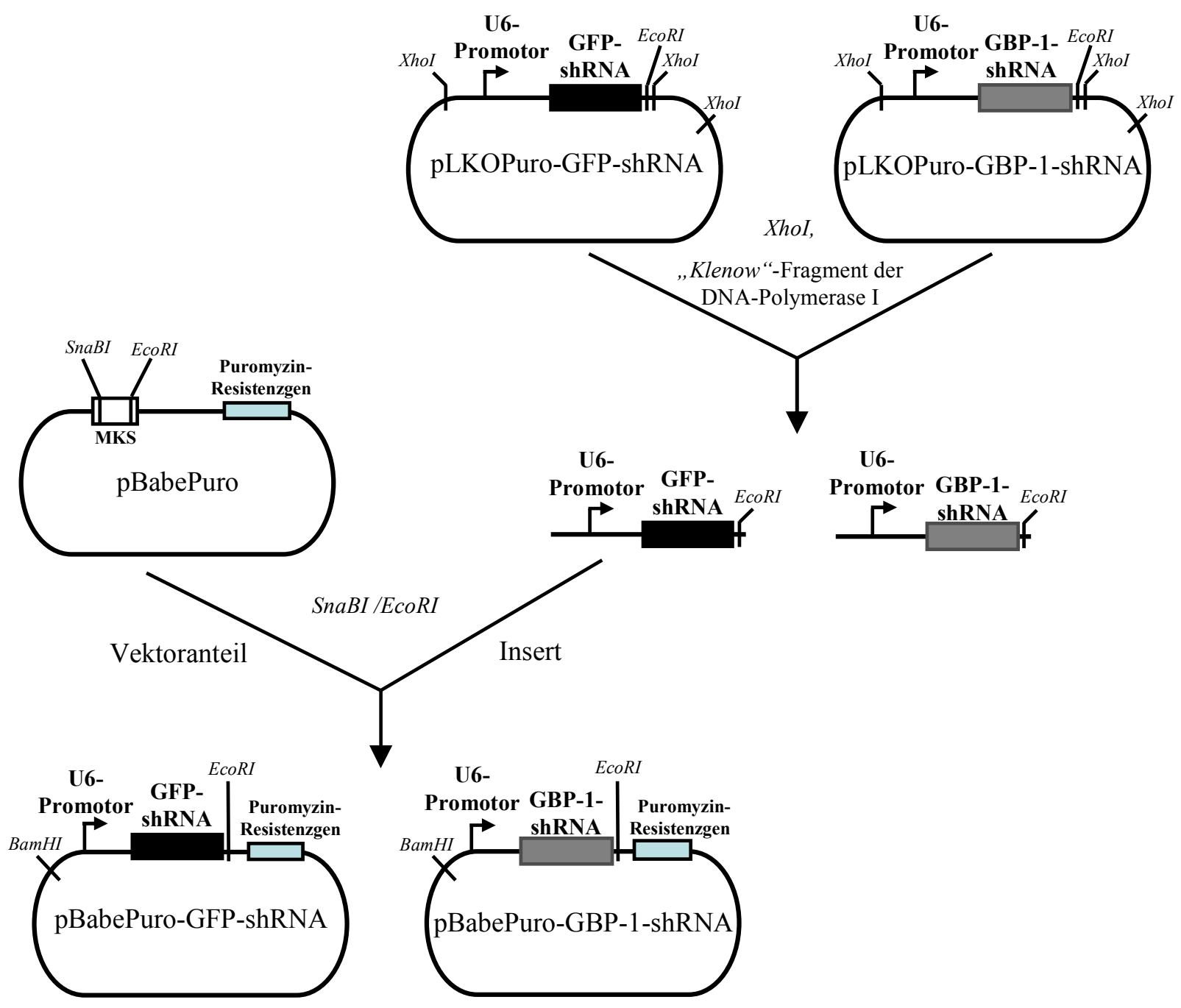

Abb. 22: Klonierung der GFP-shRNA (Ktrl-shRNA) und der GBP-1-shRNA in das retrovirale Plasmid pBabePuro.

Plamide sind durch Ovale, Gene und kodierende Bereiche durch gefüllte Rechtecke und Promotoren durch Pfeile dargestellt. Wichtige Restriktionsenzym-Schnittstellen sind gekennzeichnet (kursiv). Die shRNAs gegen GFP (dient als Kontrolle; Ktrl-shRNA) und GBP-1 (GBP-1-shRNA) wurden zusammen mit dem U6-Promotor aus den pLKOPuro-Plasmiden mit dem Enzym XhoI herausgeschnitten und die 5'-Überhänge der DNA-Fragmente mit Hilfe des „Klenow“-Fragments der DNA-Polymerase I mit Nukleotiden aufgefüllt. Diese Fragmente wurden anschließend mit EcoRI verdaut und in die multiple Klonierungsstelle (MKS) des proviralen Plasmids pBabePuro eingesetzt. Das Plasmid pBabePuro wurde vorher mit den Enzymen SnaBI und EcoRI geschnitten. 


\subsubsection{Nachweis von endogenem GBP-1 in Ktrl-shRNA- und GBP-1-shRNA- exprimierenden HUVEC nach Stimulation mit IL-1 $\beta$ und TNF- $\alpha$}

Um die endogene GBP-1-Expression zu hemmen, wurden HUVEC mit den in Abschnit 4.6.1 dargestellten retroviralen Plasmiden transduziert, welche entweder eine gegen GBP-1 gerichtete (GBP-1-shRNA-HUVEC) oder eine gegen GFP gerichtete Kontroll-shRNA (KtrlshRNA-HUVEC) kodieren. Nach der retroviralen Transduktion und 10 Tagen PuromyzinSelektion wurden die Zellen für 48 h mit IL-1 $\beta$ und TNF- $\alpha$ stimuliert und die GBP-1Expression mittels Westernblot-Analyse überprüft (Abb. 23). Die Intensitäten der GBP-1Banden wurden anschließend densitometrisch quantifiziert. Um Variationen bei der Probenbeladung der Gele ausschließen zu können, wurden die erhaltenen Werte mit den entsprechenden GAPDH-Signalen normalisiert. Ein Vergleich der so normalisierten Werte zeigte, dass die Expression von GBP-1 in GBP-1-shRNA-HUVEC im Vergleich zu den jeweiligen Ktrl-shRNA-HUVEC nach Behandlung mit IL-1 $\beta$ um $90 \%$ und mit TNF- $\alpha$ um 93\% reduziert war (Abb. 23).

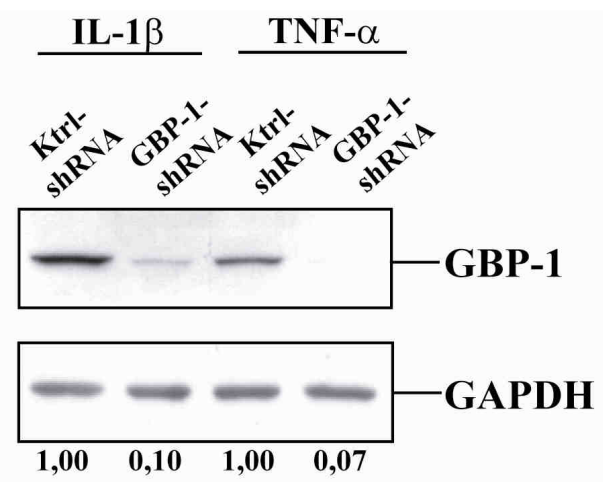

Abb. 23: Nachweis der endogenen GBP-1-Expression in GBP-1-shRNA- und Ktrl-shRNA-HUVEC nach Behandlung mit IL-1 $\beta$ und TNF- $\alpha$.

HUVEC (HUVEC1) wurden mit den retroviralen Plasmiden pBabePuro-GBP-1-shRNA und pBabePuro-GFPshRNA (Ktrl-shRNA) transduziert und für 10 Tage mit Puromyzin selektioniert. Die transduzierten Zellen wurden anschließend für $48 \mathrm{~h}$ mit IL-1 $\beta$ (200 U/ml) und TNF- $\alpha(300 \mathrm{U} / \mathrm{ml})$ stimuliert. Zur Untersuchung der endogenen GBP-1-Expression wurden die Zellen lysiert, jeweils $10 \mu \mathrm{g}$ der Gesamtzellextrakte in einem $10 \%$ PAA-Gel aufgetrennt und auf eine PVDF-Membran übertragen. Die GBP-1-Expression wurde mit dem monoklonalen, GBP-1-spezifischen Antikörper 1B1 im Westernblot analysiert. Der Nachweis von GAPDH diente als Ladekontrolle. Die Bandenintensitäten der GBP-1-Banden wurden densitometrisch bestimmt. Variationen bei der Probenbeladung des Gels wurden durch Normalisierung mit dem entsprechenden GAPDHSignal ausgeglichen. Die unten aufgeführten Werte geben die GBP-1-Expressionsstärken in relativen Einheiten an. 


\subsubsection{GBP-1 ist notwendig zur Induktion der ITGA4-Expression nach Stimulierung mit IL-1 $\beta$ und TNF- $\alpha$}

Neben der Expression von GBP-1 wurde als nächstes sowohl die mRNA-Transkription, als auch die Proteinsynthese von ITGA4 in GBP-1-shRNA- und Ktrl-shRNA-HUVEC nach Stimulierung mit IL-1 $\beta$ bzw. TNF- $\alpha$ verglichen. Mittels semi-quantitativer RT-PCR konnte gezeigt werden, dass die Anzahl an mRNA-Transkripten von itga4 in IL-1 $\beta$ - und TNF- $\alpha$ behandelten GBP-1-shRNA-HUVEC im Vergleich zu den jeweiligen Ktrl-shRNA-HUVEC reduziert war (0,4-fach IL-1 $\beta$; 0,5-fach TNF- $\alpha$ ) (Abb. 24A; ITGA4). Die Amplifikation des Haushaltsgens gapdh führte bei gleichen Verdünnungen zu Banden ähnlicher Intensität und bestätigte somit die Vergleichbarkeit der eingesetzten Probenmengen (Abb. 24A; GAPDH).

Weiterhin konnten die Ergebnisse der RT-PCR auch mittels Durchflusszytometrie auf Proteinebene bestätigt werden (Abb. 24B; ITGA4). Zytokin-behandelte GBP-1-shRNAHUVEC wiesen im Vergleich zu den jeweiligen Ktrl-shRNA-HUVEC eine verminderte Oberflächenexpression von ITGA4 auf $(0,5 \pm 0,1$-fach IL-1 $\beta ; 0,4 \pm 0,0$-fach TNF- $\alpha)$. Die Expression von ITGB1 wurde dagegen weder durch die Expression der GBP-1-shRNA noch durch die der Ktrl-shRNA beeinflusst (Abb. 24B; ITGB1).

\subsubsection{GBP-1 ist zur Hemmung der endothelialen Lamellipodienbildung auf FN- beschichteten Oberflächen nach Stimulierung mit IL-1 $\beta$ und TNF- $\alpha$ notwendig}

Im nächsten Abschnitt wurde der Einfluss der veränderten GBP-1/ITGA4-Expression auf die Lamellipodienbildung von Zytokin-behandelten HUVEC untersucht. Dazu blieben die mit GBP-1- bzw. Ktrl-shRNA-transduzierten HUVEC entweder unbehandelt (unstim.) oder wurden für 48 h mit IL-1 $\beta$ und TNF- $\alpha$ stimuliert. Nach der Stimulation wurden die Zellen auf FN-beschichteten Oberflächen in SFM ausgesät und bei $37{ }^{\circ} \mathrm{C}$ für 20 min inkubiert. Die Zellen wurden anschließend fixiert und mit Kristallviolett angefärbt (Abb. 25A). Die Größenbestimmung der Zellflächen ergab, dass die relative Anzahl an IL-1 $\beta-(25,0 \pm 4,0 \%)$ und TNF- $\alpha$-stimulierten Ktrl-shRNA-HUVEC $(32,3 \pm 2,5 \%)$ mit einer Fläche $\geq 1.600 \mu \mathrm{m}^{2}$ und somit stabilen Lamellipodien im Vergleich zu unstimulierten Ktrl-shRNA-HUVEC (95,0 $\pm 2,6 \%$ ) hoch signifikant ( $\leq 0,001)$ reduziert war (Abb. 25B; Ktrl-shRNA; $\geq 1.600 \mu \mathrm{m}^{2}$ ). Diese Ergebnisse stimmen mit den vorangehenden Resultaten von IL-1 $\beta$ - und TNF- $\alpha$ - 
stimulierten HUVEC überein und verdeutlichen, dass die Expression von unspezifischer shRNA die Bildung endothelialer Lamellipodien auf FN-Matrizes nicht verändert (vergleiche Abb. 21A und 21B).

A
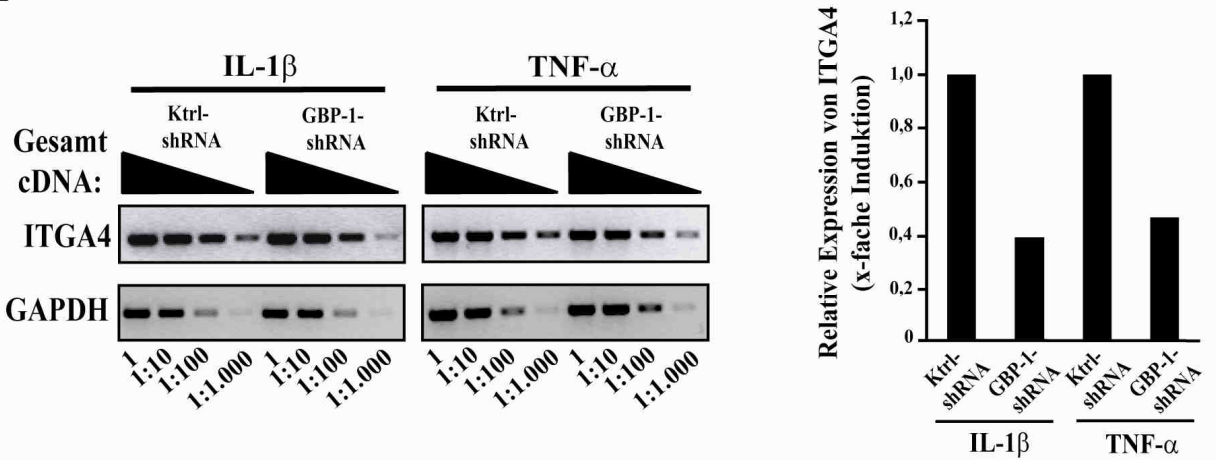

B
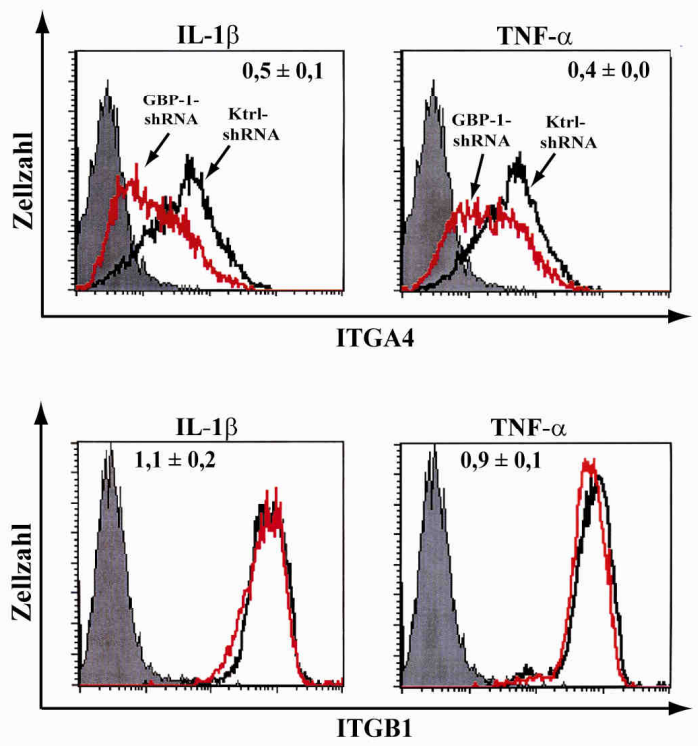

Abb. 24: GBP-1 ist notwendig zur Induktion der ITGA4-Expression nach Stimulierung mit IL-1 $\beta$ - und TNF- $\alpha$ auf RNA- und Proteinebene.

(A) RT-PCR-Analyse zum Vergleich der itga4- und gapdh-mRNA-Transkription in Ktrl-shRNA- und GBP-1shRNA-HUVEC nach Stimulierung mit IL-1 $\beta(200 \mathrm{U} / \mathrm{ml})$ und TNF- $\alpha(300 \mathrm{U} / \mathrm{ml})$ für $24 \mathrm{~h}$. Je $1 \mu \mathrm{g}$ der isolierten gesamtzellulären RNA wurde durch reverse Transkription in cDNA umgeschrieben. Für die PCR wurde die cDNA in verschiedenen Konzentrationen eingesetzt [unverdünnt (1), 1:10, 1:100 und 1:1.000]. GAPDH diente als Kontrolle, ob gleiche Mengen an Gesamt-RNA amplifiziert wurden. Die PCR-Produkte wurden bei $100 \mathrm{~V}$ für $1 \mathrm{~h}$ in einem 1\%igen Agarosegel elektrophoretisch aufgetrennt, mit Ethidiumbromid angefärbt und durch UVAnregung (302 nm) nachgewiesen. Zur Quantifizierung der itga4-Expressionsstärken wurden die Banden, welche sich nicht in der Farbtonsättigung befanden (cDNA-Verdünnung 1:1.000) densitometrisch analysiert. Variationen bei der cDNA-Synthese wurden durch Normalisierung mit dem entsprechenden gapdh-Signal ausgeglichen (cDNA-Verdünnung 1:100). Die relative Induktion der itga4-Expression in GBP-1-exprimierenden Zellen im Vergleich zu KV-HUVEC ist als Balkendiagramm dargestellt. (B) Ktrl-shRNA- und GBP-1-shRNA-HUVEC wurden für $48 \mathrm{~h}$ mit IL-1 $\beta$ (200 U/ml) und TNF- $\alpha(300 \mathrm{U} / \mathrm{ml})$ stimuliert. Zur Analyse der Oberflächenexpression von ITGA4 und ITGB1 wurden jeweils 1 x $10^{5}$ der GBP-1-shRNA-HUVEC (rot) und der Ktrl-shRNA-HUVEC (schwarz) mit dem monoklonalen, ITGA4-spezifischen Antikörper HP2/1 (obere Reihe) oder einem monoklonalen, ITGB1-spezifischen Antikörper (untere Reihe) gefärbt. Als Sekundärantikörper wurde ein an AlexaFluor 488-gekoppelter Antikörper verwendet. Zur Bestimmung des Färbehintergrunds wurden die Zellen anstelle des Erstantikörpers mit einem irrelevanten Antikörper des gleichen Isotyps in den entsprechenden Konzentrationen inkubiert (grau schattiert). Die Analyse der gefärbten Zellen erfolgte mittels Durchflusszytometrie an einem FACS-Calibur-Gerät (BD Biosciences). Die Durchschnittsfluoreszenzintensitäten von ITGA4- und ITGB1-gefärbten Zellen wurden mit den Werten der Isotypkontrollen normalisiert. Mit Hilfe der 
normalisierten Durchschnittsfluoreszenzintensitäten wurde die relative ITGA4- und ITGB1-Oberflächenexpression (x-fache Induktion) der stimulierten GBP-1-shRNA-HUVEC im Vergleich zu den jeweiligen KtrlshRNA-HUVEC bestimmt. Diese Werte sind in jedem Bild als Mittelwert \pm Standardabweichung von drei unabhängigen Experimenten angegeben.

Eine gezielte Hemmung der GBP-1-Expression mittels spezifischer shRNA führte zur Aufhebung der inhibitorischen Effekte von IL-1 $\beta$ und TNF- $\alpha$ auf die Lamellipodienbildung (Abb. 25A, B; GBP-1-shRNA). IL-1 $\beta$ - und TNF- $\alpha$-stimulierte GBP-1-shRNA-HUVEC zeigten im Vergleich $\mathrm{zu}$ unstimulierten GBP-1-shRNA-HUVEC eine identische Lamellipodienbildung (Abb. 25A, B; GBP-1-shRNA).

A

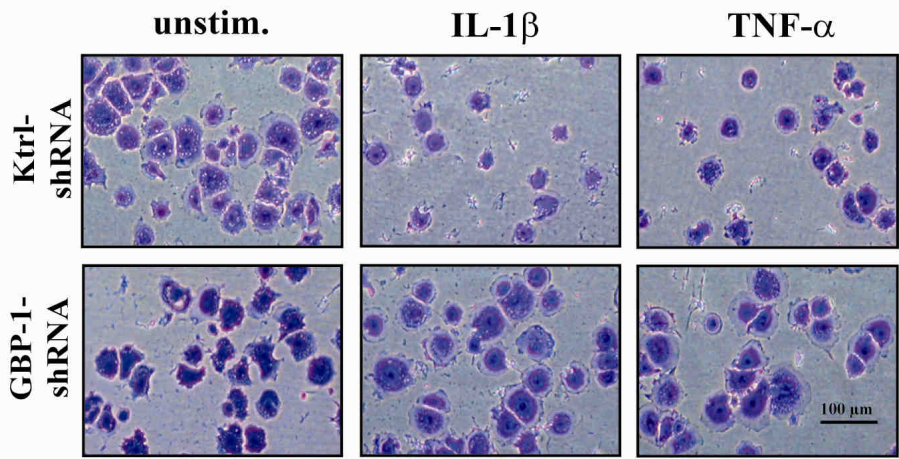

B

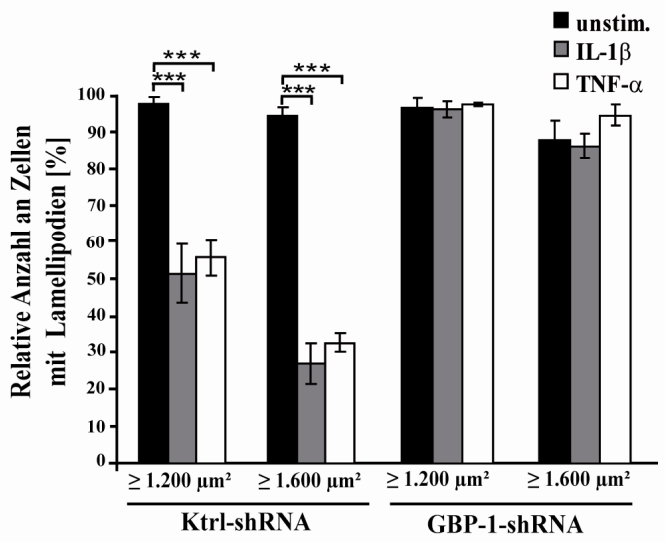

Abb. 25: GBP-1 ist zur Hemmung der endothelialen Lamellipodienbildung durch IL-1 $\beta$ und TNF- $\alpha$ auf FN-beschichteten Oberflächen notwendig.

(A) GBP-1-shRNA- und Ktrl-shRNA-HUVEC (HUVEC1) blieben entweder unbehandelt (unstim.) oder wurden für $48 \mathrm{~h}$ mit IL-1 $\beta(200 \mathrm{U} / \mathrm{ml})$ und TNF- $\alpha(300 \mathrm{U} / \mathrm{ml})$ stimuliert. Es wurden jeweils $5 \times 10^{3}$ der Zellen pro Loch in einer mit FN-beschichteten $\left(5 \mu \mathrm{g} / \mathrm{cm}^{2}\right)$ 96-Loch-Platte ausgesät. 20 min nach Anheftung wurden die Zellen in $10 \%$ Formalin fixiert und mit 0,5\% Kristallviolett angefärbt. (B) Die Fläche von jeweils 100 der in (A) dargestellten Zellen wurde mit Hilfe der OPTIMAS 6.0 Software bestimmt. Die relative Anzahl (\%) an GBP-1shRNA- und Ktrl-shRNA-HUVEC mit ausgebildeten Lamellipodien definiert über eine Fläche $\geq 1.200 \mu \mathrm{m}^{2}$ (linke Säulen) oder $\geq 1.600 \mu \mathrm{m}^{2}$ (rechte Säulen) ist im Diagramm dargestellt. Die Mittelwerte \pm Standardabweichungen von vier unabhängigen Experimenten sind gezeigt $(* * *=p \leq 0,001)$. 


\subsubsection{GBP-1 ist zur Hemmung der Migration von HUVEC durch IL-1 $\beta$ und TNF- $\alpha$ notwendig}

Abschließend wurde die Migrationsfähigkeit von IL-1 $\beta$ - und TNF- $\alpha$-behandelten GBP-1shRNA- und Ktrl-shRNA-HUVEC auf FN-beschichteten Oberflächen untersucht. Dazu wurden die Zellen in FN-beschichteten Zellkulturschalen ausgesät, bis zu einer Konfluenz von 90 - 100\% kultiviert und für 48 h mit IL-1 $\beta$ oder TNF- $\alpha$ stimuliert. Mit Hilfe einer sterilen 1 ml-Pipettenspitze wurde ein definierter, zellfreier Bereich in den konfluenten Zellrasen gekratzt und anschließend die Zellen für $10 \mathrm{~h}$ kultiviert. Im Vergleich zu den vorangehenden Migrationsversuchen erfolgte die weitere Kultivierung nicht in SFM, sondern in ECBM mit zusätzlich 0,5\% FKS. Dies war in einer erhöhten Sterberate der stimulierten shRNA-exprimierenden Zellen bei der Kultivierung in SFM begründet. Zur Bestimmung des Migrationsverhaltens wurde der Abstand zwischen den Zellfronten und somit die Fähigkeit der Zellen in den zellfreien Bereich einzuwandern zu Beginn des Versuches (Zeitpunkt $0 \mathrm{~h}$ ), nach $2 \mathrm{~h}, 6 \mathrm{~h}$ und $10 \mathrm{~h}$ bestimmt. Der zellfreie Bereich war in den mit IL-1 $\beta$ - und TNF- $\alpha$ behandelten Ktrl-shRNA-HUVEC-Kulturen nach $10 \mathrm{~h}$ größer $(2,5 \pm 0,4$-fach IL-1 $\beta ; 2,4 \pm$ 0,3-fach TNF- $\alpha$ ) als bei der unstimulierten Ktrl-shRNA-HUVEC-Kultur (Abb. 26; KtrlshRNA; 10 h). Die Hemmung der GBP-1-Expression mittels GBP-1-shRNA verhinderte den Hemmeffekt von IL-1 $\beta$ und TNF- $\alpha$ auf die Zellmigration (Abb. 26; GBP-1-shRNA; 10 h).

Zusammenfassend zeigen die in dieser Arbeit erhaltenen Ergebnisse, dass GBP-1 hinreichend und notwendig ist, um die Hemmung der endothelialen Lamellipodienbildung und der Migration durch IL-1 $\beta$ und TNF- $\alpha$ zu vermitteln. Dieser Effekt beruht auf der hier erstmals beschriebenen Induktion der ITGA4-Expression durch GBP-1 in EZ. 


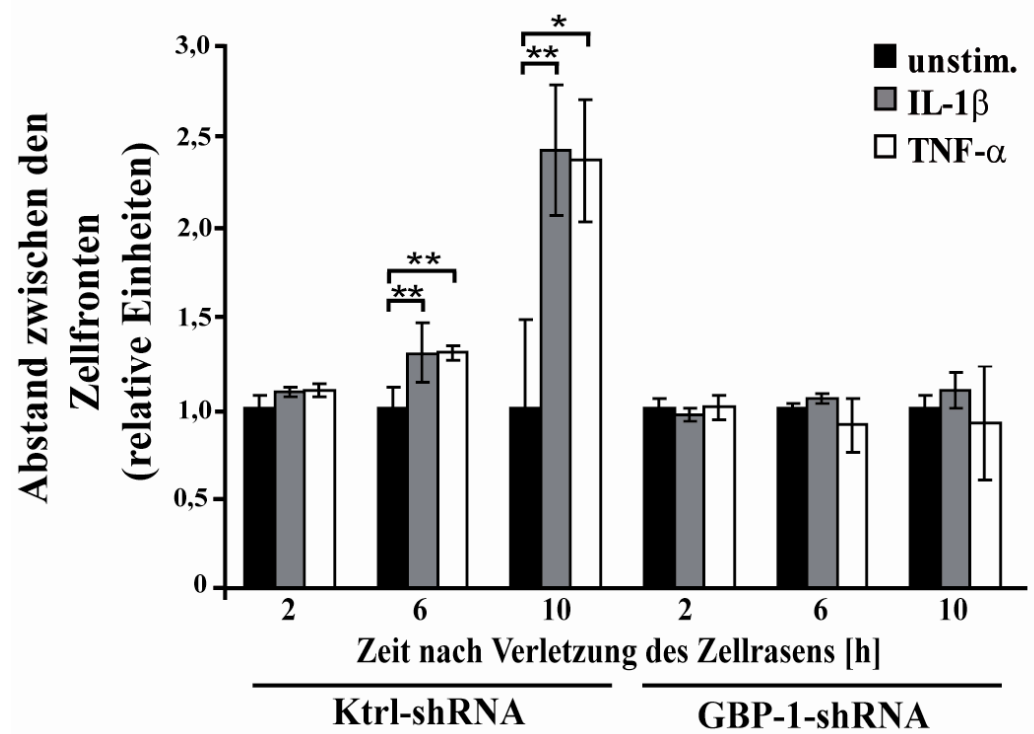

Abb. 26: GBP-1 ist notwendig für die Hemmung der Migration von IL-1 $\beta$ - und TNF- $\alpha$-behandelten HUVEC auf FN-beschichteten Oberflächen.

Zur Bestimmung der Migrationsfähigkeit von Ktrl-shRNA- und GBP-1-shRNA-HUVEC nach Behandlung mit IL-1 $\beta(200 \mathrm{U} / \mathrm{ml})$ und TNF- $\alpha(300 \mathrm{U} / \mathrm{ml})$ auf FN-Matrizes wurde ein in vitro Wundheilungstest durchgeführt. Die Zellen wurden auf FN-beschichteten Oberflächen ausgesät, bis zu einer Konfluenz von 90 - 100\% kultiviert und für $48 \mathrm{~h}$ mit dem jeweiligen Zytokin behandelt. Mit Hilfe einer sterilen $1 \mathrm{ml}$-Pipettenspitze wurde ein definierter, zellfreier Bereich in den konfluenten Zellrasen gekratzt. Die Zellen wurden anschließend für $10 \mathrm{~h}$ in ECBM-0,5\% FKS kultiviert. Der Abstand zwischen den Zellfronten wurde zu Beginn des Versuches, nach 2 h, $6 \mathrm{~h}$ und $10 \mathrm{~h}$ bestimmt und prozentual zum Abstand zum Zeitpunkt $0 \mathrm{~h}$ berechnet. Der relative Abstand zwischen den Zellfronten der Zytokin-behandelten Ktrl-shRNA- und GBP-1-shRNA-HUVEC im Vergleich zu den jeweiligen unstimulierten Zellen (auf 1 gesetzt) nach 2 h, 6 h und $10 \mathrm{~h}$ ist im Diagramm dargestellt. Die Ergebnisse sind als Mittelwerte \pm Standardabweichungen von vier unabhängigen Experimenten dargestellt $(*=\mathrm{p} \leq 0,05 ; * *=\mathrm{p} \leq$ $0,01)$. 


\section{Diskussion}

GBP-1 gehört zur Familie der großen GTPasen und wird durch die inflammatorischen Zytokine IFN- $\gamma$, IL- $1 \beta$ und TNF- $\alpha$ in EZ in vitro induziert. Angiogene Wachstumsfaktoren, wie VEGF oder bFGF hemmen die Expression von GBP-1 (Guenzi et al., 2001; Guenzi et al., 2003; Lubeseder-Martellato et al., 2002). In vivo konnte eine starke GBP-1-Expression in entzündlichen Geweben nachgewiesen werden. Hierbei war die Expression von GBP-1 fast ausschließlich auf EZ der Blutgefäße beschränkt. Alle GBP-1-positiven Gefäße waren stets von zahlreichen Monozyten umringt, welche hohe Konzentrationen an inflammatorischen Zytokinen sekretierten (Guenzi et al., 2001; Lubeseder-Martellato et al., 2002). Diese Beobachtungen zeigen, dass GBP-1 Zytokin-exponierte EZ kennzeichnet und lassen vermuten, dass GBP-1 in diesen Zellen spezifische, zellbiologische Funktionen zu erfüllen hat.

In vorangehenden Untersuchungen unserer Arbeitsgruppe konnte gezeigt werden, dass GBP-1 die antiangiogene Wirkung der inflammatorischen Zytokine IFN- $\gamma$, IL-1 $\beta$ und TNF- $\alpha$ in EZ vermittelt. GBP-1 reguliert sowohl die antiproliferativen Effekte (Guenzi et al., 2001), als auch die Hemmung der Invasion von EZ durch IFN- $\gamma$, IL-1 $\beta$ und TNF- $\alpha$ (Guenzi et al., 2003). In dieser Arbeit wurden weitere wichtige antiangiogene Eigenschaften von GBP-1 identifiziert und auf molekularer Ebene charakterisiert. Es konnte gezeigt werden, dass GBP-1 die Lamellipodienbildung und die Migration von EZ auf FN-beschichteten Oberflächen hemmt. Verantwortlich für diese inhibitorischen Effekte ist die GBP-1-abhängige Induktion von ITGA4.

\subsection{GBP-1 induziert die Expression von ITGA4 in Endothelzellen}

Die Hochregulation der ITGA4-Expression in EZ in Abhängigkeit von GBP-1 konnte durch unterschiedliche experimentelle Ansätze bewiesen werden. Zunächst wurden vergleichende Transkriptom-Analysen zur Identifikation GBP-1-regulierter Gene mittels MicroarrayTechnologie (Affymetrix) durchgeführt. Aufgrund der allgemein bekannten Heterogenität von humanen EZ, erfolgten diese Versuche mit zwei unterschiedlichen HUVEC-Kulturen von mehreren verschiedenen EZ-Spendern. Die Expression des itga4-Gens war in beiden der untersuchten, GBP-1-exprimierenden HUVEC-Kulturen hoch signifikant $(p<0,001)$ aufreguliert. Dagegen wurde die Expression anderer $\alpha$-Integrinuntereinheiten durch die 
Expression von GBP-1 entweder nicht beeinflusst (itga2, itga3, itga5, itga6) oder, wie im Fall von itgav, in beiden Kulturen unterschiedlich durch GBP-1 reguliert. GFP, welches als ein heterologes Kontrollprotein in HUVEC exprimiert wurde, hatte keinen Einfluss auf die ITGA4-Expression.

Der mit Hilfe der Microarray-Analyse erhaltene Befund, konnte auch durch verschiedene weitere Methoden bestätigt werden. Mittels semi-quantitativer RT-PCR und RPA wurde die erhöhte ITGA4-Expression in GBP-1-exprimierenden Zellen auf RNA-Ebene und mittels Durchflusszytometrie auf Proteinebene verifiziert. Darüber hinaus konnte auch gezeigt werden, dass die Induktion von ITGA4 nicht nur aufgrund von ektopisch exprimiertem GBP-1 zu beobachten ist, sondern dass sie auch durch eine Behandlung der EZ mit den inflammatorischen Zytokinen IL-1 $\beta$ und TNF- $\alpha$ induziert wird. Auch von anderen Arbeitsgruppen wurde bereits beschrieben, dass die Expression von ITGA4 an der Oberfläche von EZ nach Behandlung der Zellen mit TNF- $\alpha$ erhöht ist (Brezinschek et al., 1996).

Mit Hilfe einer shRNA gegen GBP-1 konnte schließlich gezeigt werden, dass ein gezieltes Abschalten der endogenen GBP-1-Expression die Induktion von ITGA4 in EZ nach Behandlung mit IL-1 $\beta$ bzw. TNF- $\alpha$ hemmt. Alle diese Ergebnisse führen zu der Schlussfolgerung, dass GBP-1 notwendig und hinreichend für die Induktion der ITGA4Expression in EZ durch die inflammatorischen Zytokine IL-1 $\beta$ und TNF- $\alpha$ ist.

In ersten Untersuchungen mit HUVEC, welche GTPase-Mutanten von GBP-1 (GBP-1-K51A, GBP-1-D184N) exprimieren (Praefcke et al., 2004), konnte weiterhin gezeigt werden, dass die GTPase-Aktivität von GBP-1 für die Induktion von ITGA4 wichtig ist. Die Einführung der beiden GTPase-Mutationen in das GBP-1-Protein hatte zur Folge, dass die Aufregulation der ITGA4-Expression im Vergleich zum Wildtyp-Protein um mehr als die Hälfte niedriger war. Eine Reduktion der ITGA4-Expression auf das Basalniveau von Kontrollzellen (KVHUVEC) konnte in GBP-1-K51A- und GBP-1-D184N-HUVEC jedoch nicht beobachtet werden, weshalb neben der GTPase-Aktivität noch andere, zusätzliche Strukturen/Regionen von GBP-1 an der Steuerung der ITGA4-Expression beteiligt zu sein scheinen. Um diese Strukturen/Regionen identifizieren zu können, sind weitere Studien notwendig. 


\subsection{GBP-1 ist hinreichend für die Hemmung der Lamellipodien- bildung und Migration von Endothelzellen auf FN-beschichteten Oberflächen}

Das EZM-Protein FN und die endothelialen Integrine $\alpha_{v} \beta_{3}$ und $\alpha_{5} \beta_{1}$ sind maßgeblich an der Regulation der Angiogenese beteiligt (George et al., 1997; George et al., 1993; Grant and Kleinman, 1997; Hynes, 2007; Milner and Campbell, 2006; Nicosia et al., 1993; Serini et al., 2006; Wang and Milner, 2006). FN ist das am häufigsten vorkommende Protein der EZM von noch unreifen, vaskulären Gefäßen, wohingegen in der EZM ausgereifter, ruhender Blutgefäße fast kein FN mehr nachweisbar ist (Jin and Varner, 2004; Ruegg and Mariotti, 2003). Darüber hinaus sterben Mäuse, welche kein FN mehr exprimieren können (FN-NullMäuse) sehr früh in ihrer Entwicklung (während der Gastrulation), aufgrund zahlreicher, massiver Defekte ihres vaskulären Systems (George et al., 1997; George et al., 1993). Die Bindung der endothelialen Integrine $\alpha_{v} \beta_{3}$ und $\alpha_{5} \beta_{1}$ an ihren Liganden FN führt vorrangig zur Endothelzellproliferation und zur Bildung endothelialer Lamellipodien, wodurch es zu einer Einwanderung der EZ in das neu zu vaskularisierende Gewebe kommt (Kim et al., 2000a; Kim et al., 2000b; Livant et al., 2000; White et al., 2001).

ITGA4 ist ein weiteres Mitglied der Integrin-Familie, welches mit den Untereinheiten $\beta_{1}$ und $\beta_{7}$ Heterodimere ausbildet und als $\alpha_{4} \beta_{1}$ und $\alpha_{4} \beta_{7}$ an FN binden kann. Im Gegensatz zu den bereits beschriebenen FN-Rezeptoren $\alpha_{v} \beta_{3}$ und $\alpha_{5} \beta_{1}$ sind die Heterodimere $\alpha_{4} \beta_{1}$ und $\alpha_{4} \beta_{7}$ die einzigen Integrine, welche FN an einer C-terminalen Bindestelle (Typ III Modul 14 - IIICS) erkennen. Alle anderen bekannten FN-bindenden Integrine interagieren mit FN über eine zentrale Integrinbindestelle (Typ III Modul 9 - 10) (Pankov and Yamada, 2002; Plow et al., 2000). Verschiedene Studien belegen, dass eine Expression von ITGA4 die Lamellipodienbildung von Hamster-Ovarzellen (CHO-Zellen) hemmt (Chan et al., 1992; Kassner et al., 1995; Liu et al., 1999). Weiterhin wurde beobachtet, dass eine ITGA4/FNInteraktion die Migration und Invasion von verschiedenen Zelltypen (humane Brustepithelzellen, Lungenfibroblasten und Plattenepithelzellen) auf FN stark reduziert (Ignatoski et al., 2000; Jia et al., 2004; White et al., 2003; Zhang et al., 2004). In Übereinstimmung mit diesen Beobachtungen konnte in dieser Arbeit gezeigt werden, dass die ektopische Expression von GBP-1 alleine hinreichend ist, um die Expression von ITGA4 zu induzieren und die Lamellipodienbildung und Migration von EZ auf FN-beschichteten Oberflächen zu hemmen. Auf einer Oberfläche, welche mit FN-120 beschichtet war, einem 
$120 \mathrm{kDa}$ großen FN-Fragment, dem die C-terminale $\alpha_{4} \beta_{1} / \alpha_{4} \beta_{7}$-Bindestelle fehlt, konnte weder eine Hemmung der Lamellipodienbildung noch der Migration von EZ durch GBP-1 festgestellt werden.

Es sind jedoch auch Studien bekannt, in denen eine Expression von ITGA4 die Migration von Zellen fördert (Chan et al., 1992; Kassner et al., 1995; Mostafavi-Pour et al., 2003). Die Versuche in diesen Arbeiten wurden mit einem FN-Fragment durchgeführt, welches nur die C-terminale $\alpha_{4} \beta_{1} / \alpha_{4} \beta_{7}$-Bindestelle enthält, so dass ausschließlich ITGA4 mit FN interagieren konnte. Im Gegensatz dazu wurde in den Versuchen dieser Arbeit und in den Studien der Arbeitsgruppen, die eine Migrationshemmung nach Ligation von ITGA4 beobachten konnten, immer vollständiges, intaktes FN verwendet. Dadurch konnte der zellbiologische Effekt von ITGA4 im Kontext aller anderen Integrine untersucht werden. Diese unterschiedlichen Versuchsbedingungen lassen vermuten, dass unter physiologischen Bedingungen die Signaltransduktionskaskaden der anderen Integrine einen zusätzlichen, wichtigen Einfluss auf die Regulation ITGA4-abhängiger, zellbiologischer Effekte ausüben.

\subsection{Die inflammatorischen Zytokine IL-1 $\beta$ und TNF- $\alpha$, aber nicht IFN- $\gamma$ hemmen die Bildung endothelialer Lamellipodien durch eine GBP-1-vermittelte Induktion von ITGA4}

Neben der zellbiologischen Aktivität von ektopisch exprimiertem GBP-1, wurde in dieser Arbeit auch der Einfluss der GBP-1-induzierenden Zytokine IL-1 $\beta$, TNF- $\alpha$ und IFN- $\gamma$ auf die Lamellipodienbildung von EZ analysiert. Es konnte gezeigt werden, dass die Bildung endothelialer Lamellipodien bei allen Zytokin-behandelten Zellen auf FN-beschichteten Oberflächen gehemmt war. Interessanterweise war die Exposition von ITGA4 an der Zelloberfläche von IFN- $\gamma$-behandelten HUVEC nicht erhöht, sondern im Vergleich zu unstimulierten Zellen sogar herunterreguliert. Weiterhin konnte auch die durch IFN- $\gamma$ induzierte Hemmung der endothelialen Lamellipodienbildung auf FN-120-beschichteten Oberflächen nicht aufgehoben werden. Diese Resultate zeigen, dass zwar alle inflammatorischen Zytokine (IL-1 $\beta$, TNF- $\alpha$ und IFN- $\gamma$ ) die Bildung endothelialer Lamellipodien auf FN-beschichteten Oberflächen hemmen, dass jedoch nur IL-1 $\beta$ und TNF- $\alpha$ dies abhängig von einer GBP-1-induzierten Hochregulation von ITGA4 bewirken. Im Gegensatz dazu scheint IFN- $\gamma$ die Hemmung der Lamellipodienbildung unabhängig von GBP-1 und ITGA4 zu induzieren. 
Die Aktivierung von EZ nach einer Behandlung mit IFN- $\gamma$ erfolgt über andere Signaltransduktionskaskaden als nach einer Stimulierung mit IL-1 $\beta$ bzw. TNF- $\alpha$, weshalb sich folglich auch die Genexpressionsprofile der EZ nach Behandlung mit den genannten Zytokinen stark voneinander unterscheiden (Mantovani et al., 1992; Mantovani et al., 1998). IL-1 $\beta$ und TNF- $\alpha$ führen zur Aktivierung vieler verschiedener Transkriptionsfaktoren, wie beispielsweise NF-кB (Osborn et al., 1989), C/EBP (CCAAT/enhancer-binding protein) (Darville and Eizirik, 2001) oder IRF-1 (Kroger et al., 2002). Die Aktivierung dieser Faktoren ist vor allem notwendig für die Expression endothelialer Adhäsionsmoleküle (z.B. VCAM-1, ICAM-1 und E-Selektin) (Collins et al., 1995; Ledebur and Parks, 1995; Neish et al., 1995; Schindler and Baichwal, 1994; Shu et al., 1993), die bei der Einwanderung von Leukozyten in das entzündliche Gewebe während einer Infektion eine wichtige Rolle spielen. Weiterhin tragen IL-1 $\beta$ und TNF- $\alpha$ zu einer verbesserten Blutgerinnung bei, indem sie die Expression von wichtigen Faktoren der Gerinnung (z.B. Faktor III und PAF) erhöhen (Bevilacqua et al., 1984; Nawroth and Stern, 1986). Kleine Blutgefäße werden dadurch verschlossen und die systemische Ausbreitung der Entzündung verhindert. Nach einer IFN- $\gamma$-Behandlung kommt es dagegen zur Aktivierung des JAK (Janus-Kinase)/STAT (signals transducers and activators of transcription)-Signaltransduktionswegs (Haque and Williams, 1998; Pellegrini and Dusanter-Fourt, 1997). Diese Aktivierung hat zur Folge, dass es neben einer erhöhten Expression der Adhäsionsmoleküle ICAM-1 und ELAM-1 (Leeuwenberg et al., 1990; Pober et al., 1986) auch $\mathrm{zu}$ einer erhöhten Expression der Haupthistokompatibilitätskomplexe (MHC) der Klasse I und II auf EZ kommt, wodurch die Immunität gegen viele Pathogene, wie Viren, Bakterien und Pilze während einer Entzündung erhöht ist (Ahmed et al., 2003; Mantovani et al., 1992; Mantovani et al., 1998).

Obwohl die GBP-1-Expression sowohl durch IFN- $\gamma$, als auch durch IL-1 $\beta$ und TNF- $\alpha$ in EZ induziert wird, verläuft auch die Aktivierung der GBP-1-Transkription in Abhängigkeit von der Art der Zytokin-Stimulierung über unterschiedliche Signalwege. Nach einer IFN- $\gamma-$ Behandlung von EZ erfolgt die Aktivierung der GBP-1-Expression ausschließlich über ein ISRE/GAS-Element, welches durch den Transkriptionsfaktor IRF-1 aktiviert wird (Kroger et al., 2002). Im Gegensatz dazu ist für die Induktion der GBP-1-Expression durch IL-1 $\beta$ und TNF- $\alpha$ die Beteiligung eines weiteren Promotorelements erforderlich. Hierbei handelt es sich um ein cRel-Element, welches im Rahmen eines Moduls mit dem ISRE-Element zusammenwirkt und über eine kooperative Aktivierung die GBP-1-Expression ermöglicht (Naschberger et al., 2004). 
Aufgrund der Aktivierung verschiedener Signaltransduktionskaskaden von IL-1 $\beta$ und TNF- $\alpha$ im Vergleich zu IFN- $\gamma$, die sich auch in der unterschiedlichen Regulation der GBP-1Expression wiederspiegeln, ist es vorstellbar, dass IFN- $\gamma$ neben GBP-1 Faktoren induziert, welche reprimierend auf die Expression von ITGA4 wirken. Weiterhin ist es auch denkbar, dass in IFN- $\gamma$-behandelten EZ Faktoren fehlen, welche für die ITGA4-Induktion durch GBP-1 notwendig sind. Beide Mechanismen könnten erklären, weshalb GBP-1 in IL-1 $\beta$ - und TNF- $\alpha-$ stimulierten Zellen andere Effekte auf die ITGA4-Expression ausübt, als in IFN- $\gamma$ stimulierten EZ. Darüber hinaus scheint IFN- $\gamma$ auch Faktoren zu induzieren, welche in der Lage sind, unabhängig von GBP-1 und ITGA4 die endotheliale Lamellipodienbildung zu hemmen. Dies steht im Einklang damit, dass ein inhibitorischer Effekt von IFN- $\gamma$ auf eine durch Prostaglandin $\mathrm{F}_{2 \alpha} \quad\left(\mathrm{PGF}_{2 \alpha}\right)$-vermittelte Lamellipodienbildung von primären Kardiomyozyten aufgrund eines noch unbekannten, ITGA4-unabhängigen Mechanismus bereits nachgewiesen werden konnte (Jin et al., 2005).

Zusammenfassend kann spekuliert werden, dass unter inflammatorischen Bedingungen, welche durch die Zytokine IL-1 $\beta$ und TNF- $\alpha$ reguliert werden, GBP-1 die Bildung von endothelialen Lamellipodien und die Migration von EZ aufgrund der Induktion von ITGA4 hemmt. In Situationen, bei denen das Zytokin IFN- $\gamma$ dominiert, kommt es im Gegensatz dazu zwar auch zu einer Hemmung der endothelialen Lamellipodienbildung, jedoch unabhängig von der durch GBP-1-induzierten ITGA4-Expression. Im IFN- $\gamma$-dominierten Mikromilieu scheint GBP-1 somit andere Funktionen auszuüben, welche beispielsweise zur Abwehr von Pathogenen dienen könnten. In diesem Kontext ist es auch interessant anzumerken, dass für die Mitglieder der GBP-Familie sowohl antivirale (Anderson et al., 1999; Carter et al., 2005), als auch antibakterielle Aktivitäten nachgewiesen werden konnten (Degrandi et al., 2007). 


\subsection{Modelle zur Hemmung der endothelialen Lamellipodienbildung nach Behandlung mit IL-1ß/TNF- $\alpha$ bzw. IFN- $\gamma$}

Im Rahmen dieser Arbeit konnten neue, antiangiogene Funktionen von GBP-1 während einer Entzündung beschrieben und auf molekularer Ebene charakterisiert werden. Es wurde gezeigt, dass GBP-1 hinreichend und notwendig ist, um die inhibitorischen Effekte der inflammatorischen Zytokine IL-1 $\beta$ und TNF- $\alpha$ auf die Bildung endothelialer Lamellipodien und die Migration von EZ auf FN-beschichteten Oberflächen zu vermitteln. Sowohl die Lamellipodienbildung, als auch die Migration der Zellen wurden durch die GBP-1-vermittelte Induktion der ITGA4-Expression gehemmt.

Es ist bekannt, dass zytoplasmatische GTPasen die Regulation der Genexpression beeinflussen können, wie für die kleinen GTPasen Rac, Rho und Ras gezeigt (Boyer et al., 2004; Hernandez-Perera et al., 2000; Hill et al., 1995; Kraynack et al., 2002). Die Expression des itga4 Gens wird durch viele verschiedene Transkriptionsfaktoren reguliert. Diese Faktoren können die Promotoraktivität des itga4 Gens stimulieren [Ets-Familie (Rosen et al., 1994), Pax-6 (Zaniolo et al., 2004), der Wilms-Tumorsupressor WT1 (Kirschner et al., 2006), der glial cell missing factor GCMa (Schubert et al., 2008), c-Myb (Postigo et al., 1997)] oder auch inhibieren [ZEB (Postigo et al., 1997)]. Weitere Analysen sind notwendig, um aufklären zu können, ob GBP-1 die Expression von ITGA4 aufgrund der Regulation einer dieser Faktoren oder durch posttranskriptionelle Regulation der mRNA-Stabilität erhöht.

Es wurde bereits beschrieben, dass eine Aktivierung der unterschiedlichen Integrine durch Ligandenbindung, wie beispielsweise die Interaktion von $\alpha_{5} \beta_{1}$ mit FN, zur Aktivierung zahlreicher, an der dynamischen Umstrukturierung des Zytoskeletts beteiligter Proteine führt (Hynes, 2002). Integrin-abhängig kann beispielsweise die Aktivierung der kleinen GTPase Rac induziert werden. Dies führt zu einer Reorganisation des Aktinzytoskeletts und zur Proliferation und Migration der Zellen (Dharmawardhane et al., 1997; Etienne-Manneville and Hall, 2002; Ridley, 2001). Im Gegensatz dazu konnte für die zytoplasmatische Domäne von ITGA4 ein inhibitorischer Effekt auf die Rac-Aktivierung nachgewiesen werden. Paxillin, ein Adapterprotein, bindet direkt und spezifisch an die zytoplasmatische Domäne von ITGA4, wodurch eine Integrin-vermittelte Aktivierung der kleinen GTPase Rac (z.B. durch eine $\alpha_{5} \beta_{1} / \mathrm{FN}$-Interaktion) und in Folge dessen die Polymerisation des Aktinzytoskeletts 
und die Lamellipodienbildung verhindert wird (Goldfinger et al., 2003; Liu et al., 1999; Nishiya et al., 2005).

Aufgrund dessen kann angenommen werden, dass die durch GBP-1/ITGA4-vermittelten inhibitorischen Effekte auf eine Rac-Inaktivierung zurückzuführen sind und somit gegenüber den als proangiogen beschriebenen Integrinen $\alpha_{v} \beta_{3}$ und $\alpha_{5} \beta_{1}$ eine antagonistische Wirkung zu besitzen scheinen. Erste Versuche mit dem spezifischen Rac-Inhibitor NSC23766 (Calbiochem) deuten auf eine Beteiligung der kleinen GTPase an der Regulation der hier beschriebenen, inhibitorischen Effekte hin (Ergebnisse nicht gezeigt). Eine Vorbehandlung der Kontrolzellen (KV-HUVEC) mit diesem Inhibitor führte in gleichem Maße zu einer Hemmung der endothelialen Lamellipodienbildung, wie dies bei unbehandelten GBP-1exprimierenden HUVEC auf FN-beschichteten Oberflächen zu beobachten ist. Um eine GBP-1/ITGA4-vermittelte Rac-Inaktivierung auf FN-beschichteten Oberflächen jedoch hinreichend untermauern zu können, sind weitere Versuche mit einer konstitutiv-aktiven RacMutante (RacV12) notwendig. Demnach sollte aufgrund der Expression dieser Mutante die GBP-1/ITGA4-vermittelte Hemmung der Lamellipodienbildung von EZ auf FN aufgehoben sein.

Ausgehend von den in dieser Arbeit beschriebenen Ergebnissen und diskutierten Punkten können die unterschiedlichen molekularen Mechanismen der durch IL-1 $\beta /$ TNF- $\alpha$ - bzw. IFN- $\gamma$-induzierten Hemmung der endothelialen Lamellipodienbildung jeweils in einem Modell zusammengefasst werden (Abb. 27). Dominieren während einer Entzündungsreaktion die Zytokine IL-1 $\beta$ und TNF- $\alpha$, so kommt es nach der Induktion der GBP-1-Expression zu einer Erhöhung des intrazellulären itga4 mRNA-Gehalts. Es kann angenommen werden, dass GBP-1 diese Induktion entweder durch Regulation der mRNA-Stabilität im Zytoplasma oder durch Aktivierung der itga4 mRNA-Transkription im Zellkern über noch unbekannte Mechanismen (z.B. Aktivierung von Faktor z) reguliert (Abb. 27A; 1, 2a, 2b). Nach Translation der itga4 mRNA im Zytoplasma wird das Protein ITGA4 zusammen mit ITGB1 an der Zelloberfläche als Heterodimer exponiert und es kommt zur Interaktion mit FN der EZM. Diese Interaktion führt dazu, dass das Adapterprotein Paxillin (Pax) an die zytoplasmatische Domäne von ITGA4 bindet und dadurch eine noch unbekannte Signaltransduktionskaskade ausgelöst wird, welche eine Hemmung der kleinen GTPase Rac verursacht (Abb. 27A; 3, 4). Rac kann durch verschiedene andere Integrine, wie beispielsweise dem auf EZ exprimierten Integrin $\alpha_{5} \beta_{1}$, nach Ligandenbindung aktiviert 
werden, so dass es zur Reorganisation des Aktinzytoskeletts und zur Lamellipodienbildung kommt. Aufgrund der ITGA4-vermittelten Rac-Inaktivierung wird diese Integrin-vermittelte Polymerisation des Aktinzytoskeletts verhindert und es kommt folglich zur Hemmung der endothelialen Lamellipodienbildung (Abb. 27A; 5). Im Kontext einer durch IFN- $\gamma$-induzierten Zellreaktion kommt es dagegen neben der Expression von GBP-1 auch zur Expression weiterer IFN-induzierter Proteine (Faktor x, Faktor y), welche die Expression von ITGA4 und die endotheliale Lamellipodienbildung regulieren (Abb. 27B; 1). Diese Faktoren (Faktor x) wirken den ITGA4-induzierenden Eigenschaften von GBP-1 entgegen, indem sie entweder einen erhöhten Abbau der itga4 mRNA im Zytoplasma verursachen oder eine mögliche GBP-1-induzierte itga4 mRNA-Transkription im Zellkern verhindern (Abb. 27B; 2a, 2b; Faktor $\mathrm{x}$ ). Weiterhin ist es auch denkbar, dass eine IFN- $\gamma$-Behandlung der Zellen dazu führt, dass wichtige Faktoren (Faktor z), welche für die GBP-1-vermittelte Induktion von ITGA4 notwendig sind, abgeschalten werden und somit der Zelle für die itga4 mRNA-Transkription nicht mehr zur Verfügung stehen (Abb. 27B; 2a; Faktor z). Neben der Hemmung der itga4Transkription bzw. der fehlenden Induktion scheinen diese Faktoren (Faktor y) auch anhand eines noch unbekannten, ITGA4-unabhängigen Mechanismus die Polymerisation des Aktinzytoskeletts und somit die Lamellipodienbildung von EZ zu hemmen (Abb. 27B; 3).

A

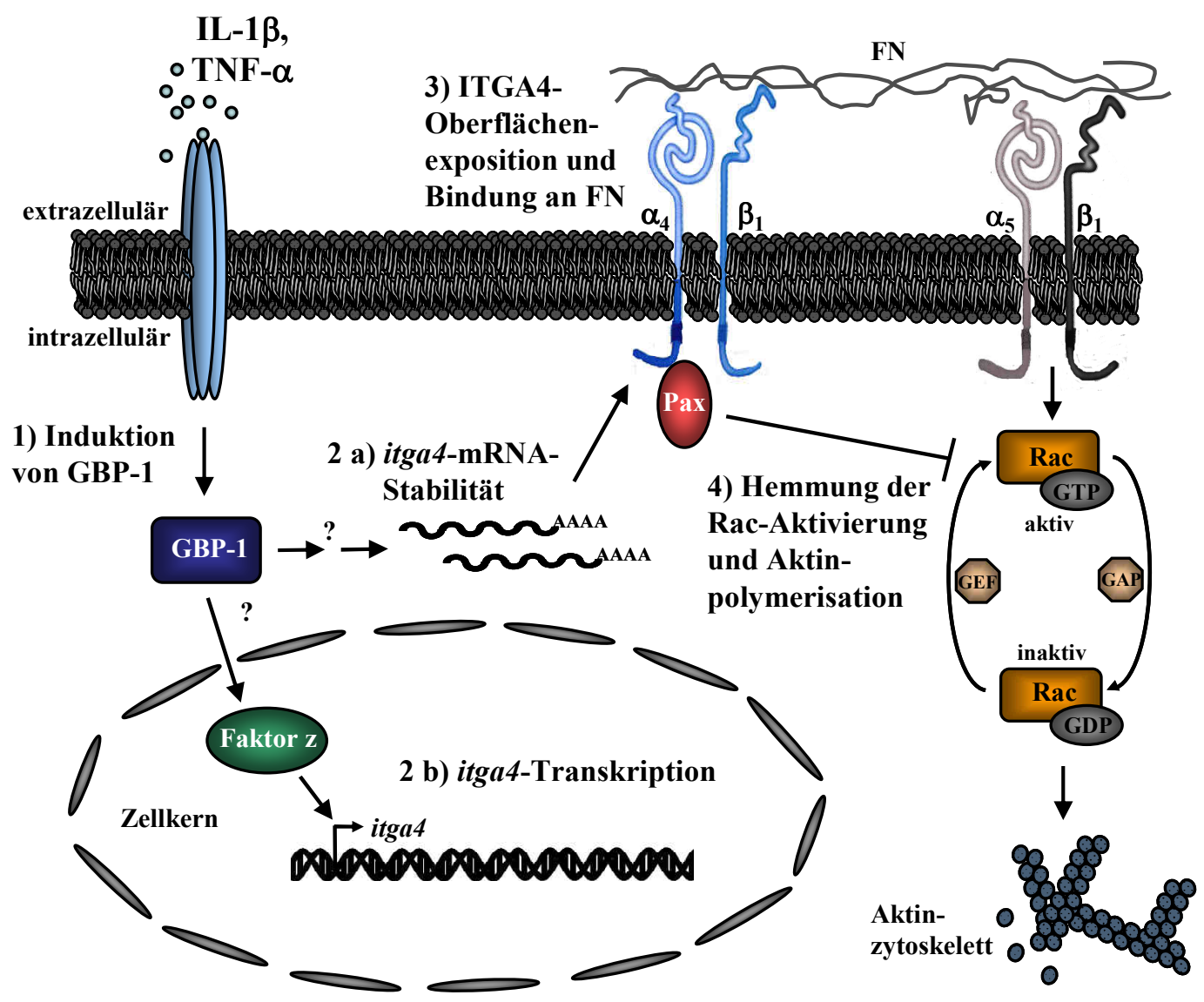




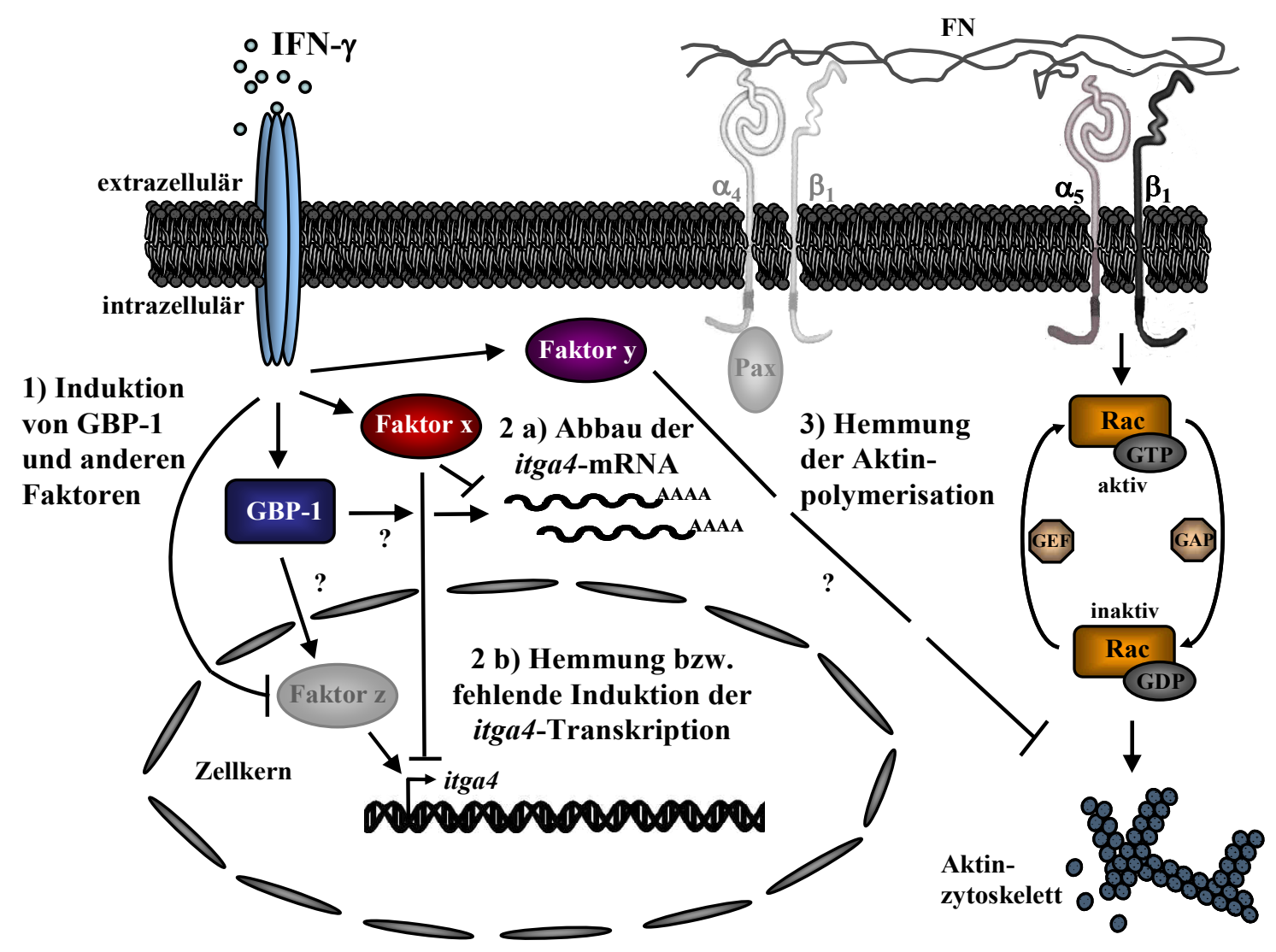

Abb. 27: Schematisches Modell zur Hemmung der endothelialen Lamellipodienbildung nach Stimulation

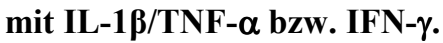

(A) 1) Während einer Entzündungsreaktion bei der IL-1 $\beta$ und TNF- $\alpha$ dominieren, binden die Zytokine an ihre jeweiligen Rezeptoren auf der Oberfläche von EZ und die Synthese von GBP-1 wird induziert. 2) GBP-1 erhöht den intrazellulären itga4 mRNA-Gehalt über noch unbekannte Mechanismen. Es kann angenommen werden, dass GBP-1 diese Induktion a) durch Regulation der mRNA-Stabilität im Zytoplasma oder b) durch Aktivierung der itga4 mRNA-Transkription im Zellkern (z.B. über Aktivierung von Faktor z) reguliert. 3) Die mRNA von itga4 wird im Zytoplasma translatiert (nicht dargestellt) und das Protein ITGA4 zusammen mit ITGB1 an der Oberfläche der EZ als Heterodimer exponiert. Integrin $\alpha_{4} \beta_{1}$ interagiert mit seinem Liganden FN der EZM, wodurch Paxillin (Pax) an die zytoplasmatische Domäne von ITGA4 bindet. 4) Durch diese Bindung kommt es über eine noch unbekannte Signaltransduktionskaskade zur Hemmung der kleinen GTPase Rac. Rac kann durch verschiedene andere endotheliale Integrine, wie beispielsweise $\alpha_{5} \beta_{1}$, nach Ligandenbindung (FN) aktiviert werden, so dass es zur Reorganisation des Aktinzytoskeletts kommt. Durch die ITGA4-vermittelte Inaktivierung von Rac wird diese Integrin-abhängige Polymerisation des Aktinzytoskeletts verhindert und es kommt zur Hemmung der Lamellipodienbildung. (B) 1) Im Kontext eines IFN- $\gamma$-dominierten Mikromilieus kommt es neben der Expression von GBP-1 auch zur Expression weiterer IFN-induzierter Proteine (Faktor x, Faktor y), welche die Expression von ITGA4 und die endotheliale Lamellipodienbildung regulieren können. 2) Diese Faktoren (Faktor $\mathrm{x}$ ) wirken den ITGA4-induzierenden Eigenschaften von GBP-1 entgegen, indem sie a) einen erhöhten Abbau der itga4 mRNA im Zytoplasma hervorrufen oder b) die GBP-1-induzierte itga4 mRNA-Transkription im Zellkern verhindern. Weiterhin ist es auch denkbar, dass eine IFN- $\gamma$-Behandlung der Zellen dazu führt, dass wichtige Faktoren (Faktor z), welche für die GBP-1-vermittelte Induktion von ITGA4 notwendig sind, abgeschalten werden und somit der Zelle für die itga4 mRNA-Transkription nicht mehr zur Verfügung stehen. 3) Darüber hinaus können diese Faktoren (Faktor y) anhand eines noch unbekannten, ITGA4-unabhängigen Mechanismus die Polymerisation des Aktinzytoskeletts und somit die Lamellipodienbildung von EZ hemmen. Proteine/Faktoren, welche nach einer IFN- $\gamma$-Stimulation im Vergleich zu IL-1 $\beta /$ TNF- $\alpha$-behandelten EZ durch GBP-1 nicht induziert bzw. aktiviert werden sind in hellgrau dargestellt. 


\subsection{Die Bedeutung der GBP-1-abhängigen ITGA4-Expression in Endothelzellen im Kontext einer Entzündungsreaktion unter physiologischen Bedingungen}

Neben den inhibitorischen Eigenschaften von ITGA4 auf die Rac-Aktivierung konnte für die zytoplasmatische Domäne von ITGA4 auch ein positiver Einfluss auf die Aktivität der kleinen GTPase Rac nachgewiesen werden. Es konnte gezeigt werden, dass die Phosphorylierung von ITGA4 an einem Serinrest an Position $+988\left(\mathrm{Ser}^{988}\right)$ dazu führt, dass die Bindung der zytoplasmatischen Domäne mit Paxillin in vitro und in vivo verhindert wird (Han et al., 2001). Folglich kommt es zu einer Rac-Aktivierung und zu einer gesteigerten Migration der Zellen (Goldfinger et al., 2003; Han et al., 2003; Nishiya et al., 2005). Verantwortlich für diese Phosphorylierung von ITGA4, welche vor allem an der Frontseite von migrierenden Zellen zu beobachten ist (Goldfinger et al., 2003), ist die Proteinkinase A (PKA) (Han et al., 2001).

Unter physiologischen Bedingungen sind die EZ eines Blutgefäßes aufgrund des ständigen Blutstroms Scherkräften von ungefähr $20 \mathrm{dyn} / \mathrm{cm}^{2}\left(1 \mathrm{dyn} / \mathrm{cm}^{2}=0,1 \mathrm{~Pa}\right)$ ausgesetzt (Lipowsky et al., 1978; Pries et al., 1998). Diese Kräfte können während einer Entzündungsreaktion um das 2- bis 3-fache ansteigen (He et al., 2002; West et al., 2002). Es konnte gezeigt werden, dass in EZ die PKA-vermittelte Phosphorylierung der zytoplasmatischen Domäne von ITGA4 durch das Einwirken dieser Scherkräfte auf die Zellen induziert wird (Goldfinger et al., 2008). Dies hat zur Folge das Rac am stromabwärts gelegenen Ende der EZ aktiviert wird, es zu einer Reorganisation des Aktinzytoskeletts kommt, sich die EZ entlang des Strömungsflusses ausrichten und ein verstärktes Migrationsverhalten aufweisen.

Aufgrund dieser Strömungs-abhängigen Regulation der PKA in EZ könnte eine Entzündungsreaktion im physiologischen Kontext, wie z.B. nach einer Verletzung und im Hinblick auf die GBP-1-abhängige Expression von ITGA4 wie folgt ablaufen. Hohe Konzentrationen an IL-1 $\beta$ und TNF- $\alpha$ führen zur Aktivierung der EZ, wodurch sich deren Expressionsprofil verändert (Mantovani et al., 1992; Mantovani et al., 1998). Beispielsweise wird die Expression von Adhäsionsmolekülen (z.B. ICAM-1, VCAM-1 und E-Selektin) in den EZ induziert, so dass die endotheliale Adhäsionskompetenz für die im Blutstrom zirkulierenden Leukozyten stark erhöht ist und eine Auswanderung der Leukozyten in das entzündliche Gewebe ermöglicht wird (Hession et al., 1990; Zhang et al., 2006). Weiterhin 
wird auch die Synthese von GBP-1 induziert (Guenzi et al., 2001; Lubeseder-Martellato et al., 2002) und es kommt folglich zu einer verstärkten ITGA4-Expression in den EZ (Ergebnisse dieser Arbeit). Unter den gesteigerten Strömungsbedingungen würden aufgrund der Strömungs-sensitiven PKA und der verstärkten ITGA4-Expression die EZ ein erhöhtes Migrationsverhalten aufweisen. Aufgrund der angelagerten Leukozyten kann jedoch angenommen werden, dass während der Entzündungsreaktion die Wirkung des Strömungsstress auf die EZ stark verringert ist. Dies hat zur Folge, dass die PKA-Aktivität in den EZ abnimmt, Paxillin an die zytoplasmatische Domäne von ITGA4 binden kann und somit die GBP-1-induzierte ITGA4-Expression zu einer Hemmung der endothelialen Lamellipodienbildung und Migration führt. Da die ITGA4-vermittelte Hemmwirkung eine Stabilisierung des Endothels zur Folge hat, kann so eine Auswanderung der Leukozyten in das entzündliche Gewebe gewährleistet werden. Darüber hinaus tragen auch die bereits gezeigten antiproliferativen und antiinvasiven Eigenschaften von GBP-1 zur Gefäßstabilisierung während der Entzündungsreaktion bei (Guenzi et al., 2001; Guenzi et al., 2003). Nachdem alle Erreger im entzündlichen Gewebe von den ausgewanderten Leukozyten durch Phagozytose beseitigt worden sind und die Entzündung am Abklingen ist, beginnt die Phase der Wundheilung, bei dem die Angiogenese eine wichtige Rolle spielt (Gillitzer and Goebeler, 2001; Griffioen and Molema, 2000). Es kann spekuliert werden, dass in dieser Phase die Hemmung der ITGA4-vermittelten endothelialen Lamellipodienbildung und Migration aufgrund der nun wieder massiv einwirkenden Scherkräfte des Blutstroms auf die EZ aufgehoben ist. ITGA4 kann durch die Strömungs-abhängige PKA erneut phosphoryliert werden (Goldfinger et al., 2008) und eine verstärkte Migration der EZ in das neu zu vaskularisierende Gewebe findet statt. Darüber hinaus wird bei der Auflösung der Entzündung von den ausgewanderten Monozyten verstärkt VEGF sekretiert (Dvorak et al., 1995; Sunderkotter et al., 1994). Diese Sekretion wirkt sowohl der GBP-1-Expression in den EZ, als auch den antiangiogenen Eigenschaften von GBP-1 entgegen (Guenzi et al., 2001; Guenzi et al., 2003). In Folge dessen kommt es neben der Migration zu einer erhöhten Proliferationsrate der EZ und schließlich zu einer vermehrten Gefäßneubildung in den verwundeten Bereichen. 


\section{Literaturverzeichnis}

Aebi, M., Fah, J., Hurt, N., Samuel, C.E., Thomis, D., Bazzigher, L., Pavlovic, J., Haller, O. and Staeheli, P. (1989) cDNA structures and regulation of two interferon-induced human $\mathrm{Mx}$ proteins. Mol Cell Biol, 9, 5062-5072.

Ahmed, C.M., Burkhart, M.A., Mujtaba, M.G., Subramaniam, P.S. and Johnson, H.M. (2003) The role of IFNgamma nuclear localization sequence in intracellular function. J Cell Sci, 116, 3089-3098.

Anderson, S.L., Carton, J.M., Lou, J., Xing, L. and Rubin, B.Y. (1999) Interferon-induced guanylate binding protein-1 (GBP-1) mediates an antiviral effect against vesicular stomatitis virus and encephalomyocarditis virus. Virology, 256, 8-14.

Asahara, T., Masuda, H., Takahashi, T., Kalka, C., Pastore, C., Silver, M., Kearne, M., Magner, M. and Isner, J.M. (1999) Bone marrow origin of endothelial progenitor cells responsible for postnatal vasculogenesis in physiological and pathological neovascularization. Circ Res, 85, 221-228.

Bazzoni, G., Dejana, E. and Lampugnani, M.G. (1999) Endothelial adhesion molecules in the development of the vascular tree: the garden of forking paths. Curr Opin Cell Biol, 11, 573581 .

Bevilacqua, M.P., Pober, J.S., Majeau, G.R., Cotran, R.S. and Gimbrone, M.A., Jr. (1984) Interleukin 1 (IL-1) induces biosynthesis and cell surface expression of procoagulant activity in human vascular endothelial cells. J Exp Med, 160, 618-623.

Boehm, U., Klamp, T., Groot, M. and Howard, J.C. (1997) Cellular responses to interferongamma. Annu Rev Immunol, 15, 749-795.

Bouck, N. (1990) Tumor angiogenesis: the role of oncogenes and tumor suppressor genes. Cancer Cells, 2, 179-185.

Boyer, L., Travaglione, S., Falzano, L., Gauthier, N.C., Popoff, M.R., Lemichez, E., Fiorentini, C. and Fabbri, A. (2004) Rac GTPase instructs nuclear factor-kappaB activation by conveying the SCF complex and IkBalpha to the ruffling membranes. Mol Biol Cell, 15, 1124-1133.

Brezinschek, R.I., Brezinschek, H.P., Lazarovits, A.I., Lipsky, P.E. and Oppenheimer-Marks, N. (1996) Expression of the beta 7 integrin by human endothelial cells. Am J Pathol, 149, 1651-1660.

Brooks, P.C., Clark, R.A. and Cheresh, D.A. (1994a) Requirement of vascular integrin alpha $\mathrm{v}$ beta 3 for angiogenesis. Science, 264, 569-571. 
Brooks, P.C., Montgomery, A.M., Rosenfeld, M., Reisfeld, R.A., Hu, T., Klier, G. and Cheresh, D.A. (1994b) Integrin alpha $\mathrm{v}$ beta 3 antagonists promote tumor regression by inducing apoptosis of angiogenic blood vessels. Cell, 79, 1157-1164.

Carmeliet, P. (2000) Mechanisms of angiogenesis and arteriogenesis. Nat Med, 6, 389-395.

Carmeliet, P. (2003) Angiogenesis in health and disease. Nat Med, 9, 653-660.

Carmeliet, P. (2005) VEGF as a key mediator of angiogenesis in cancer. Oncology, 69 Suppl 3, 4-10.

Carmeliet, P. and Jain, R.K. (2000) Angiogenesis in cancer and other diseases. Nature, 407, 249-257.

Carter, C.C., Gorbacheva, V.Y. and Vestal, D.J. (2005) Inhibition of VSV and EMCV replication by the interferon-induced GTPase, mGBP-2: differential requirement for wild-type GTP binding domain. Arch Virol, 150, 1213-1220.

Chan, B.M., Kassner, P.D., Schiro, J.A., Byers, H.R., Kupper, T.S. and Hemler, M.E. (1992) Distinct cellular functions mediated by different VLA integrin alpha subunit cytoplasmic domains. Cell, 68, 1051-1060.

Chen, C.A. and Okayama, H. (1988) Calcium phosphate-mediated gene transfer: a highly efficient transfection system for stably transforming cells with plasmid DNA. Biotechniques, 6, 632-638.

Cheng, Y.S., Colonno, R.J. and Yin, F.H. (1983) Interferon induction of fibroblast proteins with guanylate binding activity. $J$ Biol Chem, 258, 7746-7750.

Clark, E.A., King, W.G., Brugge, J.S., Symons, M. and Hynes, R.O. (1998) Integrin-mediated signals regulated by members of the rho family of GTPases. J Cell Biol, 142, 573-586.

Clemetson, K.J. and Clemetson, J.M. (1998) Integrins and cardiovascular disease. Cell Mol Life Sci, 54, 502-513.

Collins, T., Read, M.A., Neish, A.S., Whitley, M.Z., Thanos, D. and Maniatis, T. (1995) Transcriptional regulation of endothelial cell adhesion molecules: NF-kappa B and cytokineinducible enhancers. FASEB J, 9, 899-909.

Conway, E.M., Collen, D. and Carmeliet, P. (2001) Molecular mechanisms of blood vessel growth. Cardiovasc Res, 49, 507-521.

Cotran, R.S. and Pober, J.S. (1990) Cytokine-endothelial interactions in inflammation, immunity, and vascular injury. J Am Soc Nephrol, 1, 225-235. 
Cozzolino, F., Torcia, M., Aldinucci, D., Ziche, M., Almerigogna, F., Bani, D. and Stern, D.M. (1990) Interleukin 1 is an autocrine regulator of human endothelial cell growth. Proc Natl Acad Sci U S A, 87, 6487-6491.

Cramer, T. and Johnson, R.S. (2003) A novel role for the hypoxia inducible transcription factor HIF-1alpha: critical regulation of inflammatory cell function. Cell Cycle, 2, 192-193.

Curfs, J.H., Meis, J.F. and Hoogkamp-Korstanje, J.A. (1997) A primer on cytokines: sources, receptors, effects, and inducers. Clin Microbiol Rev, 10, 742-780.

Darville, M.I. and Eizirik, D.L. (2001) Cytokine induction of Fas gene expression in insulinproducing cells requires the transcription factors NF-kappaB and C/EBP. Diabetes, 50, 17411748 .

Decker, T., Lew, D.J. and Darnell, J.E., Jr. (1991) Two distinct alpha-interferon-dependent signal transduction pathways may contribute to activation of transcription of the guanylatebinding protein gene. Mol Cell Biol, 11, 5147-5153.

Degrandi, D., Konermann, C., Beuter-Gunia, C., Kresse, A., Wurthner, J., Kurig, S., Beer, S. and Pfeffer, K. (2007) Extensive Characterization of IFN-Induced GTPases mGBP1 to mGBP10 Involved in Host Defense. J Immunol, 179, 7729-7740.

Denekamp, J. (1984) Vascular endothelium as the vulnerable element in tumours. Acta Radiol Oncol, 23, 217-225.

Dharmawardhane, S., Sanders, L.C., Martin, S.S., Daniels, R.H. and Bokoch, G.M. (1997) Localization of p21-activated kinase 1 (PAK1) to pinocytic vesicles and cortical actin structures in stimulated cells. J Cell Biol, 138, 1265-1278.

Diatloff-Zito, C., Gordon, A.J., Duchaud, E. and Merlin, G. (1995) Isolation of an ubiquitously expressed cDNA encoding human dynamin II, a member of the large GTPbinding protein family. Gene, 163, 301-306.

Dow, J.K. and deVere White, R.W. (2000) Fibroblast growth factor 2: its structure and property, paracrine function, tumor angiogenesis, and prostate-related mitogenic and oncogenic functions. Urology, 55, 800-806.

Dvorak, H.F., Brown, L.F., Detmar, M. and Dvorak, A.M. (1995) Vascular permeability factor/vascular endothelial growth factor, microvascular hyperpermeability, and angiogenesis. Am J Pathol, 146, 1029-1039.

Eliceiri, B.P., Paul, R., Schwartzberg, P.L., Hood, J.D., Leng, J. and Cheresh, D.A. (1999) Selective requirement for Src kinases during VEGF-induced angiogenesis and vascular permeability. Mol Cell, 4, 915-924.

Elkin, M., Ilan, N., Ishai-Michaeli, R., Friedmann, Y., Papo, O., Pecker, I. and Vlodavsky, I. (2001) Heparanase as mediator of angiogenesis: mode of action. FASEB J, 15, 1661-1663. 
Enaida, H., Ito, T., Oshima, Y., Sakamoto, T., Yago, K., Kato, K. and Kochi, H. (1998) Effect of growth factors on expression of integrin subtypes in microvascular endothelial cells isolated from bovine retinas. Fukushima J Med Sci, 44, 43-52.

Etienne-Manneville, S. and Hall, A. (2002) Rho GTPases in cell biology. Nature, 420, 629635.

Frater-Schroder, M., Risau, W., Hallmann, R., Gautschi, P. and Bohlen, P. (1987) Tumor necrosis factor type alpha, a potent inhibitor of endothelial cell growth in vitro, is angiogenic in vivo. Proc Natl Acad Sci U S A, 84, 5277-5281.

Friesel, R., Komoriya, A. and Maciag, T. (1987) Inhibition of endothelial cell proliferation by gamma-interferon. J Cell Biol, 104, 689-696.

Gale, N.W. and Yancopoulos, G.D. (1999) Growth factors acting via endothelial cell-specific receptor tyrosine kinases: VEGFs, angiopoietins, and ephrins in vascular development. Genes Dev, 13, 1055-1066.

George, E.L., Baldwin, H.S. and Hynes, R.O. (1997) Fibronectins are essential for heart and blood vessel morphogenesis but are dispensable for initial specification of precursor cells. Blood, 90, 3073-3081.

George, E.L., Georges-Labouesse, E.N., Patel-King, R.S., Rayburn, H. and Hynes, R.O. (1993) Defects in mesoderm, neural tube and vascular development in mouse embryos lacking fibronectin. Development, 119, 1079-1091.

Gillitzer, R. and Goebeler, M. (2001) Chemokines in cutaneous wound healing. J Leukoc Biol, 69, 513-521.

Goldfinger, L.E., Han, J., Kiosses, W.B., Howe, A.K. and Ginsberg, M.H. (2003) Spatial restriction of alpha4 integrin phosphorylation regulates lamellipodial stability and alpha4beta1-dependent cell migration. J Cell Biol, 162, 731-741.

Goldfinger, L.E., Tzima, E., Stockton, R., Kiosses, W.B., Kinbara, K., Tkachenko, E., Gutierrez, E., Groisman, A., Nguyen, P., Chien, S. and Ginsberg, M.H. (2008) Localized alpha4 integrin phosphorylation directs shear stress-induced endothelial cell alignment. Circ Res, 103, 177-185.

Goumans, M.J., Lebrin, F. and Valdimarsdottir, G. (2003) Controlling the angiogenic switch: a balance between two distinct TGF-b receptor signaling pathways. Trends Cardiovasc Med, 13, 301-307.

Grant, D.S. and Kleinman, H.K. (1997) Regulation of capillary formation by laminin and other components of the extracellular matrix. EXS, 79, 317-333.

Griffioen, A.W. and Molema, G. (2000) Angiogenesis: potentials for pharmacologic intervention in the treatment of cancer, cardiovascular diseases, and chronic inflammation. Pharmacol Rev, 52, 237-268. 
Guenzi, E., Töpolt, K., Cornali, E., Lubeseder-Martellato, C., Jörg, A., Matzen, K., Zietz, C., Kremmer, E., Nappi, F., Schwemmle, M., Hohenadl, C., Barillari, G., Tschachler, E., Monini, P., Ensoli, B. and Stürzl, M. (2001) The helical domain of GBP-1 mediates the inhibition of endothelial cell proliferation by inflammatory cytokines. Embo J, 20, 5568-5577.

Guenzi, E., Töpolt, K., Lubeseder-Martellato, C., Jörg, A., Naschberger, E., Benelli, R., Albini, A. and Stürzl, M. (2003) The guanylate binding protein-1 GTPase controls the invasive and angiogenic capability of endothelial cells through inhibition of MMP-1 expression. Embo J, 22, 3772-3782.

Gupta, S.K., Hassel, T. and Singh, J.P. (1995) A potent inhibitor of endothelial cell proliferation is generated by proteolytic cleavage of the chemokine platelet factor 4. Proc Natl Acad Sci U S A, 92, 7799-7803.

Han, J., Liu, S., Rose, D.M., Schlaepfer, D.D., McDonald, H. and Ginsberg, M.H. (2001) Phosphorylation of the integrin alpha 4 cytoplasmic domain regulates paxillin binding. $J$ Biol Chem, 276, 40903-40909.

Han, J., Rose, D.M., Woodside, D.G., Goldfinger, L.E. and Ginsberg, M.H. (2003) Integrin alpha 4 beta 1-dependent $\mathrm{T}$ cell migration requires both phosphorylation and dephosphorylation of the alpha 4 cytoplasmic domain to regulate the reversible binding of paxillin. $J$ Biol Chem, 278, 34845-34853.

Haque, S.J. and Williams, B.R. (1998) Signal transduction in the interferon system. Semin Oncol, 25, 14-22.

He, C., Young, A.J., West, C.A., Su, M., Konerding, M.A. and Mentzer, S.J. (2002) Stimulation of regional lymphatic and blood flow by epicutaneous oxazolone. J Appl Physiol, 93, 966-973.

Hernandez-Perera, O., Perez-Sala, D., Soria, E. and Lamas, S. (2000) Involvement of Rho GTPases in the transcriptional inhibition of preproendothelin-1 gene expression by simvastatin in vascular endothelial cells. Circ Res, 87, 616-622.

Hession, C., Osborn, L., Goff, D., Chi-Rosso, G., Vassallo, C., Pasek, M., Pittack, C., Tizard, R., Goelz, S., McCarthy, K. and et al. (1990) Endothelial leukocyte adhesion molecule 1: direct expression cloning and functional interactions. Proc Natl Acad Sci U S A, 87, 16731677.

Hill, C.S., Wynne, J. and Treisman, R. (1995) The Rho family GTPases RhoA, Rac1, and CDC42Hs regulate transcriptional activation by SRF. Cell, 81, 1159-1170.

Hood, J.D. and Cheresh, D.A. (2002) Role of integrins in cell invasion and migration. Nat Rev Cancer, 2, 91-100.

Hynes, R.O. (1992) Integrins: versatility, modulation, and signaling in cell adhesion. Cell, 69, $11-25$. 
Hynes, R.O. (2002) Integrins: bidirectional, allosteric signaling machines. Cell, 110, 673-687.

Hynes, R.O. (2007) Cell-matrix adhesion in vascular development. J Thromb Haemost, 5 Suppl 1, 32-40.

Hynes, R.O. and Bader, B.L. (1997) Targeted mutations in integrins and their ligands: their implications for vascular biology. Thromb Haemost, 78, 83-87.

Ignatoski, K.M., Maehama, T., Markwart, S.M., Dixon, J.E., Livant, D.L. and Ethier, S.P. (2000) ERBB-2 overexpression confers PI 3' kinase-dependent invasion capacity on human mammary epithelial cells. Br J Cancer, 82, 666-674.

Jia, Y., Zeng, Z.Z., Markwart, S.M., Rockwood, K.F., Ignatoski, K.M., Ethier, S.P. and Livant, D.L. (2004) Integrin fibronectin receptors in matrix metalloproteinase-1-dependent invasion by breast cancer and mammary epithelial cells. Cancer Res, 64, 8674-8681.

Jin, H., Li, W., Yang, R., Ogasawara, A., Lu, H. and Paoni, N.F. (2005) Inhibitory effects of interferon-gamma on myocardial hypertrophy. Cytokine, 31, 405-414.

Jin, H. and Varner, J. (2004) Integrins: roles in cancer development and as treatment targets. Br J Cancer, 90, 561-565.

Juliano, R.L. (2002) Signal transduction by cell adhesion receptors and the cytoskeleton: functions of integrins, cadherins, selectins, and immunoglobulin-superfamily members. Annu Rev Pharmacol Toxicol, 42, 283-323.

Kassner, P.D., Alon, R., Springer, T.A. and Hemler, M.E. (1995) Specialized functional properties of the integrin alpha 4 cytoplasmic domain. Mol Biol Cell, 6, 661-674.

Kerr, J.R. (1999) Cell adhesion molecules in the pathogenesis of and host defence against microbial infection. Mol Pathol, 52, 220-230.

Kim, S., Bell, K., Mousa, S.A. and Varner, J.A. (2000a) Regulation of angiogenesis in vivo by ligation of integrin alpha5betal with the central cell-binding domain of fibronectin. $\mathrm{Am} J$ Pathol, 156, 1345-1362.

Kim, S., Harris, M. and Varner, J.A. (2000b) Regulation of integrin alpha vbeta 3-mediated endothelial cell migration and angiogenesis by integrin alpha5beta1 and protein kinase A. $J$ Biol Chem, 275, 33920-33928.

Kirschner, K.M., Wagner, N., Wagner, K.D., Wellmann, S. and Scholz, H. (2006) The Wilms tumor suppressor Wt1 promotes cell adhesion through transcriptional activation of the alpha4integrin gene. J Biol Chem, 281, 31930-31939.

Koblizek, T.I., Weiss, C., Yancopoulos, G.D., Deutsch, U. and Risau, W. (1998) Angiopoietin-1 induces sprouting angiogenesis in vitro. Curr Biol, 8, 529-532. 
Kraynack, N.C., Corey, D.A., Elmer, H.L. and Kelley, T.J. (2002) Mechanisms of NOS2 regulation by Rho GTPase signaling in airway epithelial cells. Am J Physiol Lung Cell Mol Physiol, 283, L604-611.

Kroger, A., Koster, M., Schroeder, K., Hauser, H. and Mueller, P.P. (2002) Activities of IRF1. J Interferon Cytokine Res, 22, 5-14.

Laemmli, U.K. (1970) Cleavage of structural proteins during the assembly of the head of bacteriophage T4. Nature, 227, 680-685.

Larrick, J.W. and Kunkel, S.L. (1988) The role of tumor necrosis factor and interleukin 1 in the immunoinflammatory response. Pharm Res, 5, 129-139.

Lauffenburger, D.A. and Horwitz, A.F. (1996) Cell migration: a physically integrated molecular process. Cell, 84, 359-369.

Ledebur, H.C. and Parks, T.P. (1995) Transcriptional regulation of the intercellular adhesion molecule-1 gene by inflammatory cytokines in human endothelial cells. Essential roles of a variant NF-kappa B site and p65 homodimers. J Biol Chem, 270, 933-943.

Leeuwenberg, J.F., von Asmuth, E.J., Jeunhomme, T.M. and Buurman, W.A. (1990) IFNgamma regulates the expression of the adhesion molecule ELAM-1 and IL-6 production by human endothelial cells in vitro. J Immunol, 145, 2110-2114.

Legler, G., Muller-Platz, C.M., Mentges-Hettkamp, M., Pflieger, G. and Julich, E. (1985) On the chemical basis of the Lowry protein determination. Anal Biochem, 150, 278-287.

Liotta, L.A., Steeg, P.S. and Stetler-Stevenson, W.G. (1991) Cancer metastasis and angiogenesis: an imbalance of positive and negative regulation. Cell, 64, 327-336.

Lipowsky, H.H., Kovalcheck, S. and Zweifach, B.W. (1978) The distribution of blood rheological parameters in the microvasculature of cat mesentery. Circ Res, 43, 738-749.

Liu, S., Thomas, S.M., Woodside, D.G., Rose, D.M., Kiosses, W.B., Pfaff, M. and Ginsberg, M.H. (1999) Binding of paxillin to alpha4 integrins modifies integrin-dependent biological responses. Nature, 402, 676-681.

Livant, D.L., Brabec, R.K., Kurachi, K., Allen, D.L., Wu, Y., Haaseth, R., Andrews, P., Ethier, S.P. and Markwart, S. (2000) The PHSRN sequence induces extracellular matrix invasion and accelerates wound healing in obese diabetic mice. J Clin Invest, 105, 1537-1545.

Lubeseder-Martellato, C., Guenzi, E., Jörg, A., Töpolt, K., Naschberger, E., Kremmer, E., Zietz, C., Tschachler, E., Hutzler, P., Schwemmle, M., Matzen, K., Grimm, T., Ensoli, B. and Stürzl, M. (2002) Guanylate-binding protein-1 expression is selectively induced by inflammatory cytokines and is an activation marker of endothelial cells during inflammatory diseases. Am J Pathol, 161, 1749-1759. 
Luscinskas, F.W. and Lawler, J. (1994) Integrins as dynamic regulators of vascular function. FASEB J, 8, 929-938.

Maisonpierre, P.C., Suri, C., Jones, P.F., Bartunkova, S., Wiegand, S.J., Radziejewski, C., Compton, D., McClain, J., Aldrich, T.H., Papadopoulos, N., Daly, T.J., Davis, S., Sato, T.N. and Yancopoulos, G.D. (1997) Angiopoietin-2, a natural antagonist for Tie2 that disrupts in vivo angiogenesis. Science, 277, 55-60.

Mantovani, A., Bussolino, F. and Dejana, E. (1992) Cytokine regulation of endothelial cell function. Faseb J, 6, 2591-2599.

Mantovani, A., Garlanda, C., Introna, M. and Vecchi, A. (1998) Regulation of endothelial cell function by pro- and anti-inflammatory cytokines. Transplant Proc, 30, 4239-4243.

Markowitz, D., Goff, S. and Bank, A. (1988) A safe packaging line for gene transfer: separating viral genes on two different plasmids. J Virol, 62, 1120-1124.

Miller, A.D., Garcia, J.V., von Suhr, N., Lynch, C.M., Wilson, C. and Eiden, M.V. (1991) Construction and properties of retrovirus packaging cells based on gibbon ape leukemia virus. J Virol, 65, 2220-2224.

Milner, R. and Campbell, I.L. (2006) Increased expression of the beta4 and alpha5 integrin subunits in cerebral blood vessels of transgenic mice chronically producing the proinflammatory cytokines IL-6 or IFN-alpha in the central nervous system. Mol Cell Neurosci, 33, 429-440.

Morgenstern, J.P. and Land, H. (1990) Advanced mammalian gene transfer: high titre retroviral vectors with multiple drug selection markers and a complementary helper-free packaging cell line. Nucleic Acids Res, 18, 3587-3596.

Mostafavi-Pour, Z., Askari, J.A., Parkinson, S.J., Parker, P.J., Ng, T.T. and Humphries, M.J. (2003) Integrin-specific signaling pathways controlling focal adhesion formation and cell migration. J Cell Biol, 161, 155-167.

Mullis, K.B. and Faloona, F.A. (1987) Specific synthesis of DNA in vitro via a polymerasecatalyzed chain reaction. Methods Enzymol, 155, 335-350.

Nakajima, M., Irimura, T. and Nicolson, G.L. (1988) Heparanases and tumor metastasis. $J$ Cell Biochem, 36, 157-167.

Nantais, D.E., Schwemmle, M., Stickney, J.T., Vestal, D.J. and Buss, J.E. (1996) Prenylation of an interferon-gamma-induced GTP-binding protein: the human guanylate binding protein, huGBP1. J Leukoc Biol, 60, 423-431.

Naschberger, E., Lubeseder-Martellato, C., Meyer, N., Gessner, R., Kremmer, E., Gessner, A. and Stürzl, M. (2006) Human guanylate binding protein-1 is a secreted GTPase present in increased concentrations in the cerebrospinal fluid of patients with bacterial meningitis. $\mathrm{Am} J$ Pathol, 169, 1088-1099. 
Naschberger, E., Werner, T., Vicente, A.B., Guenzi, E., Töpolt, K., Leubert, R., LubesederMartellato, C., Nelson, P.J. and Stürzl, M. (2004) Nuclear factor-kappaB motif and interferonalpha-stimulated response element co-operate in the activation of guanylate-binding protein-1 expression by inflammatory cytokines in endothelial cells. Biochem J, 379, 409-420.

Nawroth, P.P. and Stern, D.M. (1986) Modulation of endothelial cell hemostatic properties by tumor necrosis factor. $J$ Exp Med, 163, 740-745.

Neish, A.S., Read, M.A., Thanos, D., Pine, R., Maniatis, T. and Collins, T. (1995) Endothelial interferon regulatory factor 1 cooperates with NF-kappa B as a transcriptional activator of vascular cell adhesion molecule 1. Mol Cell Biol, 15, 2558-2569.

Nelson, A.R., Fingleton, B., Rothenberg, M.L. and Matrisian, L.M. (2000) Matrix metalloproteinases: biologic activity and clinical implications. J Clin Oncol, 18, 1135-1149.

Nicosia, R.F., Bonanno, E. and Smith, M. (1993) Fibronectin promotes the elongation of microvessels during angiogenesis in vitro. $J$ Cell Physiol, 154, 654-661.

Nishiya, N., Kiosses, W.B., Han, J. and Ginsberg, M.H. (2005) An alpha4 integrin-paxillinArf-GAP complex restricts Rac activation to the leading edge of migrating cells. Nat Cell Biol, 7, 343-352.

Nobes, C.D. and Hall, A. (1995) Rho, rac, and cdc42 GTPases regulate the assembly of multimolecular focal complexes associated with actin stress fibers, lamellipodia, and filopodia. Cell, 81, 53-62.

O'Reilly, M.S., Holmgren, L., Shing, Y., Chen, C., Rosenthal, R.A., Moses, M., Lane, W.S., Cao, Y., Sage, E.H. and Folkman, J. (1994) Angiostatin: a novel angiogenesis inhibitor that mediates the suppression of metastases by a Lewis lung carcinoma. Cell, 79, 315-328.

Olszewski, M.A., Gray, J. and Vestal, D.J. (2006) In silico genomic analysis of the human and murine guanylate-binding protein (GBP) gene clusters. J Interferon Cytokine Res, 26, 328-352.

Osborn, L., Kunkel, S. and Nabel, G.J. (1989) Tumor necrosis factor alpha and interleukin 1 stimulate the human immunodeficiency virus enhancer by activation of the nuclear factor kappa B. Proc Natl Acad Sci U S A, 86, 2336-2340.

Ostman, A. (2004) PDGF receptors-mediators of autocrine tumor growth and regulators of tumor vasculature and stroma. Cytokine Growth Factor Rev, 15, 275-286.

Pankov, R. and Yamada, K.M. (2002) Fibronectin at a glance. J Cell Sci, 115, 3861-3863.

Patan, S., Haenni, B. and Burri, P.H. (1996) Implementation of intussusceptive microvascular growth in the chicken chorioallantoic membrane (CAM): 1. pillar formation by folding of the capillary wall. Microvasc Res, 51, 80-98. 
Pellegrini, S. and Dusanter-Fourt, I. (1997) The structure, regulation and function of the Janus kinases (JAKs) and the signal transducers and activators of transcription (STATs). Eur $J$ Biochem, 248, 615-633.

Pepper, M.S. (1996) Positive and negative regulation of angiogenesis: from cell biology to the clinic. Vasc Med, 1, 259-266.

Plate, K.H., Breier, G., Weich, H.A. and Risau, W. (1992) Vascular endothelial growth factor is a potential tumour angiogenesis factor in human gliomas in vivo. Nature, 359, 845-848.

Plow, E.F., Haas, T.A., Zhang, L., Loftus, J. and Smith, J.W. (2000) Ligand binding to integrins. J Biol Chem, 275, 21785-21788.

Pober, J.S. and Cotran, R.S. (1990) Cytokines and endothelial cell biology. Physiol Rev, 70, 427-451.

Pober, J.S., Gimbrone, M.A., Jr., Lapierre, L.A., Mendrick, D.L., Fiers, W., Rothlein, R. and Springer, T.A. (1986) Overlapping patterns of activation of human endothelial cells by interleukin 1, tumor necrosis factor, and immune interferon. J Immunol, 137, 1893-1896.

Postigo, A.A., Sheppard, A.M., Mucenski, M.L. and Dean, D.C. (1997) c-Myb and Ets proteins synergize to overcome transcriptional repression by ZEB. EMBO J, 16, 3924-3934.

Praefcke, G.J., Geyer, M., Schwemmle, M., Robert Kalbitzer, H. and Herrmann, C. (1999) Nucleotide-binding characteristics of human guanylate-binding protein 1 (hGBP1) and identification of the third GTP-binding motif. J Mol Biol, 292, 321-332.

Praefcke, G.J., Kloep, S., Benscheid, U., Lilie, H., Prakash, B. and Herrmann, C. (2004) Identification of residues in the human guanylate-binding protein 1 critical for nucleotide binding and cooperative GTP hydrolysis. J Mol Biol, 344, 257-269.

Prakash, B., Praefcke, G.J., Renault, L., Wittinghofer, A. and Herrmann, C. (2000a) Structure of human guanylate-binding protein 1 representing a unique class of GTP-binding proteins. Nature, 403, 567-571.

Prakash, B., Renault, L., Praefcke, G.J., Herrmann, C. and Wittinghofer, A. (2000b) Triphosphate structure of guanylate-binding protein 1 and implications for nucleotide binding and GTPase mechanism. Embo J, 19, 4555-4564.

Pries, A.R., Secomb, T.W. and Gaehtgens, P. (1998) Structural adaptation and stability of microvascular networks: theory and simulations. Am J Physiol, 275, H349-360.

Raucher, D. and Sheetz, M.P. (2000) Cell spreading and lamellipodial extension rate is regulated by membrane tension. $J$ Cell Biol, 148, 127-136.

Ren, X.D., Kiosses, W.B. and Schwartz, M.A. (1999) Regulation of the small GTP-binding protein Rho by cell adhesion and the cytoskeleton. EMBO J, 18, 578-585. 
Ridley, A.J. (2001) Cyclin' round the cell with Rac. Dev Cell, 1, 160-161.

Ridley, A.J., Schwartz, M.A., Burridge, K., Firtel, R.A., Ginsberg, M.H., Borisy, G., Parsons, J.T. and Horwitz, A.R. (2003) Cell migration: integrating signals from front to back. Science, 302, 1704-1709.

Risau, W. (1997) Mechanisms of angiogenesis. Nature, 386, 671-674.

Rodriguez-Manzaneque, J.C., Lane, T.F., Ortega, M.A., Hynes, R.O., Lawler, J. and IruelaArispe, M.L. (2001) Thrombospondin-1 suppresses spontaneous tumor growth and inhibits activation of matrix metalloproteinase-9 and mobilization of vascular endothelial growth factor. Proc Natl Acad Sci U S A, 98, 12485-12490.

Rosen, G.D., Barks, J.L., Iademarco, M.F., Fisher, R.J. and Dean, D.C. (1994) An intricate arrangement of binding sites for the Ets family of transcription factors regulates activity of the alpha 4 integrin gene promoter. $J$ Biol Chem, 269, 15652-15660.

Ruegg, C., Dormond, O. and Mariotti, A. (2004) Endothelial cell integrins and COX-2: mediators and therapeutic targets of tumor angiogenesis. Biochim Biophys Acta, 1654, 51-67.

Ruegg, C. and Mariotti, A. (2003) Vascular integrins: pleiotropic adhesion and signaling molecules in vascular homeostasis and angiogenesis. Cell Mol Life Sci, 60, 1135-1157.

Rupp, P.A. and Little, C.D. (2001) Integrins in vascular development. Circ Res, 89, 566-572.

Samuel, C.E. (2001) Antiviral actions of interferons. Clin Microbiol Rev, 14, 778-809, table of contents.

Sanger, F., Nicklen, S. and Coulson, A.R. (1977) DNA sequencing with chain-terminating inhibitors. Proc Natl Acad Sci U S A, 74, 5463-5467.

Sauder, D.N. (1989) Interleukin 1. Arch Dermatol, 125, 679-682.

Schindler, U. and Baichwal, V.R. (1994) Three NF-kappa B binding sites in the human Eselectin gene required for maximal tumor necrosis factor alpha-induced expression. Mol Cell Biol, 14, 5820-5831.

Schonherr, E. and Hausser, H.J. (2000) Extracellular matrix and cytokines: a functional unit. Dev Immunol, 7, 89-101.

Schubert, S.W., Lamoureux, N., Kilian, K., Klein-Hitpass, L. and Hashemolhosseini, S. (2008) Identification of integrin-alpha4, Rb1, and syncytin a as murine placental target genes of the transcription factor GCMa/Gcm1. J Biol Chem, 283, 5460-5465.

Schweigerer, L., Malerstein, B. and Gospodarowicz, D. (1987) Tumor necrosis factor inhibits the proliferation of cultured capillary endothelial cells. Biochem Biophys Res Commun, 143, 997-1004. 
Schwemmle, M. and Staeheli, P. (1994) The interferon-induced 67-kDa guanylate-binding protein (hGBP1) is a GTPase that converts GTP to GMP. J Biol Chem, 269, 11299-11305.

Serini, G., Valdembri, D. and Bussolino, F. (2006) Integrins and angiogenesis: a sticky business. Exp Cell Res, 312, 651-658.

Shapiro, S.D. (1998) Matrix metalloproteinase degradation of extracellular matrix: biological consequences. Curr Opin Cell Biol, 10, 602-608.

Shu, H.B., Agranoff, A.B., Nabel, E.G., Leung, K., Duckett, C.S., Neish, A.S., Collins, T. and Nabel, G.J. (1993) Differential regulation of vascular cell adhesion molecule 1 gene expression by specific NF-kappa B subunits in endothelial and epithelial cells. Mol Cell Biol, 13, 6283-6289.

Shweiki, D., Itin, A., Soffer, D. and Keshet, E. (1992) Vascular endothelial growth factor induced by hypoxia may mediate hypoxia-initiated angiogenesis. Nature, 359, 843-845.

Spurlock, M.E. (1997) Regulation of metabolism and growth during immune challenge: an overview of cytokine function. J Anim Sci, 75, 1773-1783.

Stetler-Stevenson, W.G. (1999) Matrix metalloproteinases in angiogenesis: a moving target for therapeutic intervention. J Clin Invest, 103, 1237-1241.

Stolpen, A.H., Guinan, E.C., Fiers, W. and Pober, J.S. (1986) Recombinant tumor necrosis factor and immune interferon act singly and in combination to reorganize human vascular endothelial cell monolayers. Am J Pathol, 123, 16-24.

Stupack, D.G. and Cheresh, D.A. (2004) Integrins and angiogenesis. Curr Top Dev Biol, 64, 207-238.

Sunderkotter, C., Steinbrink, K., Goebeler, M., Bhardwaj, R. and Sorg, C. (1994) Macrophages and angiogenesis. J Leukoc Biol, 55, 410-422.

Tripal, P., Bauer, M., Naschberger, E., Mörtinger, T., Hohenadl, C., Cornali, E., Thurau, M. and Stürzl, M. (2007) Unique features of different members of the human guanylate-binding protein family. J Interferon Cytokine Res, 27, 44-52.

van der Flier, A. and Sonnenberg, A. (2001) Function and interactions of integrins. Cell Tissue Res, 305, 285-298.

Veikkola, T., Karkkainen, M., Claesson-Welsh, L. and Alitalo, K. (2000) Regulation of angiogenesis via vascular endothelial growth factor receptors. Cancer Res, 60, 203-212.

Wang, J. and Milner, R. (2006) Fibronectin promotes brain capillary endothelial cell survival and proliferation through alpha5beta1 and alphavbeta3 integrins via MAP kinase signalling. $J$ Neurochem, 96, 148-159. 
West, C.A., He, C., Young, A.J., Su, M., Zhao, T., Swanson, S.J. and Mentzer, S.J. (2002) Spatial variation of plasma flow in the oxazolone-stimulated microcirculation. Inflamm Res, 51, 572-578.

White, E.S., Livant, D.L., Markwart, S. and Arenberg, D.A. (2001) Monocyte-fibronectin interactions, via alpha(5)beta(1) integrin, induce expression of CXC chemokine-dependent angiogenic activity. $J$ Immunol, 167, 5362-5366.

White, E.S., Thannickal, V.J., Carskadon, S.L., Dickie, E.G., Livant, D.L., Markwart, S., Toews, G.B. and Arenberg, D.A. (2003) Integrin alpha4betal regulates migration across basement membranes by lung fibroblasts: a role for phosphatase and tensin homologue deleted on chromosome 10. Am J Respir Crit Care Med, 168, 436-442.

Williams, B.R. (1991) Transcriptional regulation of interferon-stimulated genes. Eur $J$ Biochem, 200, 1-11.

Yancopoulos, G.D., Davis, S., Gale, N.W., Rudge, J.S., Wiegand, S.J. and Holash, J. (2000) Vascular-specific growth factors and blood vessel formation. Nature, 407, 242-248.

Yee, J.K., Friedmann, T. and Burns, J.C. (1994) Generation of high-titer pseudotyped retroviral vectors with very broad host range. Methods Cell Biol, 43 Pt A, 99-112.

Young, H.A. (1996) Regulation of interferon-gamma gene expression. J Interferon Cytokine Res, 16, 563-568.

Zaniolo, K., Leclerc, S., Cvekl, A., Vallieres, L., Bazin, R., Larouche, K. and Guerin, S.L. (2004) Expression of the alpha4 integrin subunit gene promoter is modulated by the transcription factor Pax-6 in corneal epithelial cells. Invest Ophthalmol Vis Sci, 45, 16921704.

Zhang, D.H., Marconi, A., Xu, L.M., Yang, C.X., Sun, G.W., Feng, X.L., Ling, C.Q., Qin, W.Z., Uzan, G. and d'Alessio, P. (2006) Tripterine inhibits the expression of adhesion molecules in activated endothelial cells. J Leukoc Biol, 80, 309-319.

Zhang, Y., Lu, H., Dazin, P. and Kapila, Y. (2004) Functional differences between integrin alpha4 and integrins alpha5/alphav in modulating the motility of human oral squamous carcinoma cells in response to the $\mathrm{V}$ region and heparin-binding domain of fibronectin. Exp Cell Res, 295, 48-58.

Zhu, P.P., Patterson, A., Lavoie, B., Stadler, J., Shoeb, M., Patel, R. and Blackstone, C. (2003) Cellular localization, oligomerization, and membrane association of the hereditary spastic paraplegia 3A (SPG3A) protein atlastin. J Biol Chem, 278, 49063-49071.

Ziche, M., Morbidelli, L., Masini, E., Amerini, S., Granger, H.J., Maggi, C.A., Geppetti, P. and Ledda, F. (1994) Nitric oxide mediates angiogenesis in vivo and endothelial cell growth and migration in vitro promoted by substance P. J Clin Invest, 94, 2036-2044. 
Zinn, K., DiMaio, D. and Maniatis, T. (1983) Identification of two distinct regulatory regions adjacent to the human beta-interferon gene. Cell, 34, 865-879.

Zoja, C., Orisio, S., Perico, N., Benigni, A., Morigi, M., Benatti, L., Rambaldi, A. and Remuzzi, G. (1991) Constitutive expression of endothelin gene in cultured human mesangial cells and its modulation by transforming growth factor-beta, thrombin, and a thromboxane A2 analogue. Lab Invest, 64, 16-20. 


\section{Abkürzungsverzeichnis}

Abb.

Ang

APS

ATP

bFGF

BM

BSA

cDNA

C/EBP

cRNA

CTP

DMEM

DNA

DNase

ddNTP

dNTP

DTT

EBM

ECBM

ECGM

EZM

E. coli

EDTA

EGM

ELAM-1

EMV

EZ

FACS

FKS

FN

GAP

GAPDH

GAS

GBP

GDP

GEF

GFP

GM-CSF
Abbildung

Angiopoietin

Ammoniumpersulfat

Adenosintriphosphat

basischer Fibroblasten-Wachstumsfaktor

Basalmembran

bovine serum albumin

komplementäre Desoxyribonukleinsäure

CCAAT/enhancer-binding protein

komplementäre Ribonukleinsäure

Cytosintriphosphat

Dulbecco's Modifiziertes Eagle Medium

Desoxyribonukleinsäure

Desoxyribonuklease

Didesoxyribonukleosidtriphosphat

Desoxyribonukleosidtriphosphat

Dithiothreitol

Endothelzellbasalmedium von Cambrex

Endothelzellbasalmedium von PromoCell

Endothelzellwachstumsmedium von PromoCell

extrazelluläre Matrix

Escherichia coli

Ethylendiamintetraessigsäure

Endothelzellwachstumsmedium von Cambrex

endotheliales Leukozytenadhäsionsmolekül-1

Enzephalomyokarditisvirus

Endothelzelle

fluorescence activated cell sorting

fötales Kälberserum

Fibronektin

GTPase aktivierendes Protein

Glycerinaldehyd-3-Phosphatdehydrogenase

gamma-interferon activation site

Guanylatbindungsprotein

Guanosindiphosphat

Guaninnukleotid-Austauschfaktor

green fluorescent protein

Granulozyten/Makrophagen-Kolonie-stimulierender Faktor 


\begin{tabular}{|c|c|}
\hline GMP & Guanosinmonophosphat \\
\hline GMZ & glatte Muskelzelle \\
\hline GTP & Guanosintriphosphat \\
\hline HEK293T & humane embryonale Nierenzellen transformiert mit dem large T Antigen \\
\hline HIF-1 & Hypoxie-induzierbarer Faktor \\
\hline HRP & horseradish peroxidase \\
\hline HUVEC & humane Nabelschnurvenen-Endothelzellen \\
\hline ICAM & intrazelluläres Adhäsionsmolekül \\
\hline IFN- $\gamma$ & Interferon- $\gamma$ \\
\hline $\operatorname{IgG}$ & Immunglobulin $\mathrm{G}$ \\
\hline IL-1 $\beta$ & Interleukin-1 $\beta$ \\
\hline IRF-1 & interferon regulatory factor- 1 \\
\hline ISRE & interferon- $\alpha$-stimulated response element \\
\hline ITGA & $\alpha$-Integrin \\
\hline ITGB & $\beta$-Integrin \\
\hline JAK & Janus-kinase \\
\hline Ktrl & Kontrolle \\
\hline $\mathrm{KV}$ & Kontrollvektor bzw. Leerplasmid \\
\hline LB & Luria-Broth \\
\hline MCP-1 & Monozyten/Makrophagen-Kolonie-stimulierender Faktor \\
\hline $\mathrm{MHC}$ & Haupthistokompatibilitätskomplex \\
\hline MLV & murines Leukämievirus \\
\hline MMP & Matrixmetalloproteinase \\
\hline MKS & multiple Klonierungsstelle \\
\hline mRNA & messenger RNA \\
\hline $\mathrm{NF}-\kappa \mathrm{B}$ & nukleärer Faktor- $\kappa \mathrm{B}$ \\
\hline NK-Zellen & natürliche Killer-Zellen \\
\hline NO & Stickstoffmonoxid \\
\hline NOS & Nitritoxidsynthase \\
\hline PAA & Polyacrylamid \\
\hline PAF & Plättchen-aktivierender Faktor \\
\hline PAGE & Polyacrylamid-Gelelektrophorese \\
\hline $\operatorname{Pax}$ & Paxillin \\
\hline PBS & phosphate buffered saline \\
\hline pCMV & Promotor des humanen Cytomegalovirus \\
\hline PCR & Polymerasekettenreaktion \\
\hline PDGF & platelet-derived growth factor \\
\hline PF-4 & Plättchenfaktor-4 \\
\hline $\mathrm{PGF}_{2 \alpha}$ & Prostaglandin $F_{2 \alpha}$ \\
\hline $\mathrm{pH}$ & potentia hydrogenii \\
\hline
\end{tabular}




$\begin{array}{ll}\text { PVDF } & \text { Polyvinylidenfluorid } \\ \text { PKA } & \text { Proteinkinase A } \\ \text { RNA } & \text { Ribonukleinsäure } \\ \text { RNase } & \text { Ribonuklease } \\ \text { RPA } & \text { RNase Protection Assay } \\ \text { R-PE } & \text { R-Pycoerythrin } \\ \text { RT } & \text { Raumtemperatur } \\ \text { RT-PCR } & \text { reverse Transkriptase-Polymerasekettenreaktion } \\ \text { SAPE } & \text { Streptavidin-Phycoerythrin-Konjugat } \\ \text { SDS } & \text { Sodiumdodecylsulfat } \\ \text { SFM } & \text { Serum-freies Endothelzellbasalmedium } \\ \text { shRNA } & \text { short hairpin RNA } \\ \text { STAT } & \text { signal transducer and activator of transcription } \\ \text { Tab. } & \text { Tabelle } \\ \text { TAE } & \text { Tris-Acetat-EDTA } \\ \text { TBE } & \text { Tris-Borat-EDTA } \\ \text { TEMED } & \text { N, N, N', N'-Tetramethylethylendiamin } \\ \text { Tie-2 } & \text { Tyrosinkinaserezeptor-2 } \\ \text { TNF- } \alpha & \text { Tumornekrosefaktor- } \alpha \\ \text { UV } & \text { ultraviolettes Licht } \\ \text { UTP } & \text { Uridintriphosphat } \\ \text { VCAM-1 } & \text { vaskuläres Zelladhäsionsmolekül } \\ \text { VEGF } & \text { vaskulärer-endothelialer Wachstumsfaktor } \\ \text { VSV } & \text { vesikuläres Stomatitisvirus } \\ \text { WB } & \text { Westernblot } \\ & \end{array}$




\section{Einheiten:}

$\begin{array}{ll}\text { A } & \text { Ampere } \\ \text { bp } & \text { Basenpaar } \\ { }^{\circ} \mathrm{C} & \text { Grad Celsius } \\ \mathrm{cm} & \text { Zentimeter } \\ \mathrm{Da} & \text { Dalton } \\ \mathrm{g} & \text { Gramm bzw. Gravitationskonstante } \\ \mathrm{h} & \text { Stunde } \\ \mathrm{J} & \text { Joule } \\ \mathrm{l} & \text { Liter } \\ \mathrm{m} & \text { Meter } \\ \mathrm{M} & \text { molar (mol/l) } \\ \mathrm{mol} & \text { Mol } \\ \mathrm{min} & \text { Minute } \\ \mathrm{Pa} & \text { Pascal } \\ \mathrm{sec} & \text { Sekunde } \\ \mathrm{U} & \text { Unit (Einheit der Enzymaktivität) } \\ \mathrm{V} & \text { Volt } \\ & \end{array}$

\section{Vorsätze:}

$\begin{array}{lll}\mathrm{k} & \text { kilo } & 10^{3} \\ \mathrm{~m} & \text { milli } & 10^{-3} \\ \mu & \text { mikro } & 10^{-6} \\ \mathrm{n} & \text { nano } & 10^{-9} \\ \mathrm{p} & \text { piko } & 10^{-12}\end{array}$

\section{Basen der Nukleotide:}

$\begin{array}{ll}\text { A } & \text { Adenin } \\ \text { C } & \text { Cytosin } \\ \text { G } & \text { Guanin } \\ \text { T } & \text { Thymidin } \\ \text { U } & \text { Uracil }\end{array}$

\section{Aminosäuren-Nomenklatur:}

nach IUPAC-IUB-Vereinbarung (1969)

$\begin{array}{llllll}\text { Ala } & \text { A } & \text { Alanin } & \text { Leu } & \text { L } & \text { Leucin } \\ \text { Arg } & \text { R } & \text { Arginin } & \text { Lys } & \text { K } & \text { Lysin } \\ \text { Asn } & \text { N } & \text { Asparagin } & \text { Met } & \text { M } & \text { Methionin } \\ \text { Asp } & \text { D } & \text { Asparaginsäure } & \text { Phe } & \text { F } & \text { Phenylalanin } \\ \text { Cys } & \text { C } & \text { Cystein } & \text { Pro } & \mathbf{P} & \text { Prolin } \\ \text { Gln } & \mathbf{Q} & \text { Glutamin } & \text { Ser } & \mathbf{S} & \text { Serin } \\ \text { Glu } & \mathbf{E} & \text { Glutaminsäure } & \text { Thr } & \mathbf{T} & \text { Threonin } \\ \text { Gly } & \mathbf{G} & \text { Glycin } & \text { Trp } & \mathbf{W} & \text { Tryptophan } \\ \text { His } & \mathbf{H} & \text { Histidin } & \text { Tyr } & \mathbf{Y} & \text { Thyrosin } \\ \text { Ile } & \mathbf{I} & \text { Isoleucin } & \text { Val } & \mathbf{V} & \text { Valin }\end{array}$




\section{Lebenslauf}

\section{Persönliches}

$\begin{array}{ll}\text { Name } & \text { Kristina Weinländer } \\ \text { Geboren am } & \text { 02. Januar 1979 } \\ \text { Geburtsort } & \text { Fürth, Bayern } \\ \text { Nationalität } & \text { deutsch } \\ \text { Familienstand } & \text { ledig }\end{array}$

\section{Hochschulausbildung}

seit 08/2004 Promotion in der Abteilung für Molekulare und Experimentelle Chirurgie unter der Leitung von Prof. Dr. Michael Stürzl, Universitätsklinikum Erlangen;

Titel der Arbeit: „Charakterisierung molekularer Mechanismen der antiangiogenen Aktivität von GBP-1 in Endothelzellen“

10/1998-02/2004 Studium der Biologie an der Friedrich-Alexander-Universität Erlangen-Nürnberg mit Hauptfach Biochemie

Abschluss: Diplom-Biologin (Dipl.-Biol. Univ.), Note : 1,0 (mit Auszeichnung bestanden)

Titel der Diplomarbeit: „Charakterisierung von Sekundärstrukturelementen des inhibitorischen Glycinrezeptors“

\section{Schulische Ausbildung}

09/1989-06/1998 Wolfgang-Borchert-Gymnasium, Langenzenn

Abschluss: allgemeine Hochschulreife 


\section{Publikationen}

1.

Weinländer, K., Naschberger, E., Lehmann, M. H., Tripal, P., Paster, W., Stockinger, H., Hohenadl, C., Stürzl, M.; "Guanylate binding protein-1 inhibits spreading and migration of endothelial cells through induction of integrin alpha4 expression"; FASEB J. (2008), im Druck

2.

Weinländer, K., Naschberger, E., Lehmann, M. H., Hohenberger, W., Stürzl, M.; „Charakterisierung molekularer Mechanismen der antiangiogenen Aktivität von GBP-1 in Endothelzellen“; Chirurgisches Forum 2008, 37, 47-48, (2008)

3. Thurau, M., Sander, G., Gonin-Laurent, N., Weinländer, K., Naschberger, E., Jochmann, R., Alkharsah, K.R., Schulz, T.F., Thome, M., Neipel, F., Stürzl, M.; "The viral inhibitor of vFLIP/K13 protects endothelial cells against superoxide-induced cell death“, J. Virol. (2008), in Revision

4.

Schellerer, V. S., Croner, R. S., Weinländer, K., Hohenberger, W., Stürzl, M., Naschberger, L.; "Endothelial cells of human colorectal cancer and healthy colon reveal phenotypic differences in culture"; Lab. Invest. 87, 1159-1170, (2007)

\section{Posterpräsentationen}

1.

Weinländer, K., Naschberger, E., Lehmann, M. H., Tripal, P., Stürzl, M.; "Guanylate binding protein-1 inhibits spreading and migration of endothelial cells through induction of integrin alpha4 expression"; 8 . Erlanger IZKF-Workshop; Juli 2008; Erlangen

2.

Weinländer, K., Naschberger, E., Lehmann, M. H., Stürzl, M.; "GBP-1 inhibits spreading of endothelial cells on fibronectin by induction of integrin alpha4 expression"; Tagung der European Life Scientist Organization (ELSO); September 2007; Dresden 
3.

Weinländer, K., Naschberger, E., Lehmann, M. H., Stürzl, M.; “GBP-1 inhibits spreading of endothelial cells on fibronectin by induction of integrin alpha4 expression"; 7. Erlanger IZKF-Workshop; Juli 2007; Erlangen

4.

Weinländer, K., Pogoda, K., Hohenberger, W, Stürzl, M.; "hGBP-1 inhibits nuclear accumulation of p53 tumor suppressor in human umbilical vein endothelial cells"; 27. Deutscher Krebskongress; März 2006; Berlin

\section{$\underline{\text { Vorträge }}$}

1.

Kongress der Deutschen Gesellschaft für Chirurgie 2008, April 2008; Berlin; „Charakterisierung molekularer Mechanismen der antiangiogenen Aktivität von GBP-1 in Endothelzellen”

2.

2nd GBP-1 meeting; Oktober 2006, Erlangen; "GBP-1 inhibits nuclear accumulation of p53 tumor suppressor in human umbilical vein endothelial cells"

\section{$\underline{\text { Preise }}$}

1.

3. Preis bei der Posterpräsentation im Rahmen des 7. Erlanger IZKFWorkshops; Juli 2007

2.

Diplom-Preis der Biologie 2004; verliehen durch die Fachgruppe Biologie der Friedrich-Alexander-Universität Erlangen-Nürnberg für herausragende Leistungen in den mündlichen Prüfungen und in der Diplomarbeit; Januar 2005 